\title{
Depósitos de Pb-Zn-Cu-Ba-F-Sr epigenéticos estratoligados en series sedimentarias en relación con salmueras de cuenca: depósitos de tipo "Mississippi Valley" (MVT) y similares en México
}

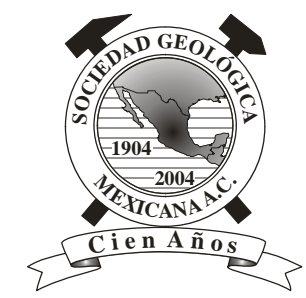

\author{
Jordi Tritlla ${ }^{1, *}$; Gilles Levresse ${ }^{1}$; Rodolfo Corona-Esquivel ${ }^{2}$; David Banks ${ }^{3}$; \\ Hector Lamadrid ${ }^{1}$, Julien Bourdet ${ }^{4}$ \\ ${ }^{1}$ Programa de Geofluidos, Centro de Geociencias, Universidad Nacional Autónoma de México, Campus Juriquilla, \\ Carr. Qro-SLP km 15,5, Santiago de Querétaro, Qro. 76230, México \\ ${ }^{2}$ Museo de Geología-Instituto de Geología, Universidad Nacional Autónoma de México, \\ J. Torres Bodet No. 176, Col. Sta Ma. La Ribera, D. F. 06400, México \\ ${ }^{3}$ School of Earth Environment, Institute of Geological Sciences, The University of Leeds, \\ Leeds LS2 9JT, Reino Unido de la Gran Bretaña \\ ${ }^{4}$ UMR 7566 G2R-CREGU, Université H. Poincaré, B.P. 239 Vandoeuvre-lès-Nancy, 54506 France \\ *jordit@geociencias.unam.mx
}

\section{Resumen}

Los depósitos de $\mathrm{Pb}-\mathrm{Zn}-\mathrm{Cu}-\mathrm{Ba}-\mathrm{F}-\mathrm{Sr}$ epigenéticos estratoligados en series sedimentarias han constituido una de las mayores fuentes de metales en la historia de la humanidad. Aún en la actualidad continuan siendo un objetivo prioritario de exploración para las compañias mineras, debido tanto a su fácil metalurgia como a los grandes tonelajes que presentan los distritos clasificados bajo esta tipología.

En México existen todo un conjunto de mineralizaciones de $\mathrm{Pb}-\mathrm{Zn}-\mathrm{Ba}-\mathrm{F}$ que han sido sistemáticamente consideradas como pertenecientes a tipologías diversas (skarns, reemplazamientos de alta temperatura, epitermales, etc.) que, bajo una nueva pespectiva, responden a un modelo de circulación de fluidos de cuenca enriquecidos en metales, flúor y bario durante su tránsito por la serie sedimentaria. Estos fluidos han dado lugar a un conjunto de cuerpos mineralizados estratoligados que aparecen encajonados dentro de las series de plataforma carbonatada mesozoicas del centro, $\mathrm{N}$ y $\mathrm{NE}$ de México. Típicamente, no están asociados genéticamente a magmatismo alguno, no causan una alteración muy acusada en la roca encajonante, suelen estar asociados a la presencia de materia orgánica (hidrocarburos líquidos, bitúmen), presentan una mineralogía muy sencilla, a menudo casi monominerálica (barita, celestina, fluorita, esfalerita, galena) y suelen presentar temperaturas de formación dentro del rango de $90-150^{\circ} \mathrm{C}$ con salinidades variables. Todo este conjunto de características hacen a estos depósitos plenamente comparables con los MVT del subtipo Alpino-Apalachiano.

En este artículo se lleva a cabo una revisión sobre el conocimiento que se tiene sobre este tipo de depósitos a nivel global para, después, pasar a discutir la presencia de esta tipología en suelo mexicano y sus características geológicas y geoquímicas más relevantes.

Palabras clave: Depósitos de tipo MVT, generalidades, geoquímica, depósitos en México, estado del arte.

\begin{abstract}
The low temperature, epigenetic and stratabound $\mathrm{Pb}-\mathrm{Zn}-\mathrm{Cu}-\mathrm{Ba}-\mathrm{F}$-Sr-bearing ore deposits enclosed within sedimentary series have been one of the major sources of metals in history. Presently, exploration companies still find these deposits
\end{abstract}


a profitable target due to its simple mineralogy as well as the large tonnage they can present, always considering the mineral disctricts as a whole.

In north-east Mexico, several non-magmatic, low-temperature Pb-Zn-F-Ba deposits have been sistematically considered to represent magmatic-related typologies (skarns, high-temperature replacement deposits, epithermal deposits, etc.). Recently, these deposits have been re-studied and placed within an scenario of deep fluid circulation of basinal brines through the Mesozoic sedimentary series, being enriched in Ba, F and metals during its transit. These fluids gave rise to a series of stratabound epigenetic ore deposits scattered throughout the whole Mesozoic carbonate platform. These deposits are not related with any magmatic period whatsoever; do not cause an intense alteration to the host rocks; oftenly, they present a close association with organic matter, either liquid hydrocarbons or bitument; they display a very simple mineralogy (barite, celestite, fluorite, sphalerite, galena) and present low formation temperatures $\left(90-105^{\circ} \mathrm{C}\right)$ coupled with variable salinities. All these characteristics make these deposits similar to the Mississippi Valley-Type Deposits, Alpine-Apalachian subtype.

In this paper firstly we pretend to perform a revision on the global knowledge of the MVT tipology and, subsequentely, to discuss the presence of this type of deposits within the Mesozoic sedimentary series in Mexico.

Key words: MVT deposits, general characteristics, geochemistry, deposits in Mexico, state of the art.

\section{Generalidades sobre los depósitos MVT}

\subsection{Introducción}

El término "Mississippi Valley-Type" fue inicialmente utilizado en referencia al conjunto de depósitos de $\mathrm{Zn}-\mathrm{Pb}$ localizados en la cuenca del río Mississippi, en el centro de los Estados Unidos. Las características básicas que definen a este tipo de depósitos son aspectos químicos y geológicos muy generales, por lo que ha sido posible clasificar numerosos depósitos de $\mathrm{Zn}-\mathrm{Pb}-\mathrm{F}$ y otras substancias dentro de la tipología MVT. Junto con los depósitos singenéticos de metales base encajados en sedimentos (VMS, Sedex), los depósitos de tipo MVT constituían a finales de los años 80 el $65 \%$ de las reservas mundiales de zinc y el $77 \%$ de las de plomo (Tikkanen, 1986). Debido a su importancia económica, estos depósitos han sido el foco de estudio de numerosos investigadores a nivel mundial abarcando tanto aspectos geológicos como geoquímicos, reflejándose en la gran cantidad de literatura científica al respecto. No obstante, existe un conjunto de aspectos básicos sobre su génesis que aun son controversiales, como los mecanismos de flujo de los fluidos mineralizantes, el régimen tectónico al que responden y hasta los procesos de precipitación. Esto es debido a que algunas de dichas características no son extrapolables a la mayoría de los depósitos.

Las mineralizaciones generalmente denominadas como Mississippi Valley-type (MVT) son epigenéticas, normalmente estratoligadas, y están formadas a partir de soluciones hidrotermales de baja temperatura y presión, con o sin la presencia de hidrocarburos.

Debido a que estos depósitos guardan en común un conjunto de características geológicas y geoquímicas muy amplias, se ha podido incluir dentro de esta tipología a un conjunto de mineralizaciones muy similares que aparecen a nivel mundial (Figura 1). Así, si se tiene en cuenta tanto la paragénesis mineral como el tipo de soluciones que dieron origen a estos depósitos, el espectro de sub-tipologías que aparecen es muy amplio, incluyendo no solo los depósitos estratoligados encajonados en rocas carbonatadas, dolomitizadas o no, si no también depósitos estratoligados encajados en rocas siliciclásticas, depósitos de $\mathrm{Pb}-\mathrm{Zn}-\mathrm{Ag}-\mathrm{Ba}-\mathrm{F}$ en fracturas, y un largo etcétera.

Entre las mineralizaciones estratoligadas de metales base existe una cierta distinción mineralógica, al menos en lo que se refiere a las menas metálicas, entre aquellas encajadas en rocas carbonatadas y las que lo están en rocas siliciclásticas. Las diferencias son probablemente resultado de las variaciones químicas provocadas en la solución mineralizante por la interacción con un acuífero carbonatado o siliciclástico (Sverjensky, 1984). Por lo tanto, hemos distinguido estos dos grupos y, en uno de ellos, se han realizado subdivisiones que responden esencialmente a la mineralogía presente.

\subsection{Depósitos de tipo MVT "clásicos"}

En este apartado se incluyen todas aquellas mineralizaciones en las que la roca encajonante es carbonatada, independientemente de los minerales que la formen. Aunque las llamadas "carbonate-hosted" (Beaty et al., 1990; Russell y Skauli, 1991) hacen referencia específica a las mineralizaciones de metales base ( $\mathrm{Pb}-\mathrm{Zn}-\mathrm{Cu})$, aquí hemos incluido también los depósitos que contienen otros metales. En general se trata de los clásicamente conocidos como Mississippi Valley-type (MVT), si bien algunos autores (Sangster, 1990, por ejemplo) consideran que este término solo se debería de aplicar a aquellas mineralizaciones que se localizan en Norte América.

Históricamente, el distrito más importante en el que se localizan estas mineralizaciones es el de Tri-State, situado entre los estados de Missouri y Oklahoma (Hagni, 1976), y las minas del SW del estado de Wisconsin y Illinois (Hey y 


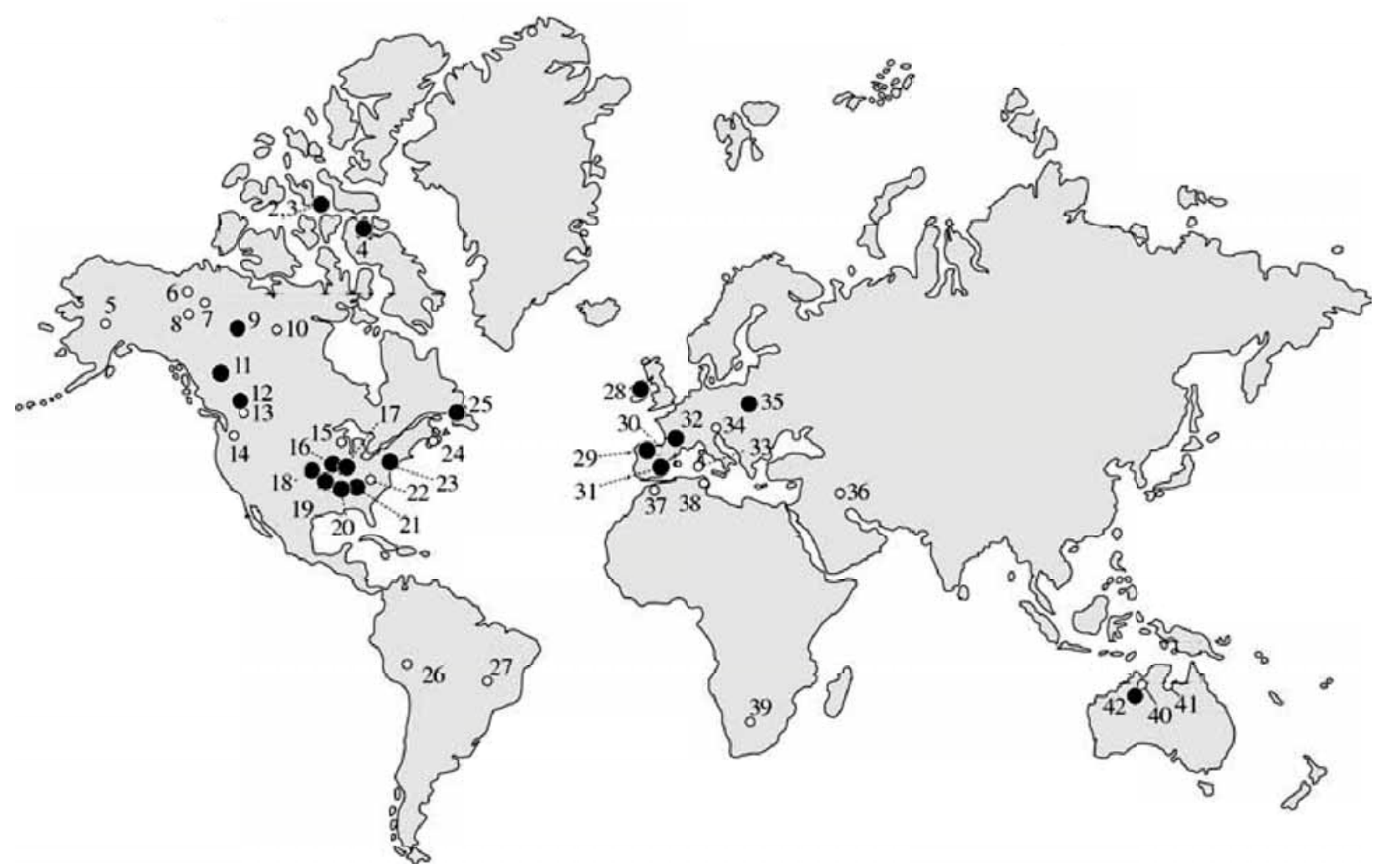

Figura 1. Localización de los depósitos y distritos MVT en el mundo (modificado de Sangster, 1990): 1, Polaris; 2, Eclipse; 3, Nanisivik; 4, Gayna; 5, Bear-Twit; 6, Godlin; 7, Pine Point district; 8, Lake Monte; 9, Nancy Island; 10, Ruby Lake; 11, Robb Lake; 12, Monarch-Kicking Horse; 13, Giant; 14, Silver Basin; 15, Gays River; 16, Daniels Harbour; 17, Metaline district; 18, distrito Upper Mississippi Valley ; 19, distrito southeast Missouri (Old Lead Belt, Viburnum Trend, Indian Creek); 20, distrito central Missouri; 21, distrito Tri-State; 22, distrito northern Arkansas ; 23, Austinville; 24, Friedensville; 25, distrito central Tennessee ; 26, distrito east Tennessee; 27, San Vicente; 28, Vazante; 29, Harberton Bridge; 30, distrito de Silesia; 31, distrito Alpino; 32, Pering; 33, Sorby Hills; 34, Coxco; 35-37, distrito de Lennard Shelf (Cadjebut, Blendvale, Twelve Mile Bore); 38, distrito El-Abadekta.

West, 1982). Tambien han sido importantes los distritos del centro y este de Tennessee (Hoagland, 1976; Rhodes et al., 1984). No obstante, es posible encontrar depósitos similares en todo el mundo (Figura 1), como son en América del Sur los depósitos de los Andes (Fontboté y Gorzawski, 1990); en México, en el Estado de Coahuila (González-Partida et al. 2003, Tritlla et al., 2004a, b); en Europa los de Silesia-Cracovia (Polonia) (Sass-Gustkiewicz et al., 1982; Górecka, 1993), los de los Pennines de Inglaterra (Dunham, 1983), de Eslovénia (Drovenik, 1985), de Francia (Ramboz y Charef, 1988), del N de España (Gómez-Fernández et al., 2000; Grandia et al., 2003a, 2003b) y de Cerdeña (Boni, 1985); en Asia los del oeste del Pakistán (Anderson y Lydon, 1990); en África los de Zambia (Kamona et al., 1991) y, los del oeste de Australia (Cadjebut, Tompkins et al., 1994a, 1994b).

\subsubsection{Principales características}

A pesar de que los depósitos de tipo MVT son una de las tipologías más estudiadas en los últimos años, no existe un acuerdo para explicar su génesis. Las características comunes de los depósitos son (Kisvarsanyi et al., 1983;
Sangster, 1983; Sverjensky, 1986, 1989; Anderson y Mcqueen, 1988; Leach y Sangster, 1993; Tritlla y Canals, 1997):

1) Suelen encajonar en series carbonatadas de plataforma, de grosor variable.

2) Son mineralizaciones epigenéticas de sulfuros de zinc y plomo (esfalerita y galena), acompañados de sulfuros de hierro (pirita y marcasita), y carbonatos (calcita y dolomita). Pueden también aparecer barita, fluorita, calcopirita y cuarzo que pueden llegar a ser localmente abundantes $\mathrm{o}$, en algunos casos, llegar a constituir la mayor parte de la mineralización. La relación $\mathrm{Zn} /(\mathrm{Zn}+\mathrm{Pb})$ suele estar comprendida entre 0.6 y 1 , y casi siempre se cumple que $\mathrm{Zn}>\mathrm{Pb} \gg>>\mathrm{Cu}$.

3) En muchos distritos, estos depósitos están acompañados de hidrocarburos, a menudo bajo la forma de bitumen o bien en inclusiones fluidas de hidrocarburos líquidos y sólidos atrapados en los minerales que constituyen el depósito.

4) La morfología de los depósitos puede ser muy varia$\mathrm{da}, \mathrm{y}$ consisten en mantos de reemplazamiento, masivos a bandeados; relleno de bolsadas, a veces de origen kárstico 
(karst hidrotermal); cementando brechas hidráulicas o de colapso; cementos ocupando la porosidad de antiguos biostromas, a menudo de rudistas o coralinos; relleno de fracturas o filones; etc. (Figura 2). Estos depósitos suelen estar limitados a un solo nivel estratigráfico, generalmente dolomitizado, aunque esto no siempre se cumple.

5) Los distritos suelen estar formados por un número elevado de depósitos de pequeño tonelaje $\left(<2 \cdot 10^{6} \mathrm{Mt}\right)$, con unas leyes máximas alrededor del $10 \%$ de $\mathrm{Zn}+\mathrm{Pb}$ (Figura 3 ). La distribución de estos depósitos suele estar controlada por elementos estratigráficos (límites litológicos, cambios de facies, distribucion de porosidad, karst), estructurales (fracturas, cabalgamientos, brechas tectónicas, etc.) o la combinación de ambos, localizándose siempre en unos niveles determinados, de ahí su carácter estratoligado.

6) Texturalmente, los sulfuros muestran una gran variedad, desde reemplazamientos coloidales de tamaño de grano muy fino hasta cristales centimétricos a decimétricos ocupando cavidades. Las texturas indicativas de precipitación rápida (coloformes, dendríticas, esqueléticas) pueden ser las predominantes en algunos depósitos.

7) Estos depósitos suelen aparecer encajonados en series estratigráficas carbonatadas, mayoritariamente dolomitizadas. No obstante existen algunos depósitos (Laisvall, Suecia) que encajan en rocas siliciclásticas.

8) Se forman a poca profundidad (generalmente inferior a 1,500 metros), a menudo en altos estructurales.

9) Genéticamente, nunca están asociados a rocas ígneas.

10) Suelen estar asociados a regímenes tectónicos tanto compresionales (EE. UU.) como extensionales (algunos depósitos europeos, México).

11) No aparecen exclusivamente en periodos geológicos concretos, si no que se conocen desde el Proterozoico
(Canadá, Sudáfrica) hasta tiempos recientes (Figura 4).

12) Estos depósitos se han formado a partir de soluciones de cuenca similares a las aguas de formación petroleras, con temperaturas, determinadas mediante inclusiones fluidas en cuarzo, esfalerita, dolomita, barita, calcita y fluorita, que se sitúan entre 80 y $200{ }^{\circ} \mathrm{C}$, y salinidades de hasta el $30 \%$ en sales en peso, $\mathrm{NaCl}$ y $\mathrm{CaCl}_{2}$ esencialmente. El mecanismo más viable para el transporte de $\mathrm{Zn}$ y $\mathrm{Pb}$ es mediante complejos clorurados. El F se puede transportar mediante complejos de Mg y Ca (Spirakis, 2004; Tritlla et al., 2004b). A menudo, los fluidos acuosos están acompañados por metano, hidrocarburos líquidos y suele aparecer bitumen tanto bajo la forma de sólidos atrapados en las inclusiones fluidas como acumulado en el depósito.

13) La composición isotópica del oxígeno y del carbono de las rocas encajonantes está ligeramente empobrecida con respecto a las rocas regionales, hecho que indica que recristalizaron en presencia de un fluido.

14) Las composiciones isotópicas del oxígeno y el deuterio de las aguas contenidas en las inclusiones fluidas son similares a las de los fluidos presentes en las cuencas sedimentarias.

15) Los datos isotópicos de plomo, muy radiogénicos, sugieren un origen cortical para los metales, que muy probablemente fueron lixiviados de materiales sedimentarios de la misma cuenca, o bien de materiales presentes en el zócalo. El origen del azufre está casi siempre asociado a una fuente evaporítica (evaporación de agua marina; lavado de evaporitas), aunque el amplio rango de composiciones que suelen observarse en algunos depósitos sugiere que esta composición puede estar modificada por procesos de oxidación/reducción en presencia de materia orgánica.

16) La reconstrucción del grosor total de sedimentos por encima de la mineralización en el momento en que esta se

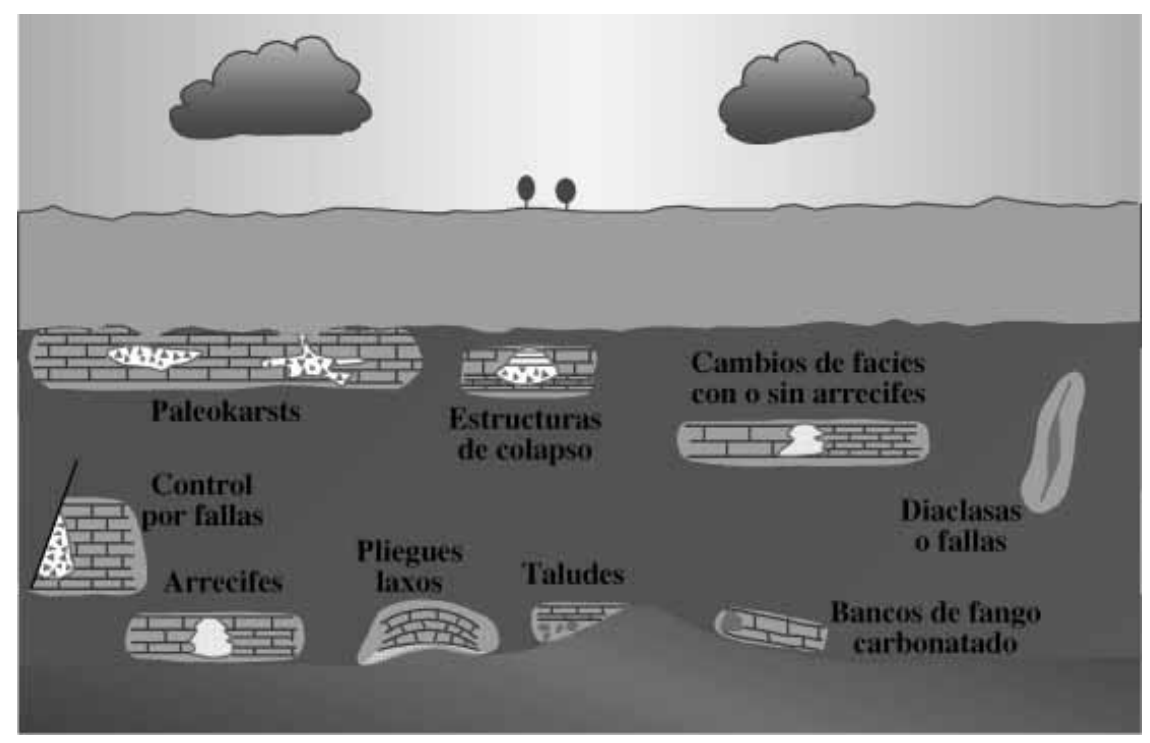

Figura 2. Tipos de trampas sedimentarias y/o estructurales que pueden facilitar la formación de depósitos MVT. Modificado de Callahan (1967). 


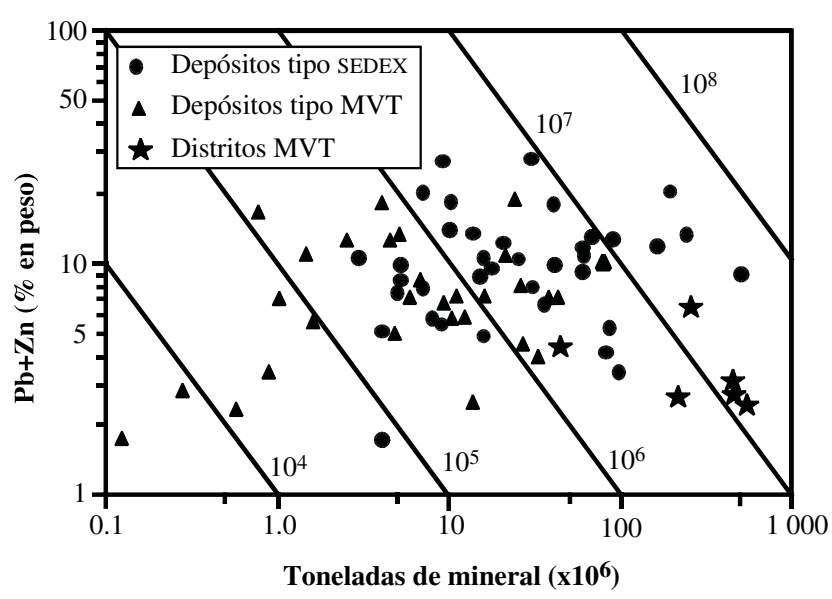

Figura 3. Relación entre la ley total de $\mathrm{Pb}+\mathrm{Zn}$ y el tonelaje para los depósitos y distritos MVT y su comparación con distritos y depósitos de tipo exhalativo (SEDEX). Las líneas diagonales representan el tonelaje total de plomo y zinc (modificado de Sangster, 1990).

formó, juntamente con un gradiente geotérmico anómalo, permiten calcular temperaturas en el área mineralizada que siempre son inferiores a las encontradas mediante inclusiones fluidas.

Tal y como se ha indicado anteriormente, la paragénesis mineral es pobre en número de especies y químicamente muy sencilla. El ejemplo típico es el del Tri-State District (Hagni, 1976), en donde los minerales precipitan siempre rellenando cavidades, no se observan reemplazamientos y comúnmente se presentan siempre como encrustaciones o drusas.

\subsubsection{Texturas}

En estos depósitos es frecuente encontrar texturas relacionadas con el relleno de espacios vacíos (drusas, geodas), tanto de aquellos que ya existían en la roca encajonante (cavidades kársticas, porosidades primarias, etc.) como de los generados por el mismo proceso mineralizante ("karst hidrotermal", Dzulinski y SassGustkiewickz, 1985). Los minerales que precipitan en estos espacios vacíos presentan texturas que van desde grandes cristales idiomórficos (decimétricos y, ocasionalmente métricos, Figura 5) hasta estructuras bandeadas con formas botroidales, constituidas por pequeños cristales alotriomórficos. En los cristales idiomórficos frecuentemente se observan zonaciones composicionales puestas de manifiesto mediante diversos métodos (ópticos, catodoluminiscencia, microsonda electrónica, SEM-EDS, zoneamiento isotópico, etc. McLimans et al., 1980; Richardson et al., 1988). Ejemplos de estas zonaciones son los contenidos en $\mathrm{Fe}$ o $\mathrm{Cd}$ de la esfalerita, el de Mn de la dolomita (Figura 5) y el contenido en elementos traza de la fluorita (Figura 5) y barita. En las estructuras bandeadas, los cristales crecen radialmente presentando cambios composicionales que pueden dar lugar a diferentes niveles coloreados, como ocasionalmente se observa en crecimientos esqueléticos de fluorita.
También son abundantes las brechas gravitacionales generadas por el colapso de la cavidad debido a movimientos sísmicos, disoluciones generalizadas, etc. (Ohle, 1985). En los clastos de estas brechas a menudo se produce la precipitación, en bandas concéntricas (cocardas) de los mismos minerales formadores del depósito.

Una de las texturas que más información aporta sobre las condiciones de precipitación es la presencia de dolomita en "silla de montar" (Figura 5) ("saddle dolomite", "baroque dolomite"; dolomita "xenotópica-c"; Radke y Mathis, 1980; Machel,1987; Gregg y Sibley, 1984). Esta dolomita suele presentarse en cristales idiomórficos con colores blanquecinos y brillo perlado a nacarado, caras y aristas curvas, extinción ondulante, abundantes inclusiones fluidas y variaciones intracristalinas en el contenido de elementos traza. Precipitan a partir de soluciones calientes $\left(>60^{\circ}\right)$ salinas y, según Machel (1987) son un producto típico de la reducción termoquímica del sulfato (TSR).

Otras texturas interesantes, pero que aparecen con mucha menor frecuencia, son los cristales lenticulares de calcita, tanto aislados como agrupados en rosetas, y también calcitas con texturas en mosaico, ambas dispuestas en el interior de una matriz de dolomita impura micrítica o esparítica fina. Estas calcitas se han interpretado como pseudomorfos de minerales evaporíticos primarios (yeso y anhidrita) y no como a partir de la precipitación asociada a la mineralización. Tanto las rosetas como los cristales lenticulares son morfológicamente similares a los cristales primarios de yeso que aparecen en ambientes tipo "sabkha" ("rosas del desierto"), mientras que las texturas en mosaico recuerdan las texturas "chicken-wire" de la anhidrita,

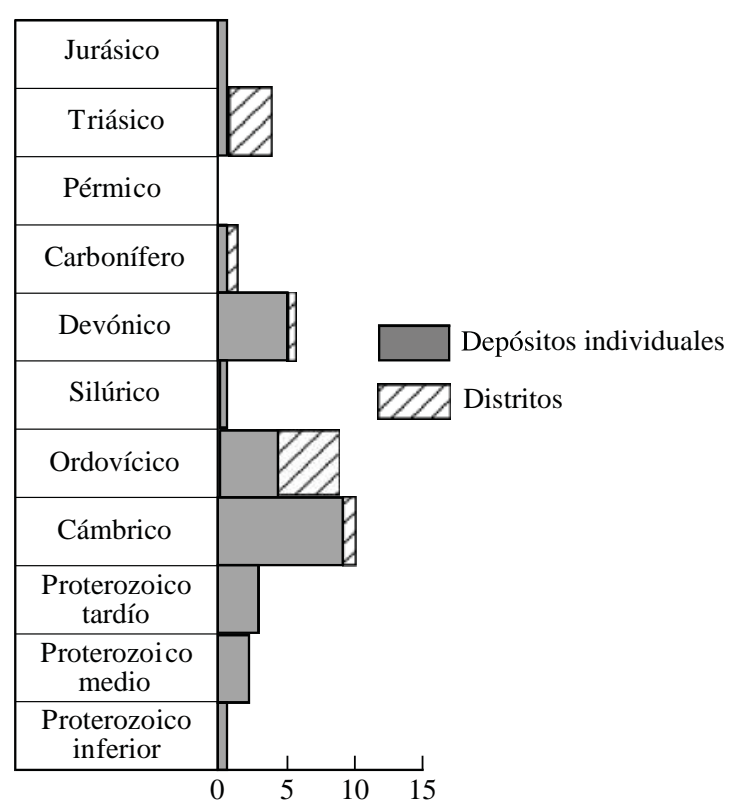

Figura 4. Distribución de los depósitos de tipo MVT en función de la edad. Las áreas en gris representan depósitos individuales; las áreas con diagonales indican distritos MVT. Modificado de Leach y Sangster (1993). 

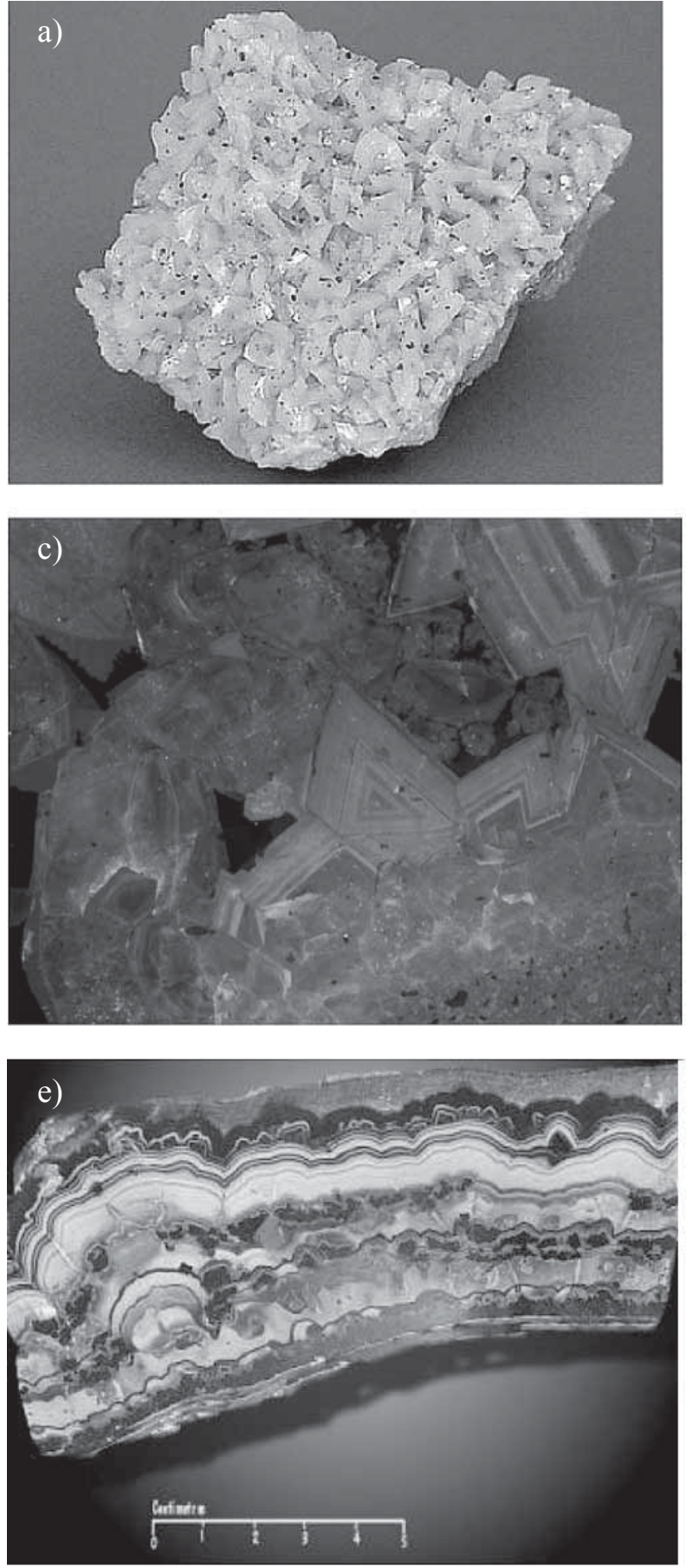
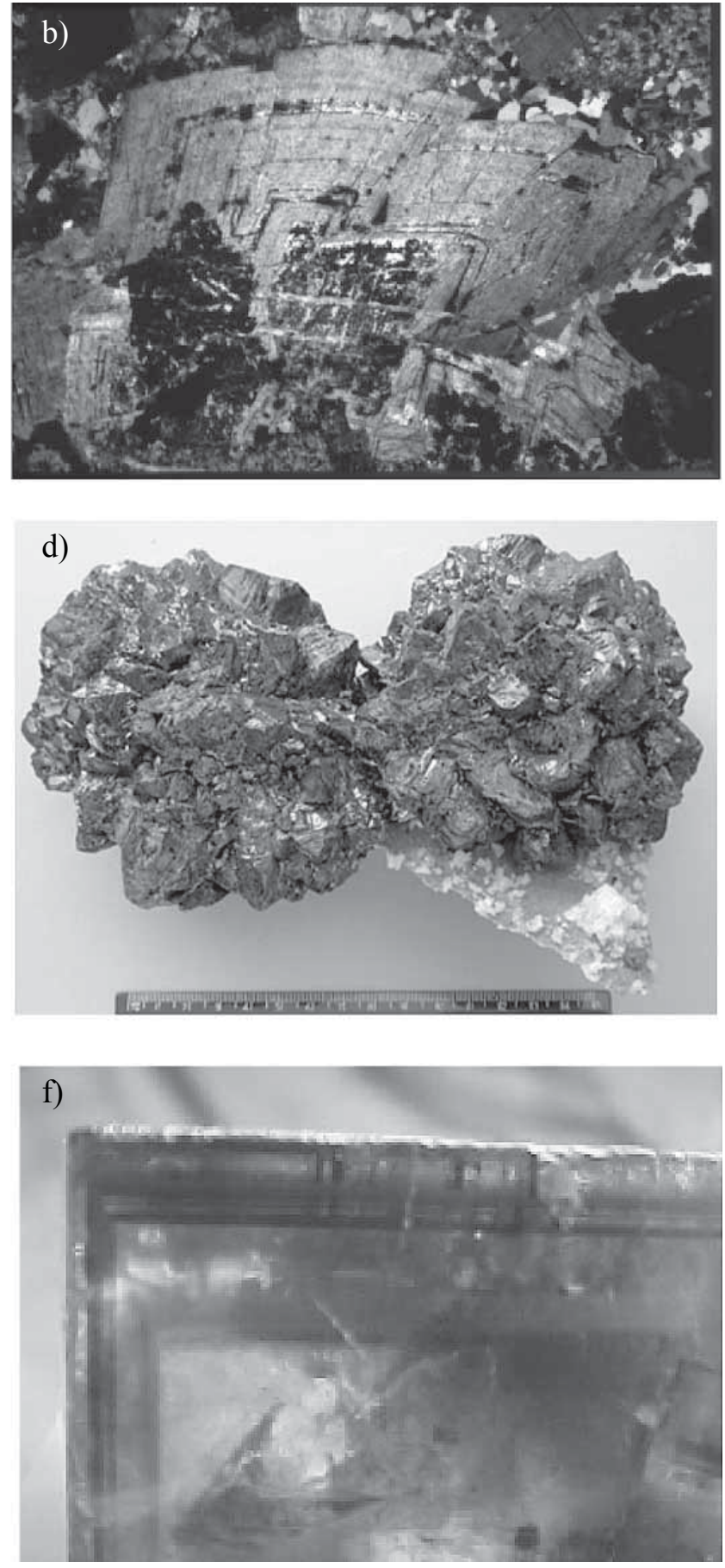

Figura 5. Texturas en minerales. (a) dolomita en "silla de montar" (saddle, baroque) con la caras y aristas curvadas y el típico brillo perlado, Reocín (Santander, España); (b) dolomita en "silla de montar" parcialmente dedolomitizada vista al microscopio petrográfico bajo nícoles cruzados, mostrando las caras y las líneas de crecimiento curvadas, Betxí (Sierra de Espadán, Castellón, España); (c ) zoneamiento en calcitas y dolomitas hidrotermales de baja temperatura bajo catodoluminiscencia; (d) dos drusas de grandes cristales de esfalerita creciendo sobre fluorita, Cave in Rock (Illinois, EE. UU.); (e) esfalerita y marcasita microgranudas dispuestas según masas de aspecto botroidal, textura indicativa de precipitación rápida, a menudo por sobresaturación, Silesia (Polonia); (f) Cristal de fluorita idomórfico que presenta zonación de color, Egleston (Cumberland, Reino Unido). 
sugiriendo que la fuente del azufre está en relación con la disolución de niveles evaporíticos. Estas calcitas han sido descritas en los depósitos de Pine Point y Gayna River en Canadá (Beales y Hardy,1980) y en los depósitos de Wagon Pass y Cadjebut en Australia (Tompkins et al., 1994a, 1994b). En este último depósito también se han descrito estructuras "teepee" y enterolíticas substituidas por la mineralización epigenética (Tompkins et al., 1994b). En México, texturas similares se han reconocido recientemente en el depósito de barita de BAROSA, en Múzquiz (Coahuila).

La reducción del sulfato puede ser provocada por la actividad bacteriogénica, tal y como lo demuestran composiciones isotópicas muy ligeras del azufre en sulfuros (Macqueen y Powell, 1984). Así, la precipitación de los minerales tiene lugar muy rapidamente, dando lugar a cre- cimientos esqueléticos (galena en esfalerita, por ejemplo) o bien esferulíticos.

Otras texturas que pueden estar asociadas a los yacimientos de tipo MVT son los bandeados conocidos como "ritmitas" (Diagenetic Crystallization Rhitmites, DCR), texturas "cebra", "rubanné" o "laminadas" (Figura 6). De acuerdo con Fontboté (1993) la ritmicidad viene dada por la alternancia de bandas oscuras y claras, correspondientes a diferentes generaciones de carbonatos. Las bandas oscuras, en donde el reemplazamiento de la fábrica sedimentaria original no se ha producido de forma total, están compuestas por un agregado de grano fino-medio de dolomita con o sin esfalerita y, subordinadamente, pirita. Las bandas claras, en donde la disolución ha sido completa, corresponden a grandes cristales de dolomita o esfalerita. Estas texturas las pueden presentar otros minerales tales como
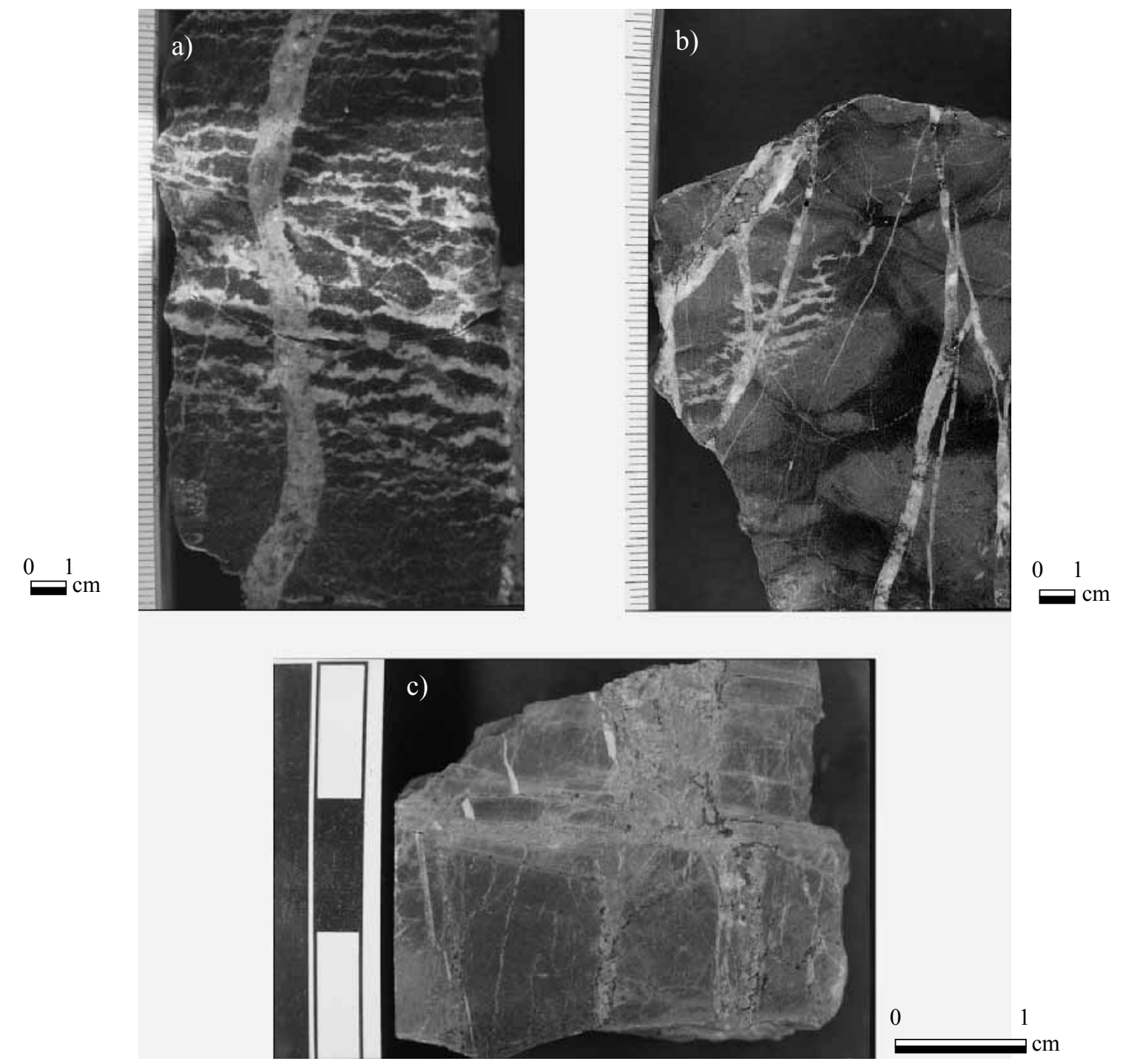

Figura 6. Texturas en rocas. (a) Ritmita de tipo "cebra" constituida por alternancias claras de dolomita hidrotermal y oscuras de dolomita recristalizada, Betxí (Castellón, España); (b) Ritmita de tipo “cebra” en dolomía cortada por un episodio de fracturación hidráulica, con mineralización de Hg, Betxí (Castellón, España); (c) Intensa fracturación hidráulica afectando una roca doloesparítica, Betxí (Castellón, España). 
barita, celestina y fluorita (Gorzawski et al., 1989; Tritlla et al., 2001a), ankeritas y sideritas (Gil et al., 1984; Gil y Velasco, 1992), magnesitas (Velasco et al., 1987), dolomita, pirita y esfalerita (Arne y Kissin, 1989; Arne et al., 1991; Tritlla y Cardellach, 1997; Tritlla et al., 2001b) (Figura 4). En las ritmitas también puede aparecer celestina, yeso, apatito, hematites, talco, cinabrio, tetraedrita, calcopirita, bornita, estibina, arsenopirita y, más raramente, scheelita y bismutinita (Pohl y Siegl, 1986).

A menudo es posible observar una transición entre las texturas ritmíticas y brechas mineralizadas (Figura 6), interpretándose como el producto de un mismo proceso. Así, si la presión del fluido responsable de la formación de las ritmitas supera al esfuerzo principal mínimo $\sigma_{3}$ se pueden generar fracturas hidráulicas que, en un estadio más evolucionado, pueden dar lugar a brechas hidráulicas (Sibson, 1990; Jebrak, 1992). En algunos casos (Espadán, España, Tritlla y Cardellach, 1997; La Encantada-Buenavista, Tritlla et al., 2004b) constituye la porosidad principal en la que precipita la mineralización económica.

\subsubsection{Alteraciones asociadas}

Las alteraciones hidrotermales en estos depósitos, debido a la capacidad tamponadora de la roca encajonante, son muy poco variadas en comparación con las que presentan las rocas silico-alumínicas (Tornos, 1997). El cambio mineralógico más extendido consiste en la dolomitización de la roca encajonante, si bien tambien pueden aparecer silicificaciones y/o muscovitizaciones. Los MVT, tal y como ya se ha comentado, encajan en calizas o en dolomías, si bien estas últimas son dominantes. En distritos como Pine Point (Canadá) y Silesia (Polonia) todo el distrito está encajado en una ámplia zona discordante de dolomía secundaria fuera de la cual la roca regional es una caliza; en otros distritos la dolomía secundaria aparece de forma local y se encuentra rodeando las zonas mineralizadas. Otras alteraciones que se han descrito y que afectan a la roca regional son la presencia de diseminaciones de sulfuros similares a los que aparecen en la mineralización (Leach, 1979; Coveney et al., 1987), la presencia de feldespatos autigénicos en las rocas carbonatadas (Hearn y Sutter, 1985; Hearn, et al., 1987), la illitización de las bentonitas (Elliot y Aronson, 1987) y la alteración hidrotermal de los carbones (Daniels et al., 1990).

\subsection{Subtipos}

La aplicación de los modelos derivados del estudio de los depósitos de $\mathrm{Pb}-\mathrm{Zn}$ del valle del Mississippi a otros distritos a nivel mundial originó que se considerase la afiliación de otros depósitos encajonados en carbonatos, de baja temperatura y ligados a salmueras de cuenca a este tipo. No obstante, algunos de estos depósitos o distritos presentan suficientes diferencias con el "modelo clásico" como para que se consideren tipos o subtipos diferentes.
En este artículo de revisión los hemos llamado "subtipos" para mantener una clasificación jerárquica, aunque algunos autores suelen considerarlos un tipo diferente a los MVT, aunque muy próximos.

\subsubsection{Subtipo Alpino-Apalachiano}

Son depósitos que presentan características muy similares a los MVT americanos. Reciben el nombre de las mineralizaciones de $\mathrm{Zn}-\mathrm{Pb}$ encajonadas en carbonatos paleozoicos o triásicos de los orógenos Apalachiano (William-Jones et al., 1992) o Alpino, aunque los mejores ejemplos parecen encontrarse al sur de la Montañas Rocosas (Laznicka, 1985).

Estos depósitos son muy similares a los de tipo MVT, con la única diferencia significativa de que encajan en materiales carbonatados deformados (Laznicka, in op. cit.), y que los depósitos tienen un marcado control estructural, en relación con áreas móviles corticales, zonas de rifting o colisión (Sawkins, 1972), en comparación con la mayor filiación de los MVT s.s. con zonas cratónicas y estables. En ocasiones, estos depósitos se asocian con fenónemos de emersión-karstificación desarrollados durante una determinada orogenia (indicios alpinos o béticos en España). En otros casos, pueden ser removilizaciones tectónicas de antiguos yacimientos MVT s.s. (distrito de MascotJefferson, EE. UU.; Laznicka, 1985).

Las mineralizaciones se desarrollan preferentemente en brechas distribuidas a lo largo de zonas de fracturación de escala variable, bolsadas irregulares a grandes rasgos paralelas a la estratificación, niveles localmente brechados a lo largo del contacto entre distintas litologías o rellenos de cavidades preexistentes.

Los depósitos del subtipo Alpino-Apalachiano clásicos contienen $\mathrm{Zn}$ y $\mathrm{Pb}$ esencialmente, aunque existen numerosos depósitos e indicios con $\mathrm{F}, \mathrm{Ba}, \mathrm{Sb}$ y $\mathrm{Hg}$ que presentan características comunes (Laznicka, 1985).

\subsubsection{Subtipo Irlandés}

Estos depósitos son problemáticos y aun existe un intenso debate sobre su origen y su carácter singenético o epigenético (relación con la roca encajonante). Presentan un conjunto de características comunes a los MVT clásicos junto con otras que son específicas para estos depósitos, por lo que se propuso denominarlos de forma diferente a los MVT “clásicos”. Los depósitos más característicos aparecen en los Irish Midlands (Navan, Tynagh, Lisheen, Silvermines, Galmoy, Ballinalack; Figura 7) y constituyen el distrito más rico en zinc conocido a nivel mundial, si se tiene en cuenta su riqueza en zinc en función de las toneladas de metal presente por kilómetro cuadrado (Singer, 1995). Típicamente, estos depósitos aisladamente presentan un tonelaje inferior a $10 \mathrm{Mt}$ con leyes de $\mathrm{Zn}$ de alrededor del 5-6\%, Pb 1-2\% y leyes de Ag de alrededor de $30 \mathrm{~g} / \mathrm{t}$. El depósito más grande conocido es Navan que ha producido $36 \mathrm{Mt}$ y con unas reservas aproximadas de $41.8 \mathrm{Mt}$ con un $8 \%$ de $\mathrm{Zn}$ y $2 \%$ de $\mathrm{Pb}$. Estos depósitos aunque en 
general son menores en tamaño que los de tipo SEDEX, resultan muy atractivos debido a que son polimetálicos y presentan una mineralogía muy simple. Otros depósitos de $\mathrm{Zn}-\mathrm{Pb}$ con estas mismas características se han localizado también en otros países (Troya, España; Kootenay Arc, Canadá). Debido tanto a su importancia industrial como a la polémica que aun suscitan, hemos decidido extendernos en su descripción.

Los depósitos irlandeses aparecen encajados en una secuencia de plataforma carbonatada transgresiva de edad Carbonífero inferior, por encima de una secuencia de lechos rojos ("red-beds") del Devónico. En general, los depósitos de tipo Irlandés presentan las siguientes características (Figura 7; Hitzman y Beaty, 1996; Hitzman et al., 2002):

1) Encajan preferencialmente en las unidades carbonatadas, no arcillosas, más inferiores.

2) Aparecen a lo largo o adyacentes a fallas normales que actuaron como conductos de ascenso de los fluidos hidrotemales. En la mayoría de los casos, estas fallas se mineralizaron dando lugar a filones o vetas con metales base que fueron explotadas en la antigüedad (Shalee Deposits cortando la Old Red Sandstone; Taylor y Andrew, 1978).

3) Alrededor de los depósitos aparece una aureola de dolomita que se extiende varias decenas de metros más allá del cuerpo de sulfuros. Esta dolomita es de grano fino, está típicamente enriquecida en hierro y localmente presenta brechificaciones. Ocasionalmente se observan halos de Mn alrededor de algunos depósitos.

4) Presentan una mineralogía muy parecida a la de los MVT s.s., con esfalerita y galena como los principales sulfuros. Los sulfuros de hierro (pirita, marcasita) aparecen en cantidades variables, aunque en algunos depósitos pueden llegar a ser predominantes. La barita aparece en todos los depósitos en cantidades también muy variables, llegando a ser dominante (Ballynoe Deposit, Boyce et al., 2003). Además, muchos depósitos también contienen cantidades menores de tenantita, calcopirita y/o sulfosales de $\mathrm{Pb}-\mathrm{Cu}$-Ag-As.

5) En general, son depósitos estratoligados ("stratabound"), normalmente mantos masivos a pequeña escala pero que presentan morfología sedimentarias a gran escala.

6) Los sulfuros suelen presentar texturas complejas. Estas van desde el reemplazamiento de la roca encajonante por sulfuros de grano fino, anhedrales y hasta coloformes, hasta el llenado de cavidades de disolución por sulfuros desde coloformes hasta cristalinos y tamaño de grano grueso. Así mismo, se encuentran texturas geopetales de precipitación de sulfuros en cavidades.

7) El estudio de inclusiones fluidas sugiere que la temperatura de las soluciones hidrotermales se situaba entre 150 y $240{ }^{\circ} \mathrm{C}$, con salinidades variables de entre 10

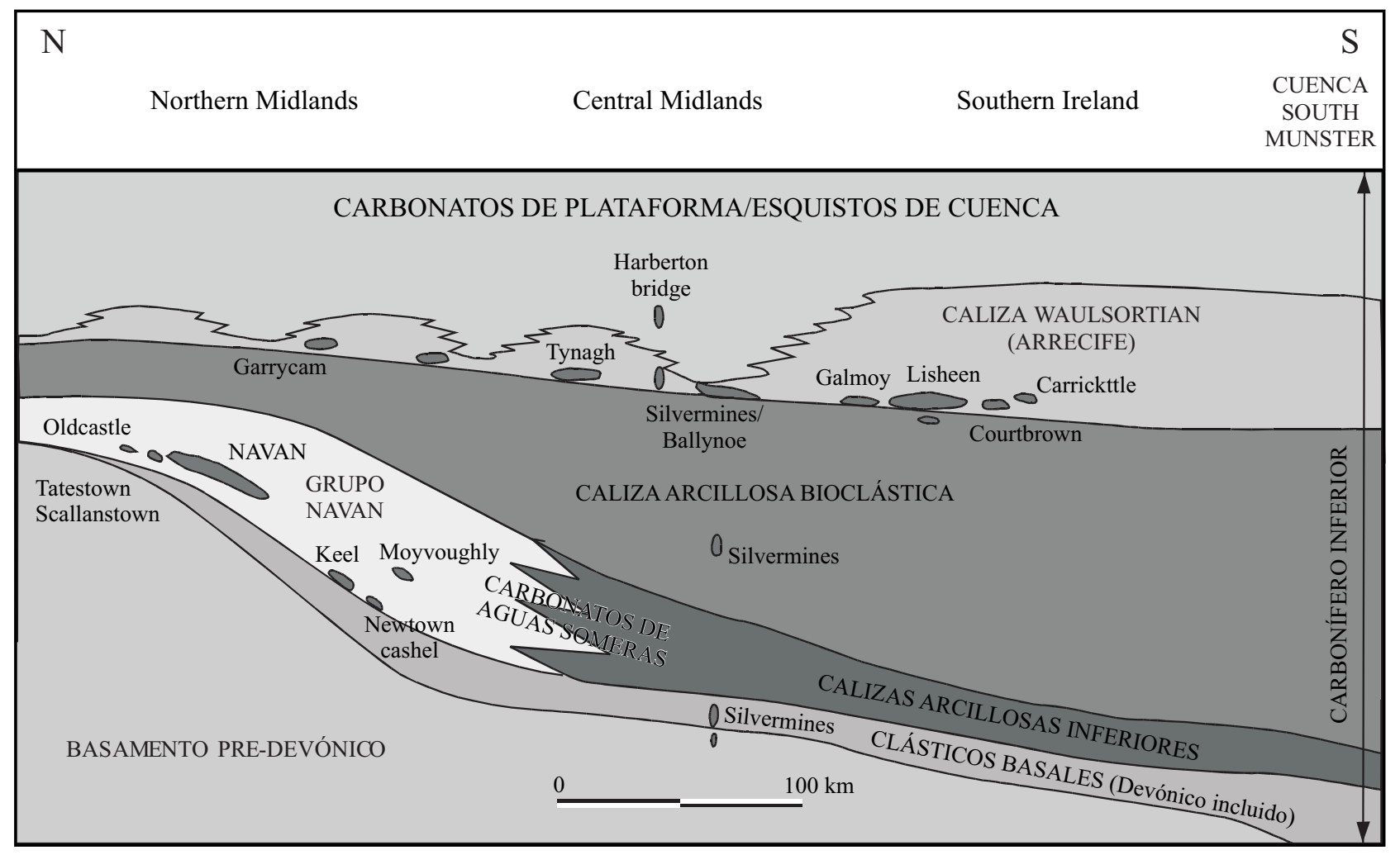

Figura 7. Distribución estratigráfica de los principales depósitos de Pb-Zn de tipo Irlandés en rocas del Carbonífero Inferior. Modificado de un folleto del Department of Communications, Marine and Natural Resources del Gobierno de Irlanda (2004). 
y $23 \%$ eq. en peso de $\mathrm{NaCl}$ en las zonas de precipitación de sulfuros.

8) Estos depósitos se han formado por la mezcla de soluciones moderadamente salinas, ligeramente ácidas y pobres en azufre que transportaban los metales con fluidos relativamente ricos en azufre, probablemente derivados del agua de mar carbonífera.

En los Irish Midlands, este tipo de depósitos presentan un zoneamiento a nivel de distrito, situandose los más ricos en $\mathrm{Cu}$ y $\mathrm{Ag}$ en la parte sur, que a su vez se corresponden con los que presentan una mayor dolomitización del carbonato encajonante.

Tanto las rocas encajonantes como la texturas que presentan los depósitos de tipo Irlandés son en muchos casos similares a los del tipo MVT s.s., aunque difieren al ser mucho más ricos en $\mathrm{Cu}, \mathrm{Ag}$ y Fe que la mayoría de los MVT. Así mismo, contienen extensas zonas de sulfuros con aspecto masivo, a menudo muy ricas en sulfuros de hierro.

Uno de lo puntos más críticos a la hora de integrar estos depósitos dentro de los MVT es su carácter singenético o epigenético. Existen evidencias que apuntan a ambos lados y que, por tanto, provocan una fuerte controversia a la hora de determinar el tiempo de formación de estos depósitos. En general, la mayor parte de los depósitos se formaron por debajo del lecho marino (Navan, Anderson et al., 1998) a favor de fallas normales que actuaron como conductos de alimentación de los cuerpos masivos, y que cortaron los depósitos de la Old Red Sandstone, de edad Devónica, descargando los fluidos en los carbonatos del Carbonífero basal. No obstante, se han encontrado evidencias de formación de algunos depósitos sobre el lecho marino (Tynagh, Silvermines y Ballynoe) como consecuencia de la descarga de los fluidos mineralizantes a favor de fracturas que cortaron toda la serie, dando origen a chimeneas de descarga hidrotermal con su fauna típica conservada constituida por gusanos tubulares piritizados y tapices bacterianos hematitizados (Larter et al., 1981; Banks, 1985; Boyce et al., 2003). Algunos autores, no obstante, niegan la existencia de características exhalativas en estos depósitos (Hitzman y Beaty, 1996; Johnston, 1999; Peace y Wallace, 2000). Estos mismos depósitos presentan evidencias de epigénesis bajo la forma de vetas de esfalerita y barita cortando la Old Red Sandstone (Ordovícico) así como la substitución de los miembros inferiores carbonatados de edad Carbonífero. Esta aparente contradicción es una de las características típicas de los depósitos de metales base en carbonatos de tipo Irlandés que, muy probablemente, representan una transición entre depósitos de tipo MVT s.s. y depósitos de tipo SEDEX.

\subsubsection{Subtipo Laisvall, encajonados en rocas siliciclás- ticas}

En este apartado se incluyen un conjunto de mineralizaciones de $\mathrm{Pb}-\mathrm{Zn}(\mathrm{Cu})$ que presentan muchas similitudes con los depósitos tipo MVT, hecho que ha provocado que se cuestione la necesidad de diferenciarlos (Barton com. per. en Barnes, 1975, en Schrijver, 1992). Ejemplos de estos depósitos son Laisvall, en los Caledónides de Suecia (Richard, 1983; Lindblom, 1986), Largentière y St. Sébastien d'Aigrefeuille en Francia (Ngoyanadji, 1988), Yava y George Lake en Canadá (Sangster y Vaillancourt, 1990), Mechernich y Maubach en Alemania (Friedrich et al., 1993) y Zeida en Marruecos (Schrijver, 1992).

Estas mineralizaciones encajan en areniscas, conglomerados o arkosas, tanto de origen continental como de origen litoral, que pasan a techo a carbonatos marinos y/o evaporitas, y que se disponen discordantes sobre un zócalo granítico o con gneises generalmente ricos en plomo (Bjorlykke y Sangster, 1981). A menudo las areniscas tienen tonalidades grisáceas por el ambiente reductor que viene favorecido por la presencia de materia orgánica.

A gran escala la mineralización se concentra en disconformidades e irregularidades topográficas. A más pequeña escala la mineralización se concentra en el fondo de canales en donde la porosidad de la arenisca se ve aumentada por el tamaño de grano, por la presencia de cicatrices erosivas, por estructuras de deformación por peso o escape de agua, etc. En algunos depósitos (Shawangungh, EE. UU.; Crawford y Beales, 1983), la mineralización puede estar relacionada con la aparición de una porosidad secundaria (pequeñas fracturas) generada durante los últimos estadios de la diagénesis. En la mayoría de los casos el periodo mineralizador fue anterior a la consolidación y la oclusión de la porosidad primaria.

La mineralización es, en general, más rica en $\mathrm{Pb}$ que en $\mathrm{Zn}$, presentando cantidades variables de $\mathrm{Ag}$ y $\mathrm{Cu}$. A pesar de que Laisvall ha sido la mina de plomo más rica de Europa, los contenidos medios son generalmente bajos: 2 al $5 \%$ de $\mathrm{Pb}, 0.2$ al $0.8 \%$ de $\mathrm{Zn}$ y 1 a $20 \mathrm{~g} / \mathrm{t} \mathrm{Ag}$, afectando su posible interés económico. Algunos de los minerales presentes son: galena, pirita, esfalerita, calcopirita, bravoita, millerita, cerusita, fluorita, barita, cuarzo, ankerita, freibergita, bournonita, jamesonita, dolomita, marcasita, piromorfita, calcita, malaquita, calcedonia, coronadita y calcosina (Tritlla y Canals, 1997).

Las temperaturas de homogeneización de las inclusiones fluidas, asimilables en muchos casos a las temperaturas de formación, varían desde los $35{ }^{\circ} \mathrm{C}$ de Largentière (Ngoyanadji, 1988) a los $188^{\circ} \mathrm{C}$ del depósito de Shawangunk (Wilbur et al., 1990 en Schrijver, 1992), con una media que supera los $100{ }^{\circ} \mathrm{C}$ en la mayoría de depósitos. Las salinidades son muy variables (entre 0.2 y $24.5 \%$ eq. en peso de $\mathrm{NaCl}$ ), con una media que supera el $15 \%$ eq. en peso de $\mathrm{NaCl}$.

\subsubsection{Subtipo fluorítico}

Un caso especial de depósitos encajados en carbonatos es el distrito de Northern Pennines (Dunham, 1983, 1990 a, 1990b). Debido a sus especiales características, Dunham (in op. cit.) propuso la creación de un subtipo "fluorítico" dentro de la categoría de los depósitos MVT en donde 
encajar estos depósitos junto con los de fluorita del distrito de Illinois-Kentucky. Muy probablemente los mecanismos y las condiciones de deposición son muy similares a las mineralizaciones hasta ahora tratadas y su principal diferencia radica en el tipo de porosidad que ha funcionado como trampa de la mineralización.

Estos depósitos encajan en fracturas y, ocasionalmente, reemplazan los carbonatos de la serie Carbonífera, dando lugar a mantos o "flats" de poca extensión, siempre en relación con fracturas que han actuado como canales para las soluciones mineralizantes. La paragénesis primaria es más compleja que la de los depósitos de tipo MVT, y se caracteriza por la substitución de la ganga sulfatada (barita) por una ganga constituida por carbonatos raros de $\mathrm{Ba}$ (witherita, baritocalcita, alstonita, etc.) y más raramente zeolitas de $\mathrm{Ba}$ (harmotoma). Otro hecho característico de estas mineralizaciones es que los carbonatos de Ba se encuentran a menudo alterados a barita microgranuda. Así mismo, la alteración de las esfaleritas ricas en mercurio puede dar lugar a la acumulación de cinabrio pulverulento. Tanto constituyendo parte de las salbandas de los depósitos como en el interior de la mineralización aparecen dickita, berthierita, chamosita, cookeita, muscovita y Ba-muscovita. En ocasiones ha sido posible determinar la presencia de hidrocarburos (parafinas y oleofinas), normalmente en la parte central de los filones (Dunham, 1990a, 1990b; Tritlla y Canals, 1997).

Los minerales primarios se disponen en bandas simétricas paralelas a los bordes de los filones, con texturas que indican la presencia de espacios abiertos (caras cristalinas creciendo hacia el centro del filón). Las temperaturas de formación se hallan dentro de los límites aceptados para las mineralizaciones MVT (110-260 ${ }^{\circ} \mathrm{C}$; Dunham, 1990a, 1990b). El emplazamiento de las mineralizaciones (filones y mantos -flats-) provoca en todos los casos la alteración de la roca de caja, dando lugar a la transformación del carbonato carbonífero en una roca ankerítica, con cantidades variables de siderita, calcedonia y, más raramente, sericita. Ocasionalmente se ha puesto de manifiesto el reemplazamiento parcial de la roca encajonante por fluorita de grano fino, así como se han encontrado fósiles substituidos por cuarzo, fluorita, sericita y galena. Si la mineralización encaja en diques de cuarzo-dolerita, esta roca se encuentra alterada a carbonatos secundarios, kaolinita, otros minerales del grupo de las arcillas, anatasa y leucoxeno, junto con cuarzo y apatito residual. Si los depósitos encajan en areniscas o en pizarras, estas últimas suelen encontrarse parcialmente silicificadas.

\subsubsection{Otros depósitos de posible afinidad}

Tipo Terlingua. Entre los depósitos de baja temperatura encajados en carbonatos es posible distinguir los depósitos de tipo "Terlingua" (Yates y Thompson, 1959; Origlieri, 1990). La mineralización está controlada por fracturas sobre las que se desarrollan cavidades kársticas en forma de embudo que son rellenadas por la mineralización.
Esta se caracteriza por la ausencia de sulfuros de metales base (galena, esfalerita, calcopirita), apareciendo en su lugar cinabrio y, en menor proporción, otros minerales de mercurio. Desgraciadamente no se disponen de datos sobre la temperatura o la composición de las soluciones mineralizantes.

Filones con ganga carbonatada. Repartidos a lo largo del Orógeno Hercínico europeo, con predominio en las zonas externas, existe un conjunto de depósitos filonianos caracterizados por presentar una asociación de sulfuros de $\mathrm{Pb}$ y $\mathrm{Zn}$ con ganga carbonatada. Ejemplos de estas mineralizaciones son los depósitos de Jebel Aouam en Marruecos, Pchibram en el Macizo de Bohemia (Zák y Dobers, 1991); Saint Salvy en el Macizo Central Francés (Jebrak, 1984), el grupo de minas San Quintín del Valle de Alcudia en Ciudad Real, (Palero et al., 1991); las minas de Cierco en los Pirineos de Lérida (Johnson et al., 1996), y las minas de Bellmunt del Priorato en las Cordilleras Costeras Catalanas, todas ellas en España (Cardellach et al., 1990; Melgarejo, 1992).

Estos depósitos filonianos presentan morfologías en bandas, generalmente muy inclinadas, con variaciones rápidas de grosor $\mathrm{y}$, a pesar de su gran desarrollo vertical (superando ocasionalmente los 1,000 m), presentan una cierta zonación vertical. La posición de estos filones viene inducida por la presencia de discontinuidades precoces: pórfidos, estratos cuarcíticos, etc. Según Jebrak (1984) estas mineralizaciones son el testimonio de sistemas hidrotermales localizados al lado de los granitos tardi-hercínicos, en condiciones de semiprofundidad (2-4 Km). Se trata de las mineralizaciones Estefanienses tardías de Michard et al. (1990).

La mineralogía de estos depósitos es muy variada y depende de cada yacimiento. La ganga es principalmente carbonatada (calcita, siderita, dolomita-ankerita), aunque localmente el cuarzo puede dominar, como pasa en algunas zonas de Pchibram (Zák y Dober, 1991).

\subsection{Geoquímica de los fluidos mineralizantes}

\subsubsection{MVT sensu stricto}

Los procesos responsables de la formación de los depósitos de tipo MVT han sido el foco de estudio y debate durante muchos años, por lo que existe gran cantidad de literatura al respecto. En este punto intentaremos hacer una síntesis de los puntos más relevantes a los que se ha llegado.

Las inclusiones fluidas en estos depósitos son normalmente abundantes, y han sido estudiadas principalmente en calcita, dolomita, fluorita, barita, cuarzo y esfalerita. Estas inclusiones suelen ser muy simples, generalmente bifásicas acuosas con una pequeña burbuja de vapor ( $<10 \%$ del volumen de la inclusión), a veces acompañadas por inclusiones acuosas monofásicas o de petróleo. Estas inclusiones suelen presentar un comportamiento complejo cuando son estudiadas a baja temperatura (Wilkinson, 
2001). En primer lugar, aparecen comportamientos metaestables a muy baja temperatura (a menudo por debajo de $-60{ }^{\circ} \mathrm{C}$ ), característicos de inclusiones fluidas de muy alta salinidad. Las primeras fusiones aparentes también se observan a muy baja temperatura, con valores reportados a menudo de hasta $-70{ }^{\circ} \mathrm{C}$, temperaturas que han servido de excusa para proponer la presencia de cationes exóticos

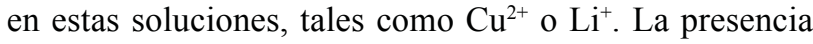
de estos cationes en cantidades importantes es más que improbable, tal y como se ha demostrado mediante la realización de análisis completos de las inclusiones fluidas mediante el método de crush-leach. La explicación más probable para las temperaturas tan bajas obtenidas durante la primera fusión radica en la presencia de fenómenos de metaestabilidad (Davis et al., 1990), o bien por un aumento del tamaño de grano del hielo en condiciones subsólidus, a medida que el hielo amorfo va recristalizando a hidratos de sal estequiométricos (Wilkinson, 2001). La primera fusión claramente observada suele aparecer alrededor de -50 a $-55^{\circ} \mathrm{C}$, correspondiendo al eutéctico estable del sistema $\mathrm{NaCl}-\mathrm{CaCl}_{2}-\mathrm{H}_{2} \mathrm{O}$. La última fase en fundir puede ser indistintamente hielo o hidrohalita en función de la salinidad total de la inclusión. La medición precisa de la temperatura de fusión de ambos sólidos (hielo e hidrohalita) permite estimar la relación $\mathrm{NaCl} / \mathrm{CaCl}_{2}$ (Oakes et al., 1990).

$\mathrm{El}$ estudio de las inclusiones fluidas ha resultado crucial en la determinación de algunas de las características más sobresalientes de los MVT. Así, las densidades de los fluidos mineralizantes son altas $\left(>1,000 \mathrm{~kg} / \mathrm{m}^{3}\right.$; Wilkinson,
2001) y exceden la de la mayoría de los fluidos crustales conocidos, por lo que tiene implicaciones muy importantes a la hora de modelizar el flujo regional de fluidos. La presión de fluido suele exceder la presión de vapor, por lo que los fenómenos de ebullición son extremadamente raros, aunque existen excepciones (Jones y Kesler, 1992). Las temperaturas determinadas son generalmente bajas, y suelen situarse por debajo de los $150^{\circ} \mathrm{C}$, con excepciones (Figura 8; Shelton et al., 1992; Tritlla y Cardellach, 1997). Las salinidades son altas (Figura 8), a menudo por encima de los $15 \%$ eq. en peso de $\mathrm{NaCl}$, y es común la presencia de compuestos orgánicos bajo la forma de inclusiones de hidrocarburos y/o bitumen sólido (Wilkinson, 2001; González-Partida et al., 2003; Tritlla et al., 2004b, por ejemplo). La fase gas de las inclusiones suele contener $\mathrm{CO}_{2}$ y $\mathrm{CH}_{4}$ en concentraciones variables llegando hasta algunas unidades de \% molar (Roedder, 1967; Norman et al., 1985; Jones y Kesler, 1992; González-Partida et al., 2003). Los cationes presentes en solución, en orden de abundancia, son: $\mathrm{Na}, \mathrm{Ca}>>\mathrm{K}, \mathrm{Mg}, \mathrm{Fe}$ y $\mathrm{B}$, característicamente con una alta relación $\mathrm{Na} / \mathrm{K}$ de alrededor de $20 \%$ en peso. Todas estas características son bastante constantes a lo largo de los MVT conocidos, aunque pueda existir una amplia variación en la cantidad y proporción de los metales, la mineralogía u otros parámetros que se puedan establecer entre distritos. Todo esto sugiere que los fluidos responsables del transporte de los metales son similares en la mayoría de casos, y que las diferencias que se observan a nivel de los diversos distritos son consecuencia de variaciones en los

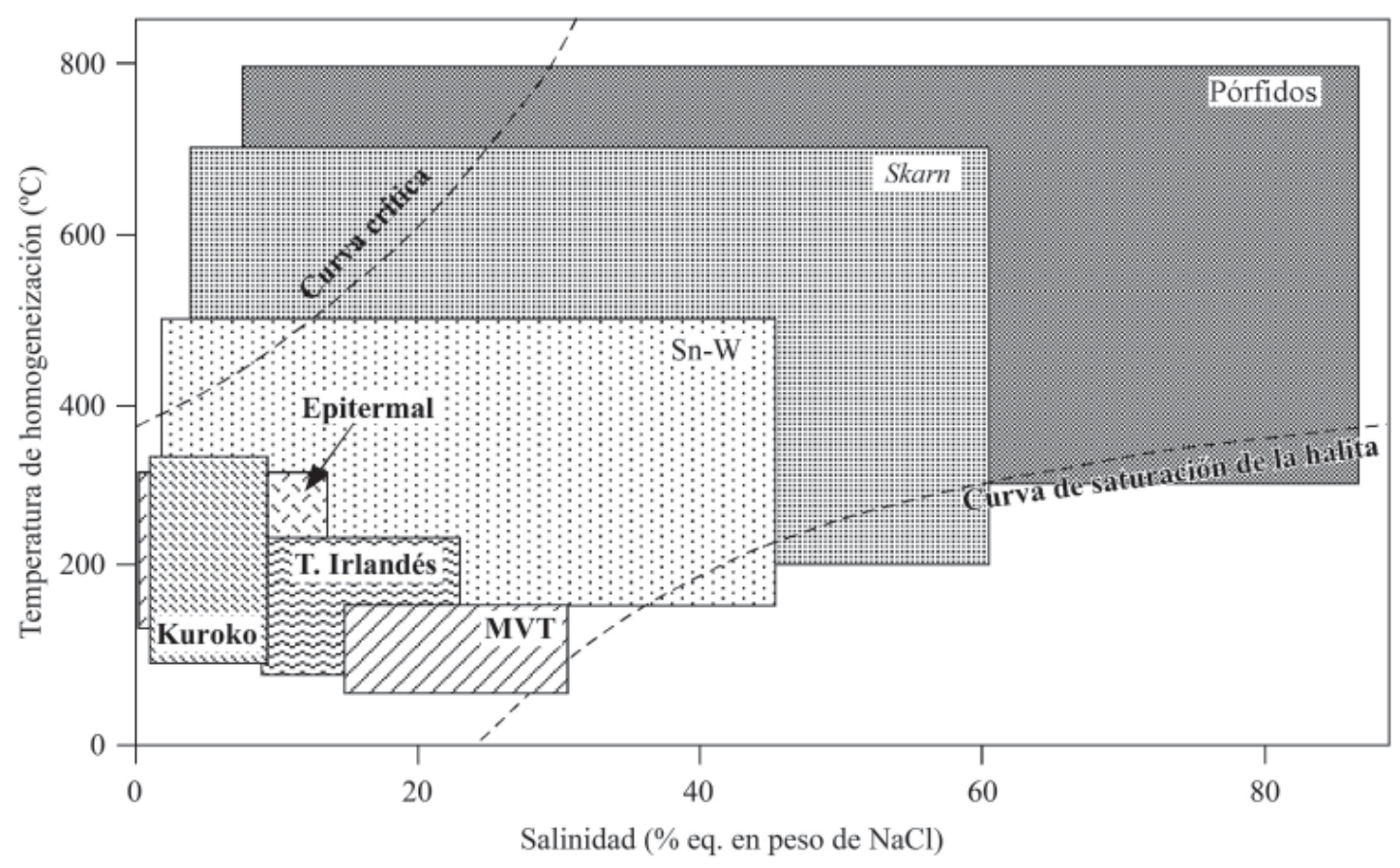

Figura 8. Diagrama temperatura de homogeneización vs. salinidad ilustrando los rangos típicos para un conjunto de depósitos. Los campos dibujados no se han de considerar definitivos, ya que existen composiciones para estos tipos de depósitos fuera de los mismos. Modificado de Wilkinson (2001). 
procesos geoquímicos que ocurren durante el transporte de las soluciones y de la interacción entre estos fluidos y la roca encajonante en el sitio de formación del depósito. Así, a partir de la gran similitud que guardan los fluidos atrapados en los depósitos tipo MVT y la composición de las salmueras petroleras, particularmente su alta salinidad, alta densidad y la riqueza en $\mathrm{CaCl}_{2}$, varios autores han concluido que dichos fluidos mineralizantes son verdaderas salmueras de cuenca (Sverjensky, 1984; Hanor, 1996; Tritlla y Cardellach, 1997; Gleeson et al., 2000; Grandia et al., 2003a, 2003b).

Tanto los datos experimentales (Barrett y Anderson, 1988), los modelos termodinámicos propuestos (Anderson, 1975; Barrett y Anderson, 1988; Sverjensky, 1981, 1984), los análisis de las inclusiones fluidas (Hall y Friedman, 1963; Roedder, 1967; Viets y Leach, 1990; Plumlee et al., 1994; Counter-Benison y Lowenstein, 1997) y su comparación con salmueras contemporáneas (Carpenter et al., 1974) han demostrado que este tipo de fluidos pueden transportar cantidades apreciables, del orden de ppm, de metales de base, corroborando, por tanto, el modelo básico propuesto para los fluidos en estos depósitos. No obstante, la presencia de grandes cantidades de metales junto con azufre reducido son dos condiciones mutuamente excluyentes si consideramos un solo fluido. Esto implica que (1) se requieren grandes volúmenes de fluido, (2) los metales y el azufre vienen de fuentes diferentes y se mezclan en la zona en la que se está formando el depósito, o (3) que el azufre es transportado bajo forma oxidada (sulfatos, esencialmente), y que se reduce en el sitio en el que se está formando el depósito. Las dos últimas posibilidades son las más ampliamente aceptadas por los diversos autores que han trabajado en este tipo de depósitos.

Aún quedan algunas cuestiones fundamentales por responder tanto sobre el origen de los metales, como del azufre y de la salinidad. Este último punto ha recibido especial atención en los últimos años debido al origen complejo de la salinidad en estos fluidos, involucrando tanto salmueras producto de evaporación del agua marina junto con salmueras secundarias, producto del lavado de depósitos de halita (Kesler et al., 1995; Viets et al., 1996; Tritlla y Cardellach, 1997; Grandia et al., 2003a, 2003b; Tritlla et al., 2004a, b).

\subsubsection{Subtipo Irlandés}

A diferencia de los MVT s.s., los datos existentes en la literatura sobre la composición de los fluidos mineralizantes son muy escasos.

En los depósitos de tipo Irlandés, las inclusiones fluidas han sido estudiadas esencialmente en dolomita, calcita, barita, cuarzo y esfalerita provenientes tanto de los depósitos en explotación, indicios mineralizados así como del sistema de filones que suelen situarse encajonados en el zócalo, siempre por debajo de los cuerpos mineralizados, y que parecen representar los conductos de alimentación de, al menos, parte de los depósitos. Aun así, los únicos depósitos estudiados en profundidad son los de Silvermines (Samson y Russell, 1987), Tynagh (Banks y Russell, 1992) y Lisheen (Thompson et al., 1992; Eyre et al., 1996; Eyre, 1998), junto con estudios fragmentarios en Navan y Keel (Everett et al., 1997, 1999).

$\mathrm{Al}$ igual que en el caso anterior las inclusiones fluidas presentes en estos depósitos son muy simples. Son predominantemente inclusiones acuosas bifásicas, con una pequeña burbuja de vapor $(<10 \%$ del volumen total de la inclusión), aunque también pueden aparecer raras inclusiones monofásicas. Se han observado tres grandes grupos de inclusiones (Figura 9):

1. Inclusiones de salinidad (10-15\% eq. en peso de $\mathrm{NaCl}$ ) y temperaturas $\left(150-200^{\circ} \mathrm{C}\right)$ moderadas, con una primera temperatura de fusión alrededor de $-20{ }^{\circ} \mathrm{C}$, indicando la predominancia de $\mathrm{NaCl}$ como sal en la solución;

2. Inclusiones con fluidos acuosos de alta salinidad (20-25\% eq. en peso de $\mathrm{NaCl}$ ) y baja temperatura de homogeneización $\left(<150{ }^{\circ} \mathrm{C}\right)$, observándose la primera fusión a temperaturas de alrededor de $-55^{\circ} \mathrm{C}$, indicativas de una salmuera mixta del tipo $\mathrm{NaCl}-\mathrm{CaCl}_{2}$.

3. Un conjunto de inclusiones subordinadas, de baja salinidad $(<5 \%$ eq. en peso de $\mathrm{NaCl})$ y con temperaturas de homogeneización bajas a moderadas $\left(120-200^{\circ} \mathrm{C}\right)$ cuya composición en electrolitos está dominada por $\mathrm{NaCl}$.

En general, se acepta que la mineralización se formó debido a la mezcla de las soluciones representadas por los fluidos 1 y 2 , tal y como se observa en los respectivos diagramas de Th vs. salinidad (Wilkinson, 2001). En principio, el fluido 1 sería el responsable del transporte de los metales junto con azufre de origen "hidrotermal" (Everett et al., 1999), mientras que el fluido 2 sería rico en azufre bacteriogénico. Recientemente, se ha detectado la presencia de $\mathrm{CO}_{2}$ (formación de clatrato) en las inclusiones en esfalerita del depósito de Navan, así como en los cuarzos de los filones infrayacentes. La presencia de $\mathrm{CO}_{2}$ se ha relacionado con la participación de fluidos de alta temperatura, originados en el basamento, y que habrían provocado la generación de acidez en el fluido hidrotermal, a través de hidrólisis debido al enfriamiento y ascenso de la solución (Wilkinson, 2001). Esta generación de acidez explicaría, al menos en parte, la disolución del carbonato en la zona mineralizada y su reemplazamiento parcial.

\subsubsection{Origen de los electrolitos en solución}

Clásicamente, se relacionó la presencia de salmueras de alta salinidad en esta tipología a la lixiviación de niveles evaporíticos presentes en la cuenca. Esto contrastaba con la ausencia de dichos niveles en algunas cuencas que, a su vez, contenían algunos de los depósitos volumétricamente más importantes, como el distrito del Upper Mississippi Valley en la cuenca de Illinois (EE. UU.).

Hanor $(1987,1994)$ propuso varios mecanismos a partir de los cuales se podrían generar dichas salmueras: 


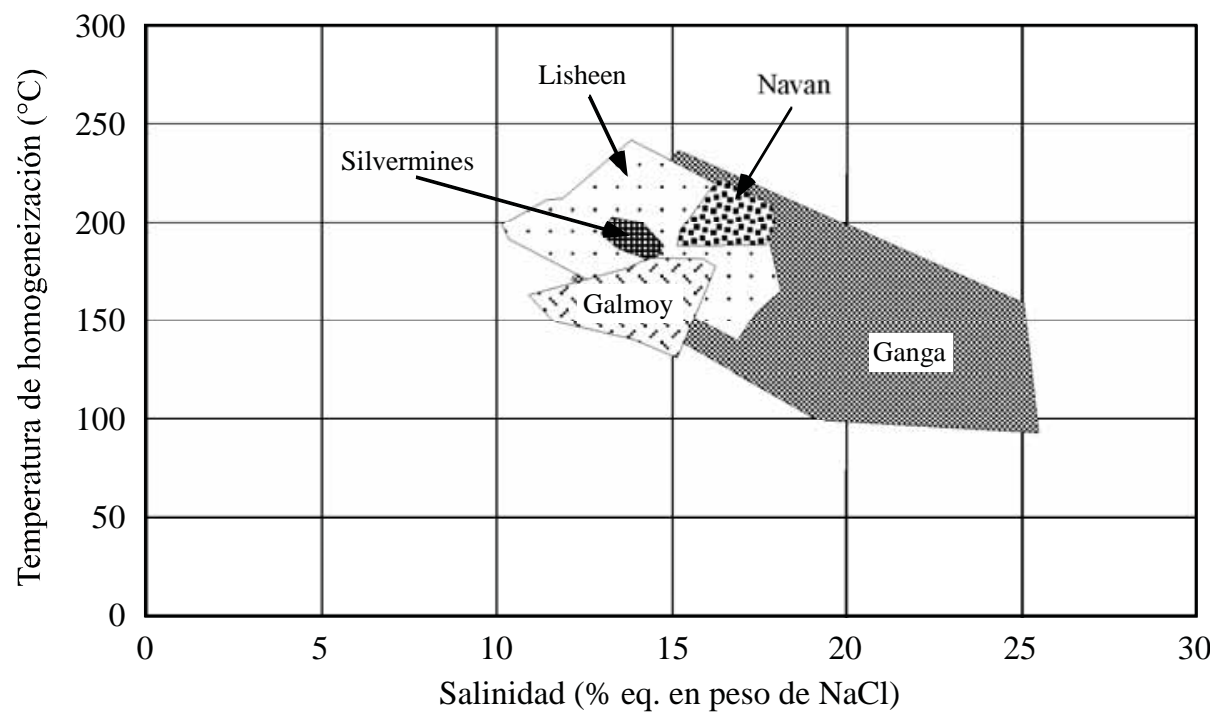

Figura 9. Diagrama temperatura de homogeneización vs. salinidad ilustrando los rangos típicos para los depósitos de tipo Irlandés. Modificado de Wilkinson (2001).

1) Evaporación de agua marina. La pérdida progresiva de agua por evaporación a partir de agua de origen marino genera aguas residuales ricas en electrolitos. La composición de esta agua va cambiando a medida que van precipitando las diferentes sales.

2) Evaporación de agua continental. A diferencia del agua marina, la evaporación de aguas continentales puede dar lugar a un amplio espectro de salmueras, normalmente con la presencia de carbonatos y sulfatos de $\mathrm{Na}$ y $\mathrm{Mg}$.

3) Disolución de evaporitas. La interacción de una agua de cualquier origen con un cuerpo de evaporitas puede dar lugar a salmueras caracterizadas por la presencia de grandes cantidades de $\mathrm{NaCl}$ o de sulfato de calcio debido a la disolución de niveles ricos en halita o en yeso (o anhidrita) respectivamente.

4) Osmosis inversa. Las salmueras se formarían por la circulación de un fluido por niveles de arcillas semipermeables. Debido a su neutralidad eléctrica, el agua pasa con facilidad por estos niveles, mientras que los iones disueltos son retenidos y concentrados en un fluido residual salino a causa de las repulsiones electrostáticas de los minerales de la arcilla. Éste es un proceso que ha sido invocado en repetidas ocasiones, pero que es de difícil comprobación.

\subsubsection{Geoquímica de halógenos}

Las relaciones entre los diferentes cationes y aniones en una solución permiten obtener información tanto sobre el origen de los solutos así como de las interacciones que dicho fluido ha sufrido con las rocas a través de las que ha circulado durante su historia. Tanto las concentraciones absolutas como las relaciones entre los halógenos se han venido utilizando como trazadores del movimiento de los fluidos debido a su comportamiento conservativo.
El trazado de este movimiento se puede relacionar con la formación de cementos y la pérdida de porosidad en reservorios de petróleo y como trazadores para la localización de depósitos de sulfuros de $\mathrm{Zn}-\mathrm{Pb}$, al actuar éstas soluciones de cuenca como vehículo para la formación de éstas mineralizaciones.

Los halógenos son unos constituyentes muy importantes de las aguas de formación sedimentarias y son muy buenos indicadores sobre el origen de los fluidos debido a la naturaleza tan conservativa que tienen tanto el $\mathrm{Cl}$ como el $\mathrm{Br}$ en solución. El Cloro es normalmente el anión mayor, constituyendo más del $90 \%$ en peso de los mismos. Se considera que los halógenos se comportan en forma conservativa, es decir, que no intervienen en interacciones diagenéticas agua-roca. Esto es debido a que en las rocas sedimentarias clásticas y en los carbonatos prácticamente no existen minerales halogenados formadores. La única circunstancia en la que las interacciones agua-roca son importantes es cuando el agua entra en contacto con cuerpos de sal.

El Br está considerado como elemento no formador de minerales en cuencas sedimentarias, con excepción hecha de las raras cuencas endorreicas que precipitan boratos (tincalconita, boracita). El I es mucho menos conservativo y se intercambia fácilmente durante las reacciones aguaroca, especialmente cuando éstas rocas son muy ricas en materia orgánica. El flúor existe bajo la forma de fluorita y es probablemente el único halógeno que puede interaccionar fuertemente con la roca encajonante.

Así mismo, la mayoría de las soluciones que circulan en la corteza contienen $\mathrm{Na}$ en solución, y su concentración puede variar en función tanto del origen de dichas soluciones (disolución o precipitación de evaporitas, hidrólisis de minerales con $\mathrm{Na}$ ) así como de la precipitación de minerales que contengan $\mathrm{Na}$ a partir de las mismas (albita). 
Todos estos datos se evaluan mediante su representación en gráficos del tipo $\mathrm{Br} v$ s. $\mathrm{Cl}, \log (\mathrm{Br} / \mathrm{Cl})$ vs. $\log (\mathrm{I} / \mathrm{Cl})$ y/o $\mathrm{Na} / \mathrm{Br}$ vs. $\mathrm{Cl} / \mathrm{Br}$ junto con su comparación con la composición media del agua del mar, de salmueras de cuenca, aguas magmáticas, aguas de sistemas geotérmicos y la evolución del agua de mar durante su evaporación (ver Fontes y Matray, 1993).

En la literatura existen abundantes datos sobre el contenido en iones de las inclusiones fluidas de muchos depósitos MVT (Channer et al., 1993; Kesler et al., 1995; Viets et al., 1996; Grandia et al., 2003a, 2003b; Tritlla y Cardellach, 1997; Tritlla et al., 2004a,b ; Wilkinson, 2001). Tal y como se puede observar en la Figura 10, la mayoría de las salmueras analizadas contienen relaciones $\mathrm{Na} / \mathrm{Br}$ y
$\mathrm{Cl} / \mathrm{Br}$ sensiblemente más bajas que la del agua marina y se sitúan sobre la curva de evaporación del agua marina, indicando que, en principio, estas salmueras se originaron por este tipo de proceso. En cambio, algunos yacimientos (Tri-State, Northern Arkansas y Central Missouri en los EE. UU.; Espadan, España) presentan una composición en halógenos compatible con el lavado de series evaporíticas con presencia de depósitos de halita.

La validez de la utilización de las relaciones anteriormente mencionadas ha sido puesta en duda recientemente por Chi y Savard (1997). Estos autores sugieren que valores más bajos de $\mathrm{Na} / \mathrm{Br}$ y Cl$/ \mathrm{Br}$ que el agua marina pueden ser producto de mezclas entre dos salmueras de composición diferente, una de ellas originada por evaporación y la
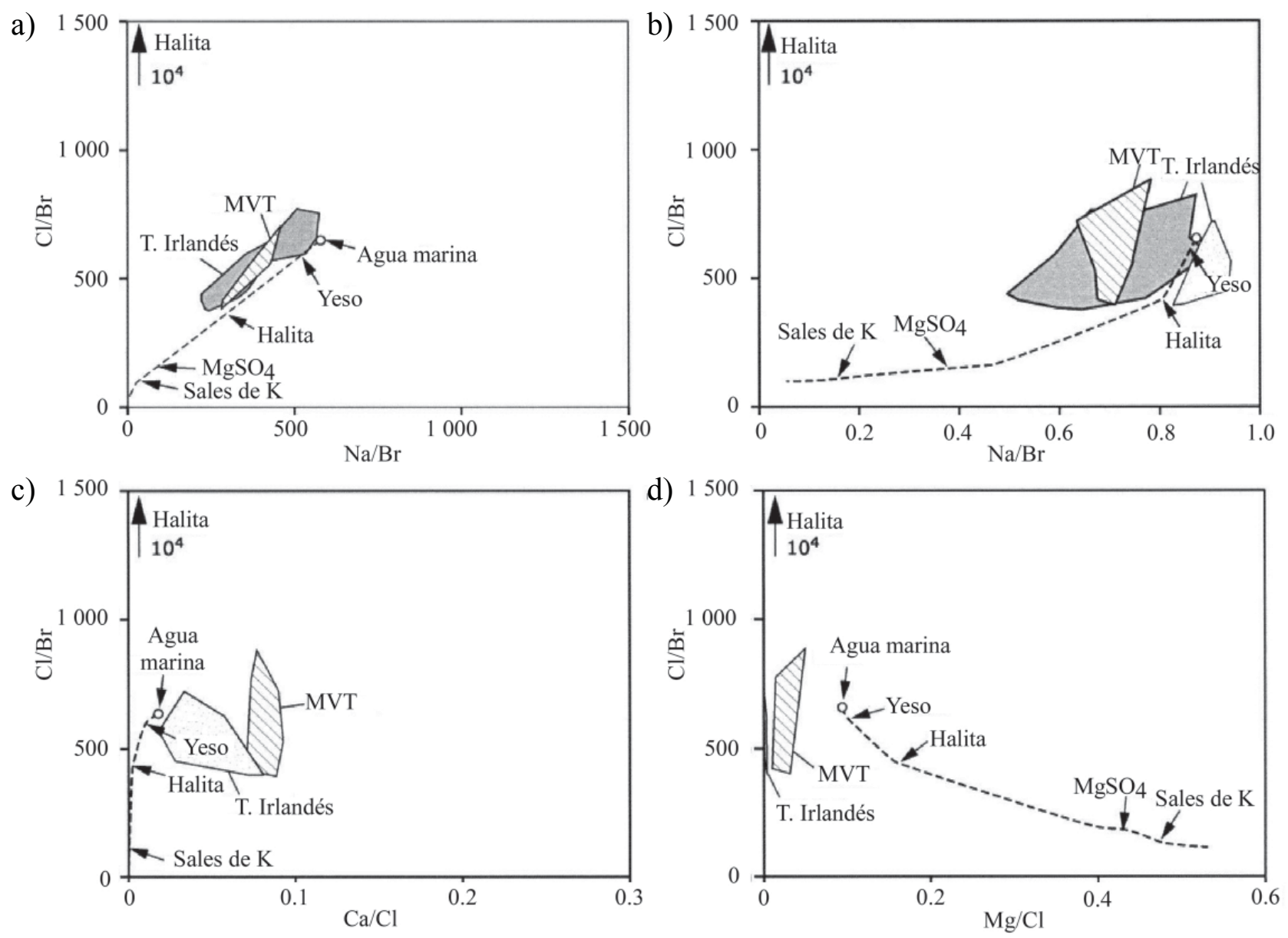

Figura 10. Diagramas utilizados para la discriminación de fluidos basados en las relaciones composicionales de halógenos; modificado de Viets et al., (1996) y Wilkinson, (2001). (a) Cl/Br vs. Na/Br; las línea discontínua representa la trayectoria de evaporación del agua marina (SET) hasta pasado el punto de precipitación de la halita, resultando una salmuera residual enriquecida en $\mathrm{Br}$; las flechas indican los puntos de aparición de minerales evaporíticos durante la secuencia de evaporación. (b) $\mathrm{Cl} / \mathrm{Br}$ vs. $\mathrm{Na} / \mathrm{Cl}$; se han representado las composiciones para las salmueras de los depósitos MVT s.s., para los depósitos del Alto Mississippi, para los depósitos del Viburnum Trend y para los fluidos de los depósitos de tipo Irlandés (datos de Everett et al., 1999); los campos que se dibujan a la izquierda de SET representan fluidos producidos a partir de agua marina evaporada que ha perdido Na, probablemente por reacciones con minerales (p. ej. albitización de las plagioclasas). (c) $\mathrm{Cl} / \mathrm{Br} v s . \mathrm{Ca} / \mathrm{Cl}$; los fluidos en general presentan un enriquecimiento en $\mathrm{Ca}$ con respecto al agua marina evaporada, posiblemente debido a procesos de albitización y/o dolomitización. (d) $\mathrm{Cl} / \mathrm{Br} v s$. $\mathrm{Mg} / \mathrm{Cl}$; las salmueras analizadas están fuertemente empobrecidas en $\mathrm{Mg}$ con respecto al agua marina, posiblemente reflejando su papel en los procesos de dolomitización en los depósitos de tipo MVT o la formación de esmectitas o cloritas en los de tipo Irlandés. Es de destacar que sólo algunos depósitos de tipo MVT presentan salmueras secundarias, producto de la disolución de halita. 
otra asociada a la lixiviación de niveles evaporíticos. No obstante, la presencia de este tipo de mezclas puede ser evaluada tanto mediante otros diagramas (ppm Cl vs. ppm $\mathrm{Na}$, ppm $\mathrm{Cl}$ vs. $\mathrm{Cl} / \mathrm{Br}$ ) como mediante microtermometría de inclusiones fluidas.

\subsection{Edad de los depósitos MVT}

Anderson y Mcqueen (1988) indicaron que el conocimiento preciso de la edad de formación de los depósitos de tipo MVT contituía el reto más importante que se tenía que afrontar ya que en este residía la clave para poder validar los modelos conceptuales y numéricos sobre la génesis de estos depósitos. No obstante, el fechamiento preciso en estos depósitos es sumamente complicado tanto por el carácter estratoligado de los mismos como por la paragenesis que presentan. En el primer caso, estos yacimientos encajan en rocas que ya han sufrido procesos diagenéticos y que actúan como canales de circulación (paleoacuíferos) de los fluidos mineralizantes. Debido a que en algunos casos las cuencas son intracratónicas, resulta muy difícil acotar la edad de los depósitos ya que estos pueden ser sensiblemente más jóvenes que las rocas que los encajan (Figura 11). Un ejemplo de esto lo encontramos en los depósitos de la Cuenca del Maestrazgo (España; Grandia et al., 2003a, 2003b) que pudieron ser fechados como Terciarios, pero que se encuentran encajonados en carbonatos de edad Aptiense-Albiense. Un problema añadido es que los minerales relacionados con la formación de los depósitos no suelen contener cantidades apreciables de ciertos elementos ( $\mathrm{Re}, \mathrm{Sm}, \mathrm{Rb}, \mathrm{U}, \mathrm{Th}, \mathrm{K}$, etc.) por lo que la utilización de métodos radiométricos convencionales basados en la desintegración de isótopos radioactivos es muy limitada o nula.

En los últimos años se han desarrollado algunas técnicas de fechamiento absoluto que han resultado aplicables a algunos de estos depósitos. Entre la técnicas radiométricas, una de las que ha dado mejor resultado es el fechamiento $\mathrm{Rb} / \mathrm{Sr}$ de esfalerita mediante la obtención de una isocrona a partir de las relaciones isotópicas ${ }^{87} \mathrm{Rb} /{ }^{86} \mathrm{Sr} y{ }^{87} \mathrm{Sr} /{ }^{86} \mathrm{Sr}$. Esta técnica presenta un problema fundamental, ya que para obtener la isocrona a partir de cantidades realmente mínimas de $\mathrm{Rb}$ y Sr se analiza el que contiene tanto la esfalerita como sus inclusiones fluidas. Este método ha permitido obtener la edad de los depósitos de Pine Point (Nakai et al., 1993) y Upper Mississippi Valley (Brannon et al., 1992) en los EE. UU.; Polaris en Canadá (Christensen et al., 1995a) Blendevale (Christensen et al., 1995b) en Australia; y el de Northern Eiffel (Schneider et al., 1999) en Alemania.

Otra técnica radiométrica utilizada ha sido el método U/ $\mathrm{Pb}$, utilizando la calcita que suele acompañar a los sulfuros en estos depósitos. Mediante esta técnica se fecharon los depósitos del Tri-State Disctrict (Brannon et al., 1996a) y de Central Tennesseee (Brannon et al., 1996b) en los EE. UU., el de Twelve Mile Bore (Brannon et al., 1996a) y los de la Cuenca del Maestrazgo (Grandia et al., 2003a, 2003b) en España. a) MTV Pre-deformación

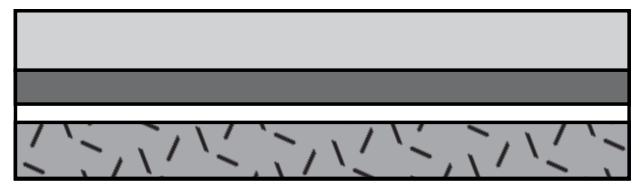

1. Depósito de la roca encajonante

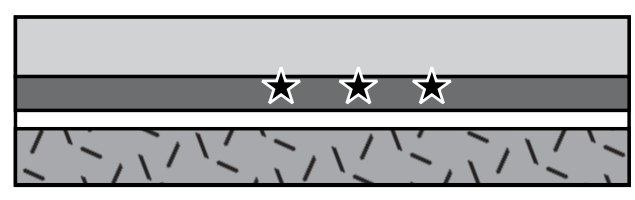

2. Mineralización MVT

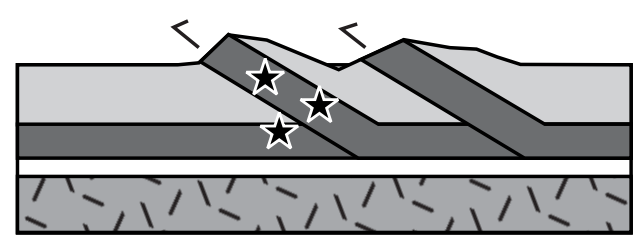

3. Deformación y cabalgamiento b) MTV Post-deformación

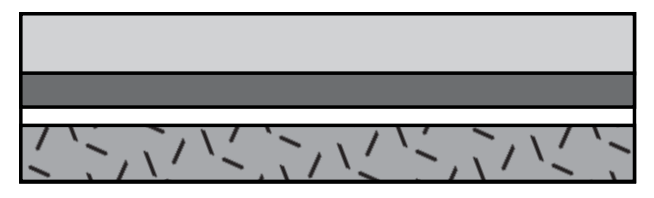

1. Depósito de la roca encajonante

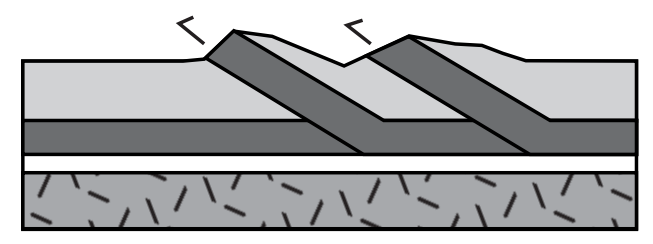

2. Deformación y cabalgamiento

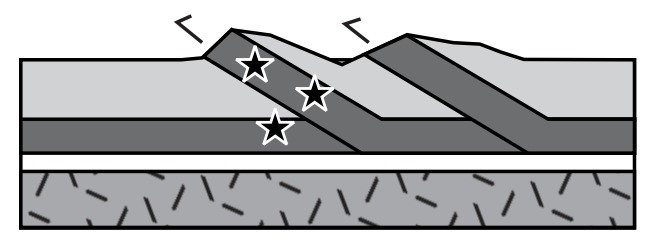

3. Mineralización MVT

Figura 11.Dos posibles secuencias de formación de depósitos MVT en cordilleras de plegamiento. En el primer caso (a) los depósitos se forman a favor de estratos plano-paralelos que son posteriormente deformados; en el segundo caso (b) la deformación de los estratos es anterior a la formación del depósito. Modificado de Bradley y Leach (2003). 


\subsection{Modelos genéticos}

Los modelos de formación de los depósitos de tipo MVT dependen en gran medida de dos factores fundamentales: el tipo de circulación de los fluidos y los procesos de precipitación.

\subsubsection{Modelos de circulación de los fluidos}

La formación de los depósitos de tipo MVT está íntimamente relacionada con la circulación de salmueras en una cuenca sedimentaria. El mecanismo de movilización de los fluidos depende del tipo de orógeno (Figura 12) y de en que estadio de evolución se encuentra la cuenca en el momento de la movilización y expulsión de los mismos. Debido a que en la mayoría de las ocasiones no se conoce la edad de formación del depósito, es habitual que se propongan modelos de flujo completamente diferentes, o hasta antagónicos, para interpretar la génesis de un mismo depósito.
Existe un conjunto de modelos de movilización de fluidos propuestos hasta la fecha, entre los que cabe destacar flujo por compactación de sedimentos (Jackson y Beales, 1967); flujo por bombeo sísmico (Sibson et al., 1975); flujo debido a procesos diagenéticos (Sharp, 1978); flujo debido a gradientes topográficos ("gravity-driven flow"; Garven y Freeze, 1984a, 1984b); y flujo debido a movimientos tectónicos ("tectonically-driven flow"; Oliver, 1986).

Uno de los primeros modelos propuestos proponía que la movilización y migración de salmueras era debida a la expulsión de las aguas connatas contenidas en la serie sedimentaria durante la compactación de los mismos (Jackson y Beales, 1967). Este modelo fue posteriormente invalidado por varios autores (Cathles y Smith, 1983; Bethke, 1986) debido a que la expulsión de fluidos por compactación presenta una muy baja velocidad de flujo por lo que el calor transportado por dichas soluciones se perdería rápidamente. En cambio, si la cuenca está sobrepresurizada (Sharp, 1978), tanto debido a la rápida acumulación de
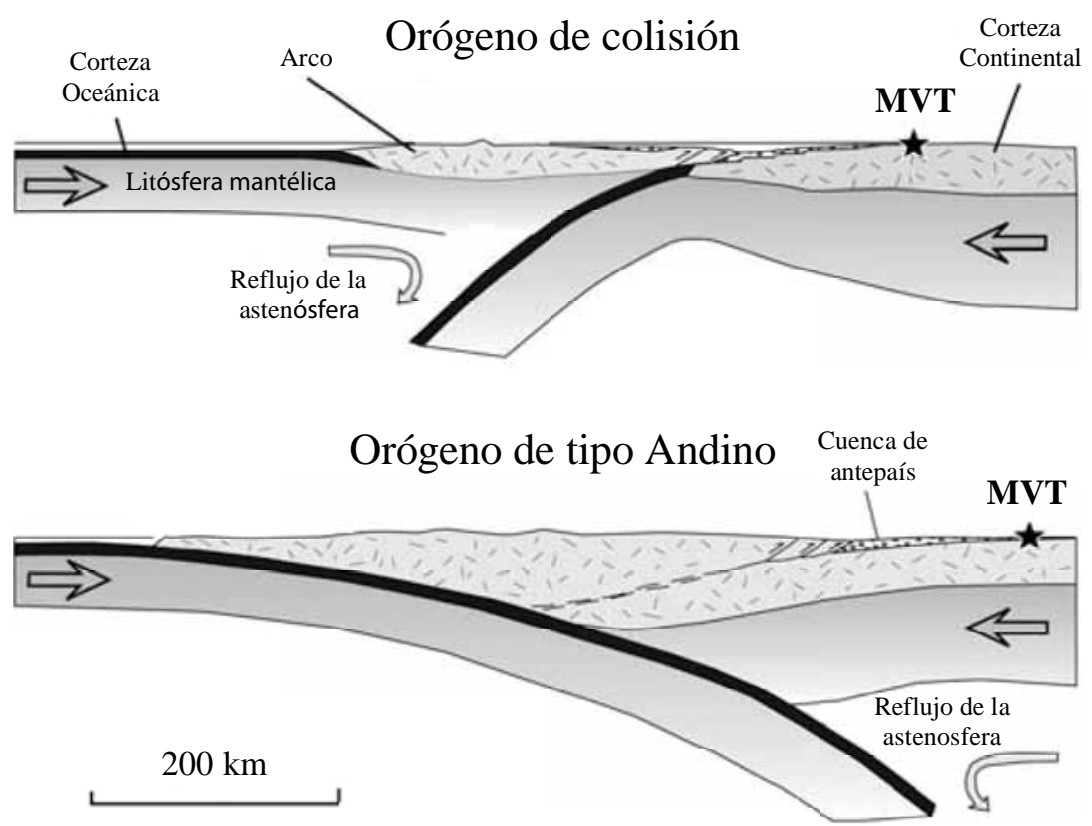

Orógeno de inversión

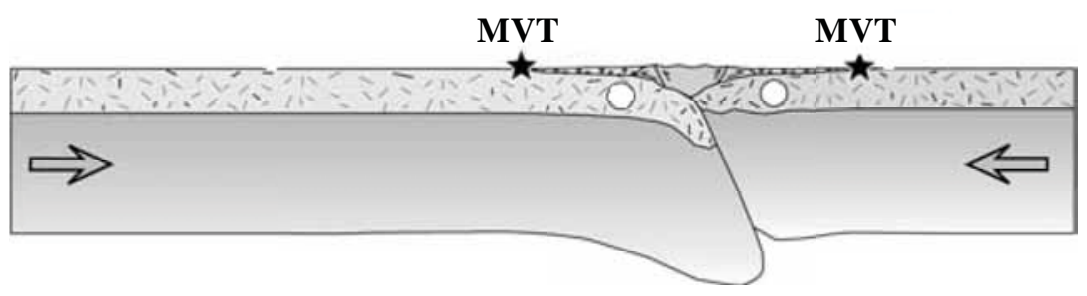

Figura 12. Comparación entre un orógeno colisional (arriba), de tipo Andino (centro) y transpresional (abajo). El orógeno de tipo colisional se corresponde con una colisión arco-margen pasivo (arriba), basado en los ejemplos neógenos de Timor (Nueva Guinea) y Taiwan. El orógeno de tipo Andino (centro) está basado en el modelo actual de los Andes y un ejemplo fósil puede ser el sistema Laramídico del Cretácico Tardío-Paleoceno del poniente de Norteamérica; la convección de la astenósfera contribuye a la subducción a escala regional del antepaís, diferenciándolo del resto de situaciones de la cuencas de este tipo. El orógeno de inversión o transpresional (abajo) se caracteriza por estar flanqueado en ambos lados por cuencas de antepaís; este último tipo está basado en el modelo de los Pirineos (Muñoz, 1992; Bradley y Leach, 2003). 
sedimentos como a reacciones diagenéticas de deshidratación o generación de hidrocarburos, dicha expulsión podría ser efectiva.

El flujo por bombeo sísmico (Sibson et al., 1975) es un mecanismo que puede generar grandes velocidades de flujo de hasta decenas de metro por año y que, a pesar de que el volumen de fluido movilizado a escala de cuenca puede no ser muy elevado, si que localmente puede ser un factor importante para la formación de depósitos minerales. Este tipo de mecanismo fue invocado por Tritlla y Cardellach (1997) en relación con los depósitos de $\mathrm{Hg}$ encajonados en carbonatos de la Sierra de Espadan (Castellón, España).

Posteriormente, Oliver (1986) propuso un modelo de convección originada por carga tectónica. Este modelo presenta un grave problema debido a que la velocidad de flujo que genera es muy baja ( $<1$ m por año; Ge y Garven, 1992), por lo que puede ser un mecanismo poco viable para la generación de volúmenes importantes de fluidos mineralizantes.

El modelo más aceptado hasta el momento y especialmente válido en los depósitos del Valle del Mississippi es el propuesto por Garven y Freeze (1984a, b) y Garven (1985), basado en la circulación de fluidos debido a gradientes topográficos (Figura 13). En contextos tectónicos compresivos la formación del orógeno implica la constitución de un importante gradiente topográfico que permite establecer el flujo de fluidos meteóricos entre las partes más elevadas tectónicamente y las cuencas de antepaís asociadas. Este tipo de modelo permite justificar la migración de fluidos a escala de cuenca u orógeno al permitir velocidades de flujo altas ( $\geq 10 \mathrm{~m}$ por año) durante largos periodos de tiempo (algunos millones de años). Además, debido a su alta velocidad de flujo, es un mecanismo muy eficiente para transportar grandes cantidades de calor.

\subsubsection{Mecanismos de precipitación}

Uno de los modelos más aceptados para la precipitación (Beales, 1975) es el que supone un transporte por separado de los metales y el azufre, produciéndose la mineralización en el sitio en donde ambos fluidos se mezclan.

En otro modelo (Barton, 1967), el sulfato y los metales son transportados por la misma solución y la precipitación se da por la reducción del sulfato cuando la solución mineralizante interacciona con materia orgánica o cualquier otro agente reductor.

Un tercer modelo propone que los metales y el azufre, en estado reducido, son transportados en la misma solución a pH bajos, dándose la precipitación por un incremento en el $\mathrm{pH}$, una dilución o un enfriamiento de la solución mineralizante (Anderson, 1983).

El cuarto modelo es el que presupone que los metales son transportados mediante complejos orgánicos (Barnes, 1983) en soluciones neutras o alcalinas, y la precipitación es consecuencia de un descenso del $\mathrm{pH}$ o de una oxidación de la solución. Intentar generalizar y aceptar uno solo de estos modelos para explicar la génesis de todos los depósitos MVT es probablemente una simplificación errónea, habiendo sido el motivo de muchas discusiones.

Uno de los modelos conceptuales más aceptados para explicar el origen de la soluciones mineralizantes y el mecanismo de movilización de las mismas, es el que involucra aguas meteóricas que se infiltrarían e irían evolucionando en profundidad a medida que interaccionasen con materiales de composición diferente, convirtiéndose paulatinamente en soluciones mineralizantes. Su movimiento sería provocado esencialmente por las variaciones en los niveles piezométricos de la cuenca (Garven, 1985; Bethke and Marshak, 1990) así como también podría ser debido a cambios de densidad del fluido debido al calentamiento de las aguas como consecuencia de un gradiente geotérmico anómalo.

Otros autores (Noble, 1963; Jackson y Beales, 1967) proponen la compactación de la cuenca como un mecanismo que daría lugar a un flujo continuo de la solución mineralizante. Para poder explicar la conservación de la temperatura de la solución durante centenares de kilómetros, Sharp (1978) y Cathles y Smith (1983) proponen un flujo episódico de la solución hacia la roca carbonatada, como consecuencia de una sobrepresión.

\section{Depósitos de tipo MVT en México}

\subsection{Introducción}

Los depósitos de tipo MVT no han sido reconocidos como tales durante mucho tiempo en México por diversos motivos, entre los que cabe destacar el que éstos esencialmente contienen metales de base (p. ej. El Diente, Nuevo León; Sierra Mojada, Coahuila), barita (Múzquiz, Coahuila), celestina (distrito de Cuatrociénegas, Coahuila) y/o fluorita (La Azul, Taxco, Guerrero, Tritlla et al., 2001a; La Encantada-Buenavista, Coahuila, González-Partida et al., 2003, Tritlla et al., 2004b), por lo que no han sido tan atractivos como los depósitos que contienen metales preciosos (skarns, epitermales) o altos tonelajes en metales base (SEDEX, vulcanogénicos), tanto para la mayoría de las empresas mineras como para el mundo científico en general.

Así mismo, y debido a la omnipresencia de cuerpos intrusivos que cortan toda la serie mesozoica en el centro y NE de México, los depósitos de esta filiación han sido sistemáticamente confundidos con depósitos ligados a fluidos o procesos magmáticos. A pesar de que algunos autores ya habian propuesto la existencia de esta tipología (De Cserna, 1989), dichas aseveraciones tuvieron muy poco eco tanto en el mundo científico como en el minero. Solo recientemente se ha reconocido la importancia de este tipo de depósitos en México, hecho que puede resultar muy relevante de cara a la exploración de nuevos recursos minerales en las plataformas carbonatadas mesozoicas del centro y NE de México. 
Estado precoz de colisión

Preparación para la mineralización posterior
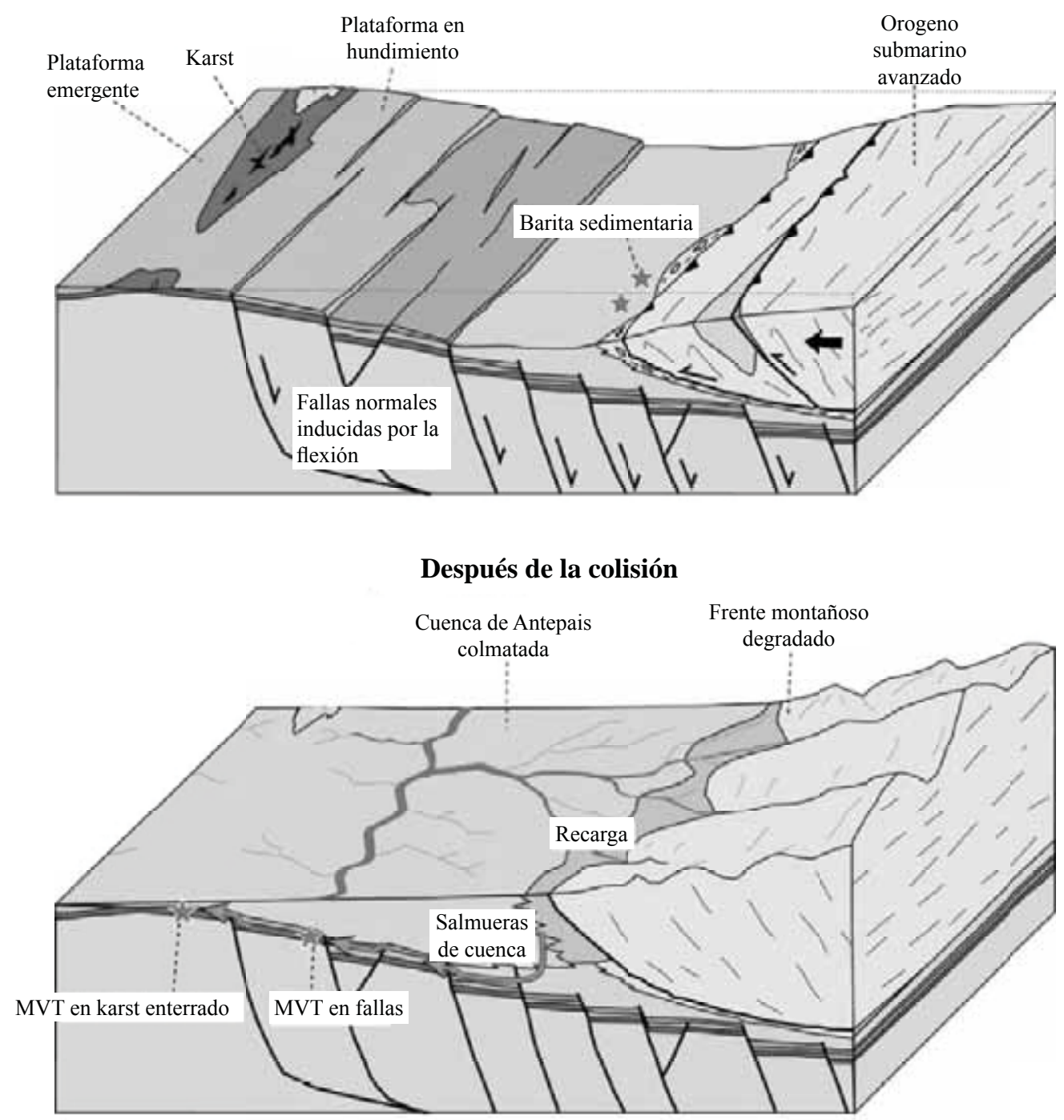

Figura 13. Bloque diagrama mostrando la evolución de una cuenca de antepaís (Bradley y Leach, 2003). El bloque de la parte superior muestra como durante la convergencia de placas, una cinturón de plegamiento submarino cabalga al margen pasivo, formándose así una cuenca de antepaís. La convergencia de las placas causa que esta situación migre en dirección a la cuenca de antepaís. Esta cuenca no se colmata debido a que el depocentro de la misma migra a medida que la deformación avanza. La posición de los depósitos de barita se basa en la posición en la que se hallan depósitos similares en los Ouachitas (Maynard y Okita 1991). En el bloque-diagrama de la parte inferior, la convergencia de placas ya ha cesado y la cuenca de antepaís ha acabado colmatándose de sedimentos, creando las condiciones hidrológicas idóneas para la formación yacimientos de tipo MVT. Esta sería una situación similar a la que dio origen a los depósitos de la región de Ozark (EE. UU.; Bradley y Leach, 2003).

\subsection{Localización de los depósitos en México}

Hasta el momento, tanto por su abundancia relativa como por su importancia económica, los depósitos que más se han estudiado son los de barita, celestina y fluorita del Edo. de Coahuila y, localmente, los de fluorita en el Edo. de Guerrero. Así, a continuación se va a efectuar un resumen del estado del arte sobre el conocimiento de esta tipología en estos estados.

\subsubsection{Depósitos en el Edo. de Coahuila}

Tal y como se ha indicado en el apartado de generalidades, la evolución paleogeográfica y tectónica resulta crucial a la hora de entender la disposición y los controles en la distribución de los cuerpos mineralizados.

La distribución de los depósitos de baja temperatura encajonados en carbonatos parece estar restringida a los bordes de las estructuras paleogeográficas (altos y bajos estructurales) si bien no se ha evaluado aún convenientemente el papel que pueda jugar el nivel y tipo de aflora- 


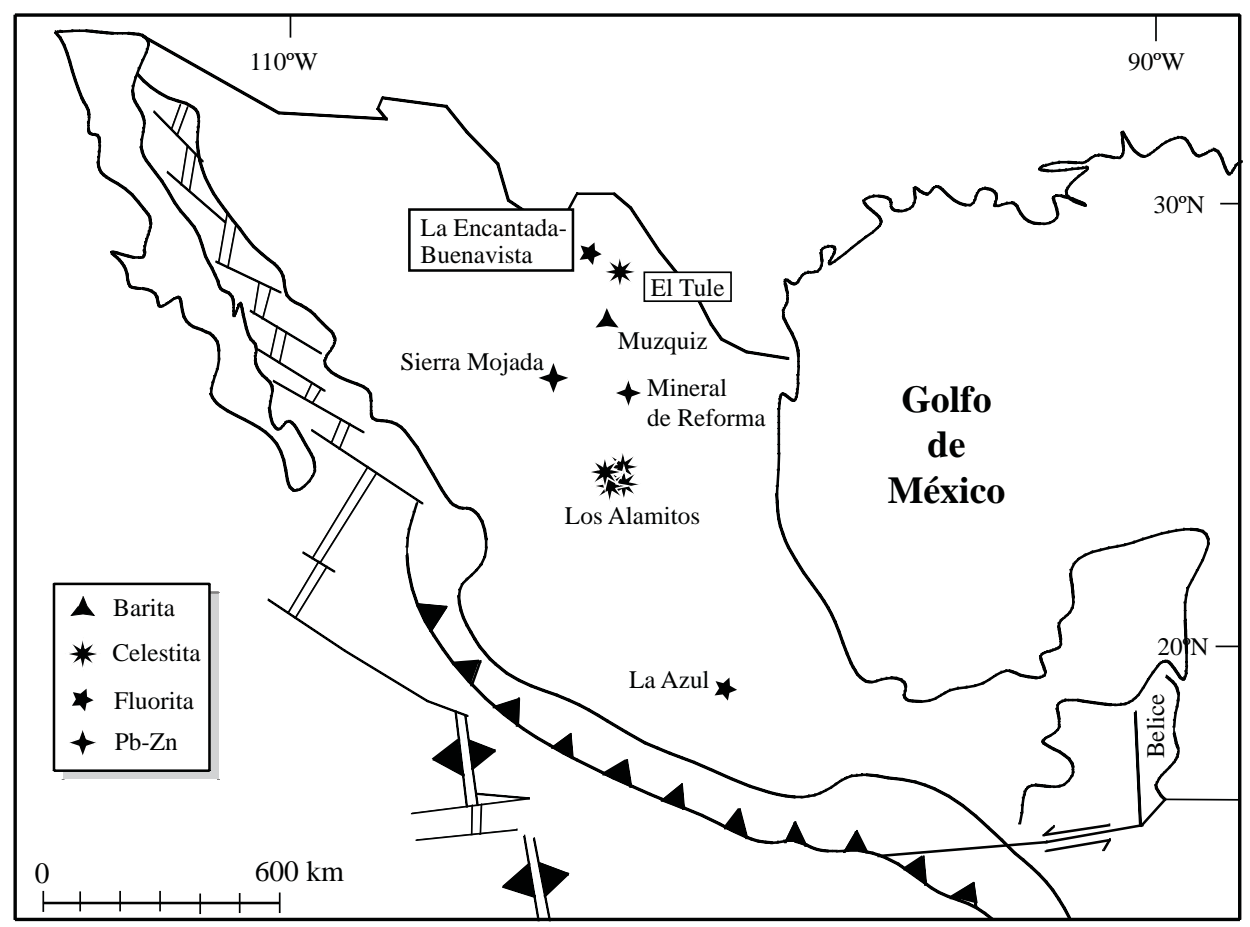

Figura 14. Distribución de los yacimientos de barita, celestina, fluorita y metales base en México reconocidos como pertenecientes a esta tipología.

miento en dicha distribución (Puente-Solís et al., 2005). Los elementos paleogeográficos en el NE de México están formados por altos del basamento, cuencas asociadas a éstos y grandes fallas regionales o lineamientos. Existen tres fallas regionales de carácter lateral izquierdo que delimitan a los altos del basamento: la falla La Babia (FLB), la falla San Marcos (FSM) (Charleston, 1981) y la megacizalla Mojave-Sonora (Anderson y Macqueen, 1988). La falla de La Babia limita al sur a la Península de Burro-Salado, mientras que la Plataforma de Coahuila está limitada al norte por la FSM y al sur por el lineamiento Torreón-Monterrey, que algunos autores definen como la traza hacia el sureste de la megacizalla Mojave-Sonora. Entre estos dos altos de basamento se encuentra la Cuenca de Sabinas, además de las islas de La Mula y Monclova.

Los depósitos de barita dominante son muy escasos, localizándose en la parte central de la Cuenca de Sabinas (Sierra de Santa Rosa), aunque suele ser común encontrar barita como "ganga" en los depósitos estratoligados de $\mathrm{Pb}$ Zn (Sierra de La Purísima y San Marcos, Sierra Mojada; Puente-Solís et al., 2005). Estos depósitos se encuentran alojados en la Fm. Cupido (Barremiano-Aptiano; Figura 15). También se ha reportado la presencia de barita hacia la parte sureste de la Cuenca de Sabinas, al NE de la Cuenca de la Popa, justo al este de la Isla Lampazos-SabinasPicachos (Bloque Tamaulipas), alojados en la Fm. Olvido (Kimmeridgiano).

Los depósitos de celestina dominante se localizan en el NE de México, mayoritariamente en la parte central de la Plataforma de Coahuila (Sierras de Alamitos, Australia y La
Paila) junto con algunos depósitos aislados que se localizan en el borde norte de la traza de la falla San Marcos y en el margen suroeste de la Cuenca de Parras (Puente-Solís et al., 2005), esencialmente encajando en los carbonatos de las Fm. Acatita y Aurora (Albiano; Figura 15).

Los depósitos de fluorita dominante se localizan al norte y sur de la traza de la falla La Babia, sobre los bordes sur y suroeste de la Península Burro-Salado, en la parte superior de la Fm. Georgetown en contacto con la Fm. Del Río (Albiano-Cenomaniano; Figura 15), ambos pertenecientes al grupo Washita (González-Partida et al., 2003; Tritlla et al., 2004b; Puente-Solís et al., 2005). Existen también algunos depósitos dispersos sobre la Plataforma de Coahuila, en la parte sur y este de la sierra de Australia, emplazados en la formación Aurora (Albiano; Puente-Solís et al., 2005).

Los yacimientos estratoligados de Plomo-Zinc (Pb$\mathrm{Zn}$ ), presentan una amplia distribución. La mayoría de ellos, ocurren cerca de los bordes de las paleoislas, aunque su relación con ellas no es tan directa como en los casos de las mineralizaciones anteriores. Las rocas encajonantes también muestran variabilidad dependiendo de la unidad paleogeográfica en la cuál se localizan; aunque se concentran de manera más amplia en rocas de la Fm. Cupido y en menor cantidad en las formaciones Aurora, Acatita y La Virgen (Figura 15; Puente-Solís et al., 2005).

A grosso modo, parece observarse un zoneamiento de los depósitos en función de la mineralogía dominante reflejando, muy probablemente, la mayor o menor movilidad de los diferentes cationes a través de la serie y también 


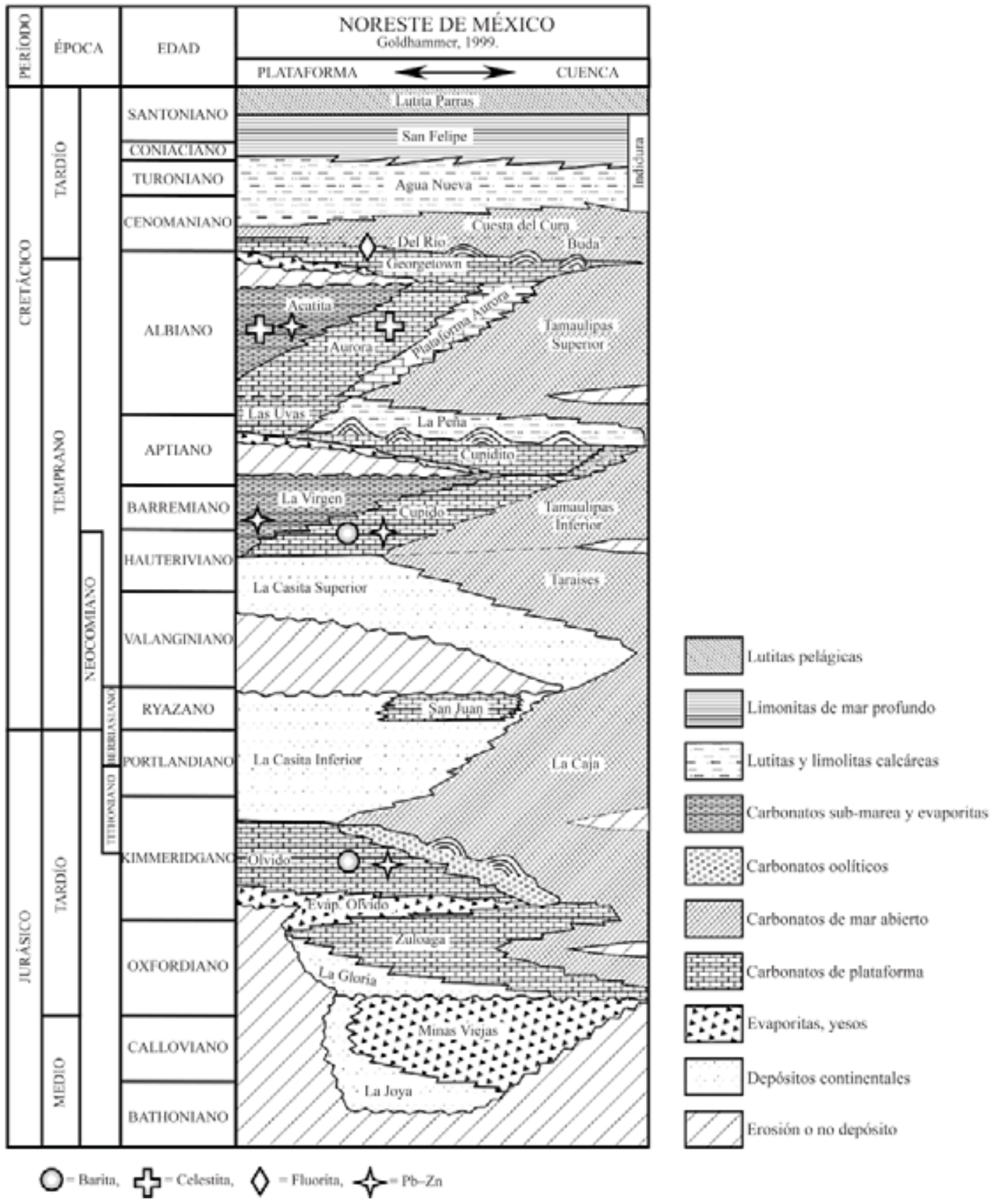

Figura 15. Tabla cronoestratigráfica del noreste de México junto con la posición general en la columna de algunos de los yacimientos estratoligados. Modificado de Goldhammer (1999) y Puente-Solís et al. (2005).

diferentes mecanismos de formación de los depósitos. Así, los niveles estratiformes de barita se localizan en la base de la serie carbonatada mesozoica, encajonados en los materiales Kimmeridgianos (Fm. Olvido); los depósitos de $\mathrm{Pb}-\mathrm{Zn}$ dominante se localizarían en la Fm. Cupido; los mantos de celestina aparecen encajonados en carbonatos de plataforma (Formaciones Aurora y Acatita) a un nivel estructural similar a los depósitos de $\mathrm{Pb}-\mathrm{Zn}$; mientras que los de fluorita dominante son los que aparecen en posiciones más altas en la seria estratigráfica, en el contacto superior de las formaciones Georgetown y Del Río.

\subsection{Tipologías presentes en México}

\subsubsection{Depósitos estratoligados de barita}

En el norte del Edo. de Coahuila aparecen un conjunto de depósitos estratoligados de gran extensión y potencia variable (hasta $3 \mathrm{~m}$ ), compuestos casi exclusivamente por barita de alta pureza, junto con cantidades accesorias de celestina y calcita encajonados en los carbonatos Kimmerigdianos de la Fm. Olvido. No se ha detectado la presencia de celestina, aunque si aparecen localmente baritas algo más ricas en $\mathrm{Sr}$ (Barosa, com. per.) sin que por 
ello se aprecien cambios texturales significativos.

Los principales cuerpos mineralizados aparecen en las cercanías de la población de Múzquiz (Coahuila). Consisten en dos niveles estratoligados de barita (minas "Cocina" y "Potrero") parcialmente deformados por la tectónica laramídica. El contacto con la roca encajonante es nítido (Figura 16a y 16b) y está marcado por la alteración de color de la misma que solo se hace evidente en algunos de los cortes observados (Figura 16 b y 16c). Esta alteración consiste en una gradual pérdida de coloración de la roca encajonante hacia el nivel de barita, hecho que indica la alteración de los contenidos en materia orgánica de la roca encajonante. Además, tanto la roca encajonante como la propia barita son "fétidas" (presencia de $\mathrm{H}_{2} \mathrm{~S}$ ).

Los cuerpos de barita están compuestos por cristales tabulares de barita de grano fino, que aparentemente se disponen al azar. Una inspección más profunda del afloramiento permite observar como la disposición de la barita parece guardar relación con la pseudomorfosis de estructuras relictas (Tritlla et al., 2005): impurezas en la barita que marcan una "pseudo-estratificación” (Figura 16d); superficies "convolutas", plegadas o boudinadas (Figura 16f); cambios en el tamaño de grano o la disposición de la "pseudo-estratificación" observadas de base a techo del nivel mineralizado; estructuras bandeadas, texturalmente similares a "ritmitas" (Figura 16a, 16b y 16e), constituidas por la alternancia de bandas "claras" y "oscuras" de barita que, ocasionalmente, forman la totalidad del nivel mineralizado; y, lo que es más revelador, agrupaciones globulares de barita, con texturas aproximadamente radiales, con una morfología general similar que recuerda muy de cerca a los "chicken-wire" de anhidrita (Figura 16d y 16f), típicos de series evaporíticas (niveles de yeso evaporítico) que han sufrido procesos diagenéticos de deshidratación/ compactación. Así mismo, es de destacar la ausencia de cavidades dentro de los cuerpos, homogeneamente masivos. Localmente, se oberva la presencia de una o dos vetas, sub-paralelas a la estratificación de calcita, que sellan las zonas de máxima circulación de fluidos. También, aparecen pequeñas vetas de calcita cortando perpendicularmente los niveles mineralizados, producto del plegamiento y/o brechificación de los niveles de barita durante la orogenia Larámide.

Las inclusiones fluidas en los niveles de barita son muy escasas, de pequeño tamaño y suelen estar afectadas por procesos de pérdida de fluido (leakeage) tanto debido a la exfoliación perfecta del la barita como a que estos niveles están afectados por la deformación larámide. No obstante, se han realizado mediciones microtermométricas en escasas inclusiones fluidas claramente primarias (E. GonzálezPartida, com. per.). Las temperaturas de homogeneización ( sin corrección de presión) obtenidas para las baritas de la Mina Cocina varian entre 60 y $150{ }^{\circ} \mathrm{C}$, sugiriendo que están afectadas por pérdidas de fluido; las temperaturas de homogeneización en Mina Potrero presentan una menor dispersión y se situan entre 60 y $100^{\circ} \mathrm{C}$. Las salinidades son muy constantes, alrededor del $20-23 \%$ en peso de sales totales, con un $18-22 \%$ en peso de $\mathrm{CaCl}_{2}$ y $1-2 \%$ en peso de $\mathrm{NaCl}$ (E. González-Partida, com. per.; Tritlla et al., 2005).

Todo este conjunto de características texturales, de alteración y la presencia de materia orgánica sugiere que estos cuerpos de barita se formaron como consecuencia de la substitución de niveles de yeso evaporítico, transformados a anhidrita durante la diagénesis, por salmueras de cuenca similares a las aguas de formación encontradas hoy en día en campos petrolíferos. El orígen del Ba resulta incierto, aunque las aguas de formación pueden acumular cantidades importantes de este elemento debido a los procesos diagenéticos de transformación de feldespatos. En este caso, los niveles evaporíticos actuaron como una trampa oxidante rica en sulfato para una solución caliente, salina y rica en $\mathrm{Ba}$. La mezcla de aguas o niveles sulfatados con materia orgánica es termodinamicamente inestable, provocando la oxidación de la materia orgánica, originando la decoloración detectada en la roca encajonante.

Kesler y Jones (1981) llevaron a cabo el análisis de la composición isotópica en $\mathrm{S}$ y $\mathrm{Sr}$ de escasas muestras de barita y celestina de todo el Edo. de Coahuila. Estos autores concluyen, basados en pocos datos analíticos, que tanto los depósitos de celestina como de barita probablemente se formaron a partir de elementos derivados de la cuenca sedimentaria durante los procesos diagenéticos. Asimismo, proponen que el $\mathrm{Ba}$ y el $\mathrm{Sr}$ de la barita muy posiblemente provienen del lavado de rocas clásticas presentes en el basamento. Debido a la gran diversidad de tipologías que presentan los yacimientos de sulfatos en Coahuila, estas conclusiones son demasiado parciales y, en muchos casos, erróneas.

\subsubsection{Depósitos estratoligados de celestina}

Las plataformas carbonatadas mesozoicas de los Edos. de Coahuila, San Luis Potosí y Chihuahua contienen una de las mayores acumulaciones de depósitos de celestina conocidas a nivel mundial. No obstante, este distrito ha recibido escasa atención hasta el momento por parte del mundo científico. Una de las características más sobresalientes de estos depósitos es, en general, su pequeño tamaño, ya que solo algunos llegan a tener tonelajes medianos pero también la gran cantidad de cuerpos mineralizados que pueden aparecer en una sola área minera, hecho que precisamente les confiere importancia minera. Es común la presencia de más de dos o tres cuerpos mineralizados en una misma columna sedimentaria local y en diferente posición estratigráfica.

Los antecedentes sobre los depósitos de $\mathrm{Sr}$ en el estado de Coahuila son escasos. Salas (1973) hace un primera descripción de los depósitos de celestina de la Sierra de Paila (Coahuila). En estos depósitos, la celestina se presenta bajo la forma de mantos constituidos por cristales blancos de celestina de grano medio, conteniendo fragmentos no reemplazados de la roca encajonante en cantidades variables. 

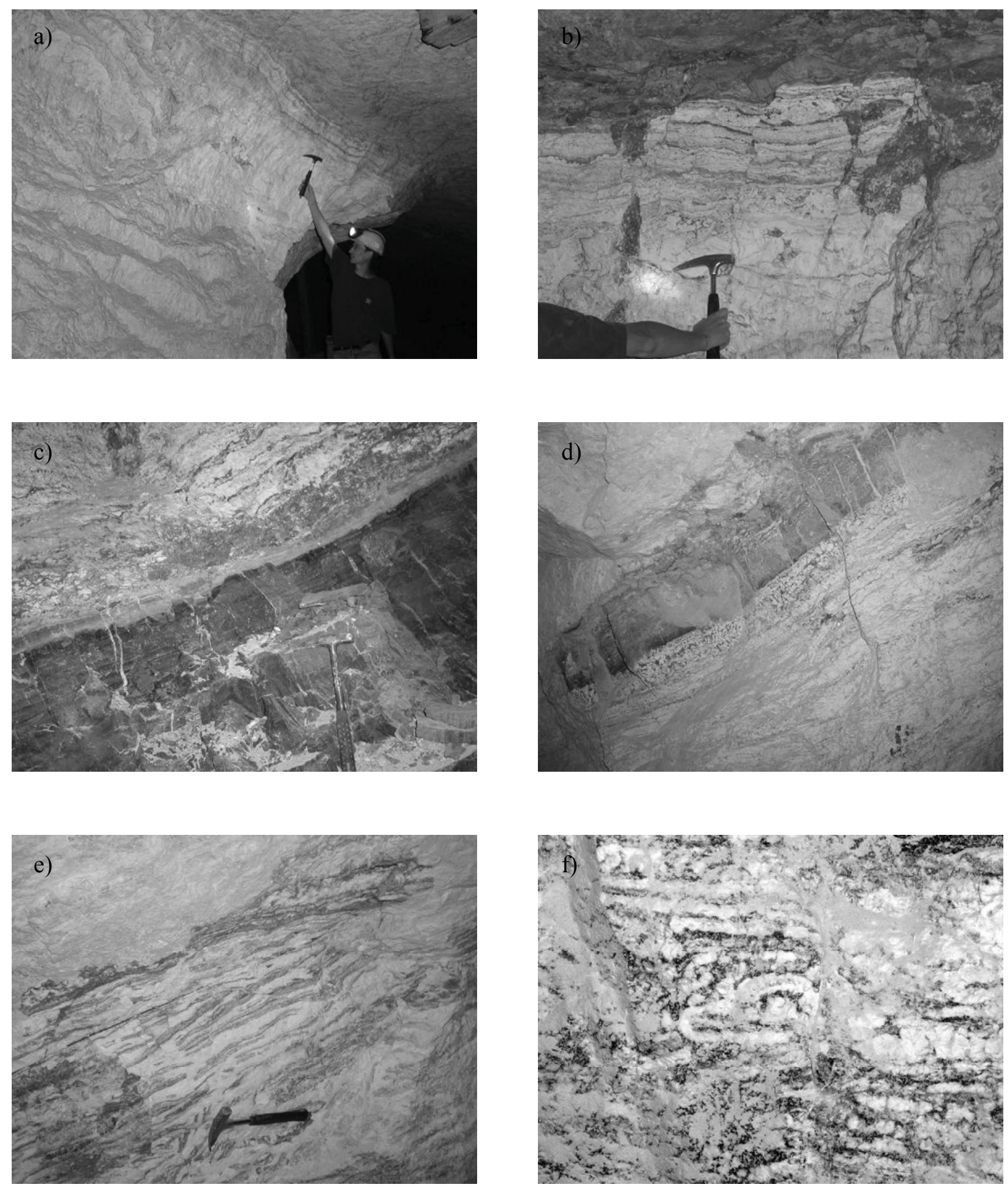

Figura 16. Depósitos de barita en Muzquiz (Coahuila). (a) Vista general del manto estratoligado de barita; observese el control ejercido por las superficies de estratificación sobre la distribución del cuerpo; el manto presenta un zoneamiento acusado determinado por la presencia de ritmitas a muro y techo del cuerpo. (b) Detalle de las ritmitas de barita en contacto con la roca encajonante; este contacto presenta una fracturación en "teclas de piano" debido a la deformación Larámide. (c ) Detalle del contacto inferior del manto de barita con la roca encajonante; nótese una zona de intensa decoloración de la roca encajonante de varios centimetros de potencia justo en el contacto con la barita. (d) "caballo" de carbonato dentro del manto de barita; nótese el cambio de "facies" de la barita justo debajo del contacto con dicha roca, sugiriendo que este cambio textural es el reflejo de una estructura "primaria" sedimentaria. (e) Detalle de las ritmitas de tipo "cebra" en barita. (f) textura enterolítica en barita similar a una textura "chiken-wire" que típicamente presentan las series evaporíticas anhidritizadas. 
Cuando los mantos son muy "puros", aparecen cavidades rellenas de cristales idiomórficos de celestina de hasta 10 $\mathrm{cm}$ de longitud, junto con cantidades variables de azufre, fluorita y yeso. Salas (1973) y Rickman (1977) sugieren que los mantos de celestina de la Sierra de Paila son epigenéticos y se formaron por reemplazamiento de los carbonatos encajonantes. Kesler y Jones (1981), en el que es el trabajo científico más moderno existente sobre estos depósitos, llevaron a cabo análisis de la composición isotópica del $\mathrm{S}$ y del $\mathrm{Sr}$ de algunas muestras de yeso, barita y celestina en Coahuila. Estos autores concluyen, basados en pocos datos analíticos (13 celestinas), que tanto los depósitos de celestina como de barita probablemente se formaron a partir de elementos derivados de la cuenca sedimentaria durante la diagénesis. Así mismo, proponen que el $\mathrm{Sr}$ en la celestina deriva de las rocas encajonantes carbonatadas, mientras que el $\mathrm{Ba}$ y el $\mathrm{Sr}$ de la barita muy posiblemente provienen del lavado de rocas clásticas presentes en el basamento. Recientemente Ramos-Rosique (2004) y Ramos-Rosique et al. (2005) realizan un estudio sobre los yacimientos de celestina de la Sierra de Alamitos (El Venado, El Volcán, La Tinaja, La Víbora, El Diablo, entre otras), presentando los primeros datos sobre microtermometría y halógenos en inclusiones fluidas para estos yacimientos.

La distribución de los yacimientos de celestina en México está restringida a elementos paleogeográficos jurásicos en el norte del país, como lo son las plataformas de Coahuila y Burro-Picacho y las Cuencas de Sabinas y Chihuahua (Puente-Solís et al., 2005; Ramos-Rosique et al., 2005). La importancia de dichos rasgos paleogeográficos radica en que es en el borde de estas plataformas en donde se aloja la mineralización.

No se conoce el número total de cuerpos de celestina que existen entre los estados de Coahuila, San Luís Potosí y Chihuahua debido a la gran abundancia de pequeñas lentes mineralizadas. Resulta muy común que junto con algún cuerpo mineralizado de importancia económica aparezcan cuerpos "satélite" que tanto pueden estar situados en el mismo nivel o ligeramente por encima o abajo del principal. Estos cuerpos aparecen interestratificados con los carbonatos de las formaciones Cupido (Aptiense) y Acatita (Albiense). Se presentan bajo la forma de lentes de entre pocos centimetros y unos $5 \mathrm{~m}$ de potencia, con una extensión lateral muy variable, a veces de más de 500 m (Figura 17a). Están compuestos por cristales de celestina tabulares, ocasionalmente prismáticos, euhedrales a subhedrales, de color blanco, azul a negro, de hasta 20 $\mathrm{cm}$ de longitud y $10 \mathrm{~cm}$ de grosor como máximo (Figura 17b). Estos depósitos presentan cantidades variables y menores de yeso selenítico tardío, ocupando las cavidades finales dejadas por la celestina, junto con calcita y escaso azufre nativo. Ocasionalmente se observa la presencia de una última generación de celestina no tabular precipitada junto con el yeso selenítico. Esto indicaría un exceso de sulfato o un cese en el aporte de Sr por parte de la solución mineralizante. El tamaño de los cristales se incrementa desde los extremos (celestina microcristalina; Figuras 17c y 17d) hasta el centro del cuerpo, que suele estar constituido por grandes cristales euhedrales de celestina (Figura 17b). Las diferentes generaciones de cristales crecen desde las paredes del cuerpo hacia el interior, disponiéndose bajo la forma de ritmitas compuestas por la alternancia de bandas de cristales de celestina oscuros a negros, debido a la presencia de abundante materia orgánica sólida (bitumen) en su interior, con bandas de cristales de color azul, mucho más pobres en inclusiones de bitumen (Figura 17b, 17c y 17d). Tanto los cristales que se disponen en las bandas oscuras como las claras son fétidos debido a la presencia de $\mathrm{H}_{2} \mathrm{~S}$ muy posiblemente atrapado en las inclusiones fluidas.

Las inclusiones fluidas son medianamente abundantes, aunque la mayoría presenta fenómenos de estrangulamiento y/o pérdida de fluido debido a la exfoliación perfecta de la celestina. Las inclusiones fluidas primarias son generalmente bifásicas, están constituidas por un fluido acuoso y una burbuja de vapor, y presentan un grado de relleno estimado visualmente de entre 0.9 y 0.95 . Las temperaturas de homogeneización son muy constantes y varían entre 80 y $130^{\circ} \mathrm{C}$, con salinidades calculadas de entre 9 y $13 \%$ eq. en peso de $\mathrm{NaCl}$, aunque localmente pueden ser más bajas (4-8\% eq. en peso de $\mathrm{NaCl}$; Ramos-Rosique et al., 2005).

Los datos sobre la composición en halógenos $(\mathrm{Br}, \mathrm{Cl}$, F) y $\mathrm{Na}$ de estas inclusiones, representados en un diagrama de relaciones molares $\mathrm{Cl} / \mathrm{Br}$ vs. $\mathrm{Na} / \mathrm{Br}$ (Figura 18; Tritlla et al., 2004a), se sitúan mayoritariamente por debajo de la linea de evaporación de agua marina, a clorinidades menores, pero paralelos a dicha trayectoria y en la zona de precipitación de halita. Este comportamiento sugiere que la salinidad de los fluidos proviene de la evolución de agua de origen marino, modificada mediante evaporación. Estas soluciones entraron en el ciclo sedimentario muy probablemente como aguas de formación y su salinidad fue principalmente modificada mediante dilución (baja clorinidad). Si se comparan los datos de temperatura, salinidad y halógenos para la celestina con los obtenidos para los depósitos de fluorita del $\mathrm{N}$ de Coahuila (distrito de la Encantada-Buenavista, ver siguiente apartado), resulta muy interesante destacar que ambos grupos de fluidos son totalmente comparables y se superponen en el diagrama de relaciones molares $\mathrm{Cl} / \mathrm{Br}$ vs. $\mathrm{Na} / \mathrm{Br}$, sugiriendo que todos estos depósitos responden a un mismo pulso de generación y movilización de fluido en la cuenca, muy probablemente en relación con la orogénia Larámide.

Un ejemplo atípico de estos depósitos lo constituye el depósito de El Tule, al N de Múzquiz (Coahuila; Kesler, 1977). Este está constituido por un cuerpo estratoligado de celestina y fluorita de potencia muy variable (hasta $2 \mathrm{~m}$ de espesor), encajonado en una superficie de corrimiento sub-horizontal a la estratificación ("layer-parallel slip"), que afecta a los carbonatos de la Fm. Buda (Washita Group). Los cristales de celestina son en general similares a los descritos en los depósitos anteriores, aunque de color blanco, presentando las mismas texturas en "ritmitas". 

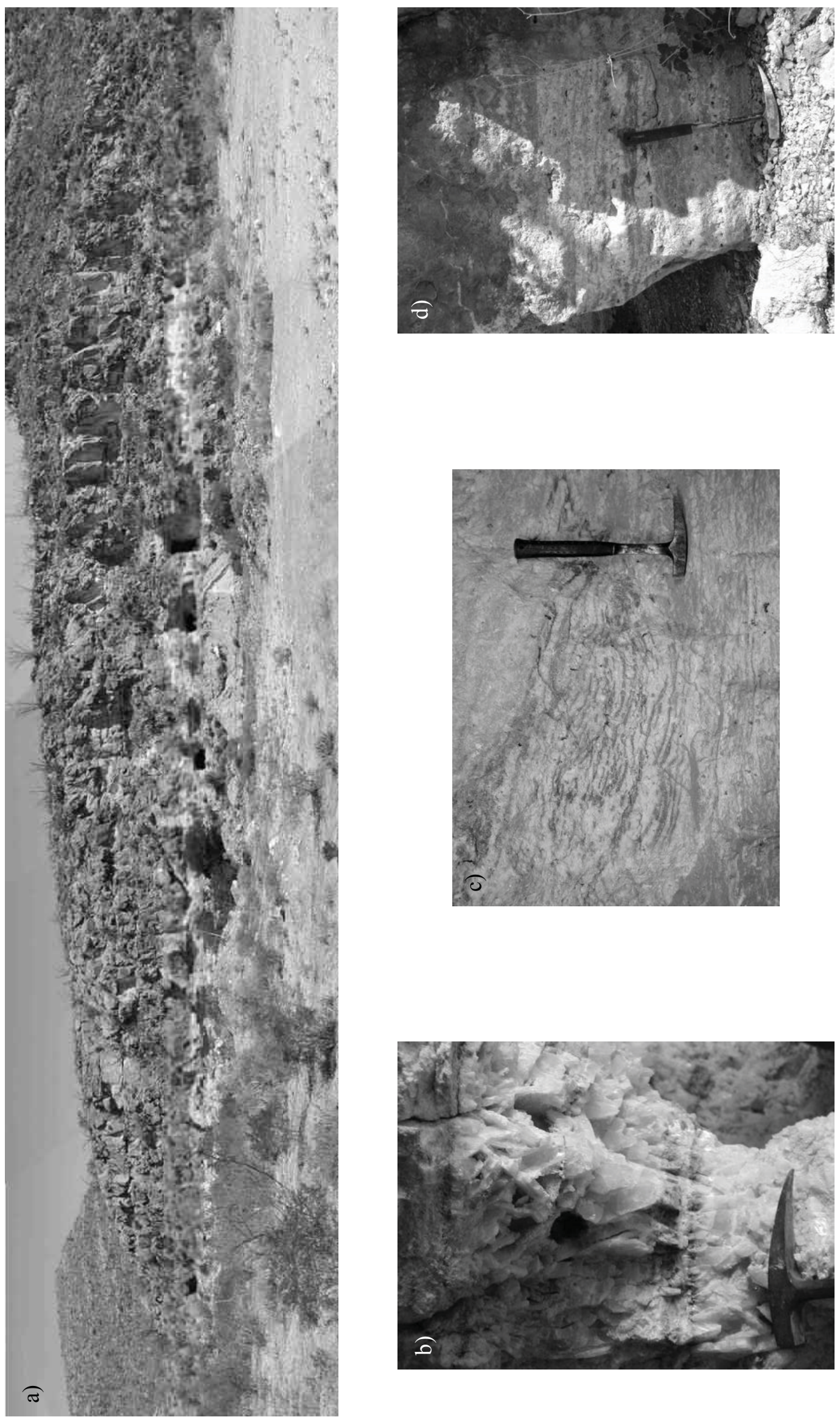

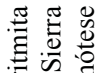

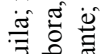

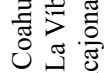

กิ

光 $\sum_{0}$

\&

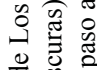

(⿻)

离 苛

हี

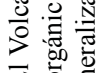

폴 클

卷苛

อิ

요

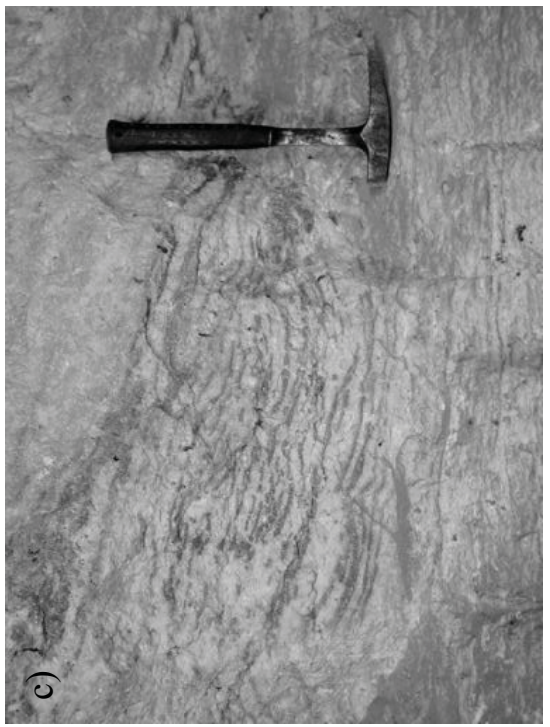

के

荌。

용

웅

는

함

흘 윻

:

웅

ए

¿

劳

is

咅造

ن : क्षे

के

竞的

远

웍

ष

可.苛

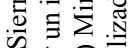

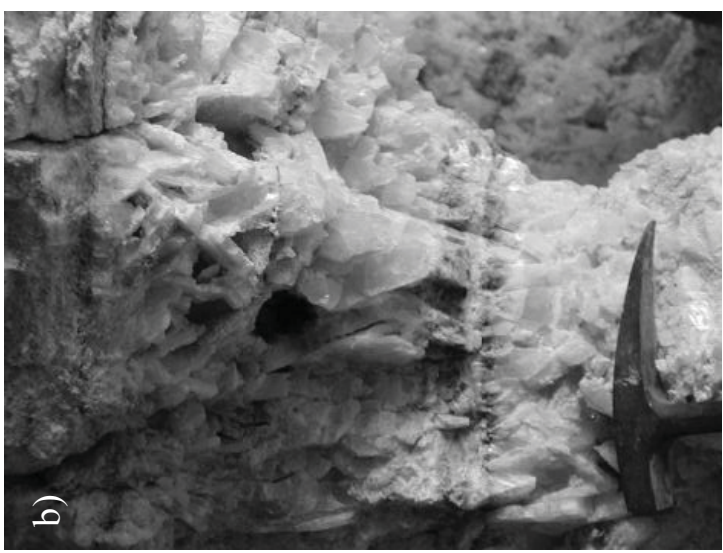

की

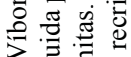

茟声苛

융 छ

욜

()

茟

㐘

ठ

ช 0

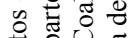

常

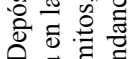

들 严

퓰 兽

兽过。 


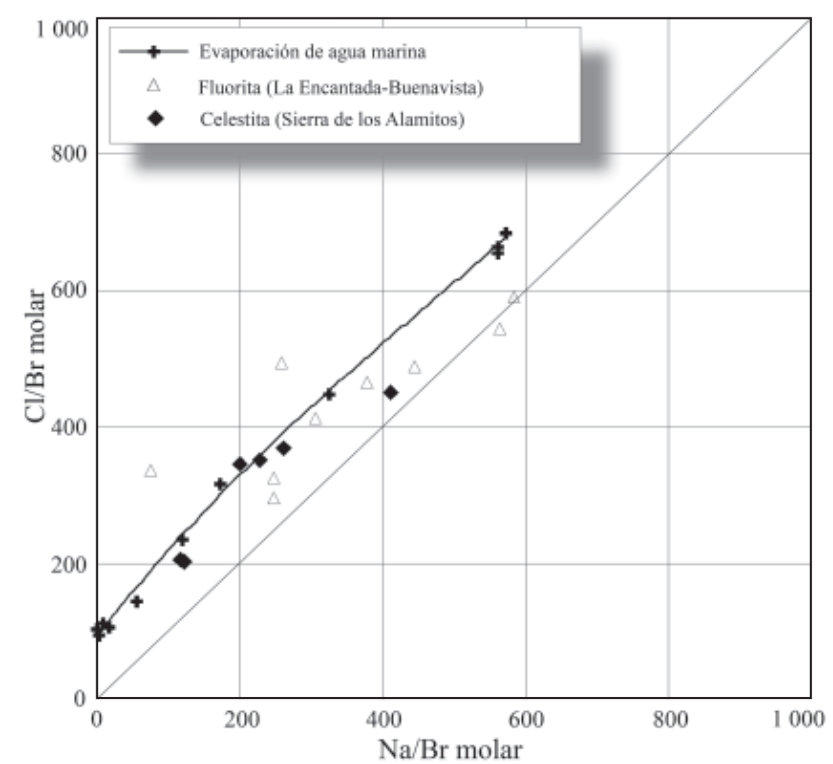

Figura 18. Diagrama $\mathrm{Na} / \mathrm{Br}$ vs. $\mathrm{Cl} / \mathrm{Br}$ para los fluidos en celestina y fluorita. Ver texto para la explicación.

La primera diferencia que se observa es que los cristales de las generaciones más tempranas están fuertemente deformados, mientras que las generaciones subsiguientes ya no presentan signos de deformación, sugiriendo que la formación de la superficie estructural, el flujo de fluido y la formación de la porosidad que ocupa la mineralización están en íntima relación con los últimos episodios de la deformación laramídica. En ningún caso se ha encontrado la presencia de yeso o una última generación no tabular de celestina.

La última fase de mineralización está formada por fluorita, bastante minoritaria, y aparece herráticamente en bolsadas, ocupando la porosidad remanente dejada por la celestina. Se presenta siempre bajo la forma de cristales idiomórficos cúbicos de color azul a violeta claro, zonados, y nunca presenta inclusiones de celestina, indicando un cambio brusco en la composición de los fluidos mineralizantes, con un fuerte empobrecimiento en sulfato y Sr.

Tanto las celestinas como las fluoritas presentan abundantes inclusiones fluidas. Lo más destacable es un cambio importante tanto en la temperatura como en la composición de los fluidos mineralizantes desde la precipitación de la celestina a la de fluorita (H. Lamadrid, com. per.). El cambio composicional se detecta mediante la aparición de inclusiones fluidas con hidrocarburos así como un decremento en la salinidad de las soluciones. La presencia de hidrocarburos atrapados coetáneamente con inclusiones de salmuera sugiere la mezcla de un fluido oxidante que habría precipitado la celestina con uno reductor, probablemente una emulsión de agua e hidrocarburo, que habría consumido el sulfato presente dando lugar a la generación de volátiles oxidados $\left(\mathrm{CO}_{2} \mathrm{y}\right.$, posiblemente $\left.\mathrm{N}_{2}\right)$ y al cambio hacia la precipitación de fluorita. Las condiciones de temperatura imperantes en la zona mineralizada sugieren que esta oxidación tuvo lugar mediante la termorreducción local del sulfato en presencia de materia orgánica. Es destacable que esta dicotomía en los fluidos atrapados en la fluorita final es precisamente la que caracteriza los depósitos de fluorita del norte de Coahuila (distrito de La Encantada-Buenavista).

Así, el depósito de celestina-fluorita de El Tule representaría un raro ejemplo de la transición entre los "mantos celestíticos" que aparecen al sur del edo. de Coahuila (Sierra de la Paila) y los "mantos fluoríticos" que aparecen en el norte de Coahuila. Así mismo, es la prueba de un cambio brusco en las condiciones de generación de fluidos en la cuenca. Es de destacar, no obstante, que en ninguno de los dos casos se ha observado la presencia de cuerpos de evaporitas precursores de dichos depósitos.

\subsubsection{Depósitos de fluorita}

Depósitos en el Estado de Coahuila. La distribución de los depósitos de fluorita en Coahuila coincide con la posición de los elementos paleogeográficos mesozoicos en las cuencas de Sabinas y Chihuahua. Se han detectado al menos tres tipos de depósitos de fluorita encajonados en estos carbonatos, claramente epigenéticos aunque clasificables como tipologías diferentes, sugiriendo la existencia de una anomalía de F en la corteza que ha sido removilizada de forma recurrente por los distintos procesos hidrotermales. El primer tipo corresponde a mantos de fluorita encajonados a favor de estructuras compresivas, sin relación alguna con intrusivos; el segundo tipo, muy raro, lo constituyen cuerpos de fluorita de escasas dimensiones en depósitos de tipo skarn desarrollados alrededor de cuellos riolíticos post-laramídicos (p. ej. El Pilote, Coahuila); el tercer tipo son cuerpos muy tardios de gran tonelaje desarrollados en los contactos por fractura entre calizas arrecifales y cuerpos riolíticos, claramente ligados a la tectónica distensiva post-laramídica (p. ej. Las Cuevas, S.L.P.). Solo el primer tipo se puede considerar similar al subtipo fluorítico, rico en materia orgánica y sin relación alguna con intrusivos de cualquier composición.

El distrito de fluorita más característico es el de La Encantada-Buenavista. Se localiza al norte del Edo. de Coahuila, en la Sierra de La Encantada. Consiste en varios mantos de fluorita con una extensión de varios kilómetros cuadrados. La mineralización aparece distribuida a favor de los diferentes niveles carbonatados que aparecen en la Sierra de la Encantada, llegando a su máximo desarrollo en los carbonatos arrecifales, muy porosos, de la Fm Aurora, en donde encajonan los principales mantos explotados hasta el momento (González-Partida et al., 2003). Por encima de la Fm. Aurora, actuando como sello, aparece el Grupo Washita. Todo este conjunto está afectado por la orogenia Larámide, provocando el plegamiento de la serie. Durante el Oligoceno Medio (Levresse et al., 2006) se produce la intrusión de cuerpos riolíticos que llegan a afectar a los mantos de fluorita previamente formados (González-Partida et al., 2003), aumentando la cantidad de sílice, hecho que los hace de poco interés industrial. 
La distribución de los cuerpos de fluorita presenta un fuerte control estructural (S. Baca, com. per.). Se encuentran en la intersección entre barreras de baja permeabilidad con fallas de muy bajo ángulo ("layer-parallel slip"; Tritlla et al., 2004b), a veces con superficies onduladas, recordando pequeñas "rampas" de despegue. Estas superficies se desarrollan aprovechando las superficies de estratificación y, en donde se presenta la mineralización, suelen abundar los materiales arcillosos, parcialmente como producto del mismo tectonismo. La precipitación de la fluorita viene precedida por un gran aumento en la permeabilidad de la roca debido a la fracturación hidráulica de la misma (Figura 19a). Los fragmentos de la roca encajonante incluidos en estas brechas suelen estar muy recristalizados y ligeramente corroídos, aunque esta corrosión es frenada rápidamente por la precipitación de fluorita que ocupa toda la porosidad remanente y que evita un episodio de corrosión mayor. Normalmente, los
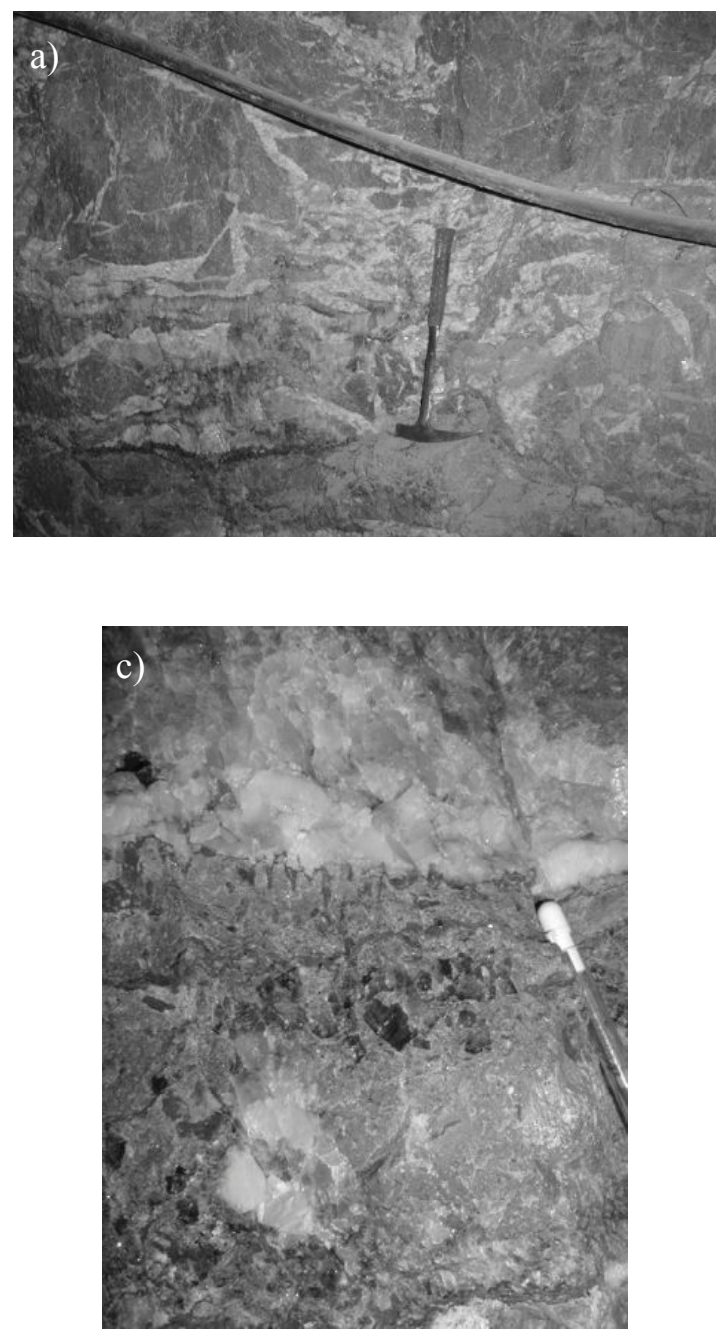

cuerpos mineralizados presentan una envoltura de calcita espática que se situa en el borde del cuerpo, pasando sin solución de continuidad a la caliza regional ligeramente recristalizada (Figura 19a).

Los cuerpos mineralizados son prácticamente monominerálicos. La fluorita aparece mayoritariamente bajo la forma de cristales blancos a incoloros, sin trazas de corrosión indicando la existencia de una sucesión pasiva en la formación del depósito, dispuestos en texturas ritmíticas (Figura 19b). Ocasionalmente se observan cavidades finales tapizadas por cristales idiomórficos, cúbicos de fluorita zonada con las últimas bandas de color púrpura (Figura 19c y 19d). Solo en estas cavidades se han localizado escalenoedros de calcita y rarísimos cristales de barita. No se ha detectado la presencia de sulfuros en la mineralización, aunque ocasionalmente se han observado (S. Baca, com. per.).

La fluorita contiene inclusiones fluidas de gran tamaño,
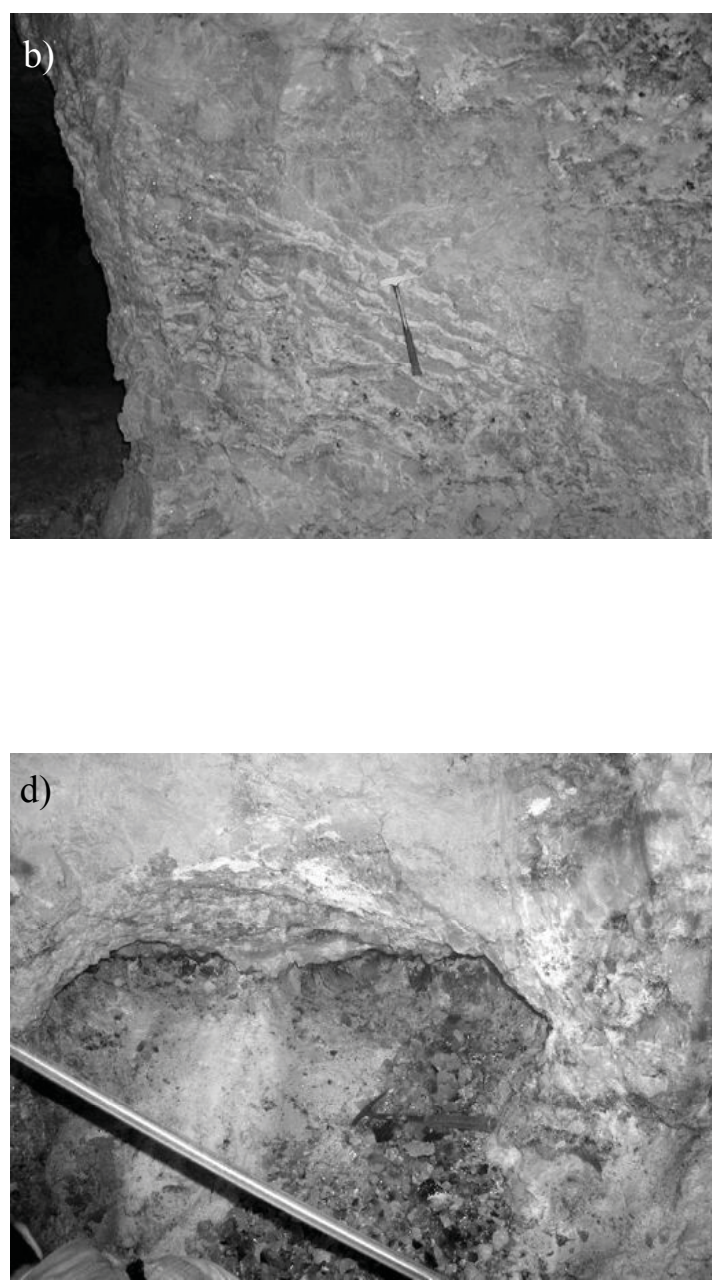

Figura 19. Mantos de fluorita de La Encantada-Buenavista (Coahuila). (a) Fracturación hidráulica de los carbonatos encajonantes al frente de la mineralización. (b) Manto principal de fluorita constituido exclusivamente por ritmitas constituidas por la alternancia de niveles de fluorita incolora y violeta. (c) Detalle del contacto del nivel mineralizado con la roca encajonante; nótese la fuerte recristalización de la caliza encajonate, desarrollándose una envolvente de calcita pura. (d) Cavidad tardía en fluorita tapizada por cristales idomórficos centimétricos a decimétricos. 
aisladas o distribuidas según las bandas de crecimiento, con caracteres claramente primarios. Suelen aparecer tres familias de inclusiones fluidas (Figura 20): (1) inclusiones acuosas bifásicas formadas por una solución salina y una burbuja de vapor; (2) inclusiones no acuosas, de color café a café oscuro, constituidas por un hidrocarburo líquido, una burbuja de gas y, ocasionalmente, bitumen sólido; y (3) inclusiones trifásicas a polifásicas mixtas formadas por una solución salina, un hidrocarburo líquido no miscible, una burbuja de gas y cantidades variables de bitumen sólido. Es común encontrar inclusiones fluidas muy oscuras, claramente decrepitadas, producto del calentamiento sufrido por algunos cuerpos debido a la intrusión de cuerpos subvolcánicos de composición riolítica. Es común encontrar todos los tipos de inclusiones atrapadas en las mismas bandas de crecimiento, con claras evidencias de coetaneidad. Las temperaturas de homogeneización reportadas para estos depósitos (González-Partida et al., 2003) varían entre 75 a $120{ }^{\circ} \mathrm{C}$, con salinidades comprendidas entre 10.5 y $14.9 \%$ eq. en peso de $\mathrm{NaCl}$. Estas inclusiones fueron modeladas termodinámicante mediante el software PIT (Thiéry et al.,

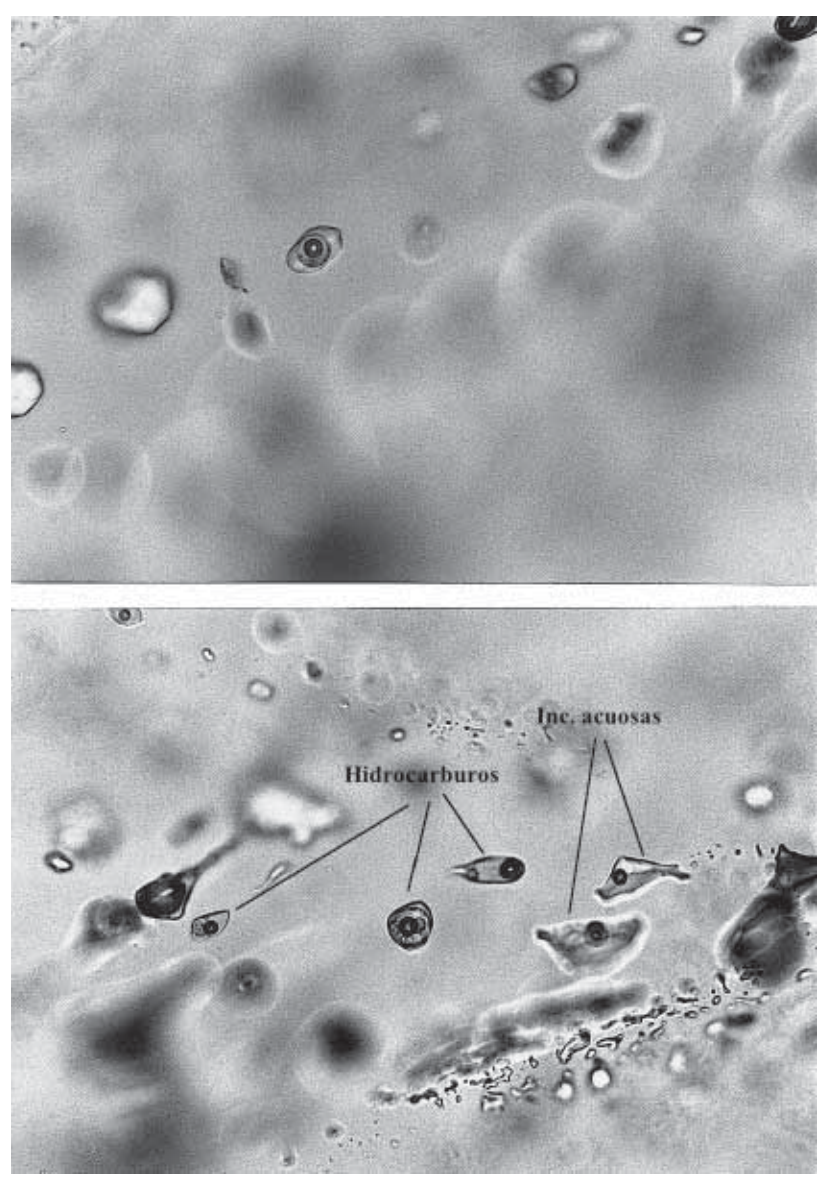

Figura 20. Inclusiones fluidas en fluorita, distrito de La EncantadaBuenavista (Coahuila). Arriba: inclusiones fluidas primarias atrapadas siguiendo los planos de crecimiento de la fluorita. Abajo: inclusiones fluidas acuosas y de hidrocarburos atrapadas coetaneamente en el mismo plano de crecimiento. Fotografías tomadas por A. Ramos.
2000). Las isocoras e isopletas calculadas corresponden a un solo tipo de aceite pesado. Las isopletas calculadas para el sistema acuoso varían en función de la cantidad de $\mathrm{CH}_{4}$ en las inclusiones. La reconstrucción de las condiciones P-T a partir del cruce de isocoras calculadas a partir de inclusiones atrapadas coetáneamente permitió determinar tres condiciones de presión-temperatura de atrapamiento de las inclusiones: (1) 108 bar and $100{ }^{\circ} \mathrm{C}$; (2) 160 bar and $120^{\circ} \mathrm{C}$; y (3) 300 bar and $105^{\circ} \mathrm{C}$ (González-Partida et al., 2003). Esta variación en las condiciones de presión puede muy bien reflejar los cambios que ocurrieron debido a la apertura del sistema hidrotermal durante los episodios de fracturación hidraúlica (Tritlla et al., 2004b).

Tanto los datos microtermométricos como la composición en halógenos de las inclusiones (Figura 18; Tritlla et al., 2004b) indican que los fluidos involucrados en la génesis de estos depósitos son de origen meteórico, muy probablemente agua marina con cierto grado de evaporación, muy modificada debido a su circulación a través de la serie sedimentaria. Así mismo, ambos conjuntos de datos indican que los fluidos atrapados en la fluorita son el producto de una mezcla, ya que las salinidades calculadas son demasiado bajas para las relaciones de halógenos determinadas, indicando una más que posible mezcla con un fluido de baja salinidad.

La presencia sistemática de bitumen atrapado junto con las inclusiones fluidas que contienen aceites pesados indica la presencia de un episodio de degradación térmica. (González-Partida et al., 2003). Tanto las evidencias de mezcla como la degradación térmica de los hidrocarburos junto con las evidencias de fracturación hidraúlica en la roca encajonante sugieren la posible maduración "in situ" de la materia orgánica debido a la mezcla de una "salmuera" salina, oxidante y rica en sulfato, que muy probablemente transportaba fluor, con otro fluido, rico en materia orgánica, presente en los carbonatos cretácicos, según un mecanismo ya invocado anteriormente (Tritlla y Cardellach, 1997: Tritlla et al., 2001b).

Depósitos en el Estado de Guerrero. Los depósitos de fluorita que pueden pertenecer a esta tipologia en el Edo de Guerrero se sitúan según un lineamiento de dirección aproximada NW-SE, entre las poblaciones de Acamitxla, Huajojutla, San Miguel de Acuitlapán y San Francisco de Acuitlapán. Todas ellos aparecen encajonados en los carbonatos de la Formación Morelos. Sobre estos cuerpos se ha desarrollado un conjunto de labores mineras de diversa importancia, destacando la mina La Azul, un tajo a cielo abierto que permite observar con detalle las relaciones entre el cuepo mineralizado y la roca encajonante.

La mina La Azul (Acamitxla, Gro.) históricamente ha llamado la atención de un conjunto de autores (SkewesSaunders, 1938; Fowler et al., 1948; González-Reyna, 1956; Osborne, 1956; Fernandez, 1956; FlorenzaniValderrama, 1974; De Cserna y Fries, 1981; Clark, 1990; Tritlla et al., 1999, 2001a; Pi et al., 2005; Tritlla y Levresse, 2006) debido a su cercanía con los depósitos epitermales a 
mesotermales de Ag- $\mathrm{Zn}-\mathrm{Pb}-\mathrm{Cu}$ de Taxco.

Este depósito consta de un solo manto estratoligado de fluorita que reemplaza la caliza fosilífera de la Formación Morelos (Cretácico). El límite superior del cuerpo es claramente visible en el tajo a cielo abierto y está constituido por un frente de reacción irregular que pasa de forma gradual a los carbonatos anteriormente mencionados (Figura 21a). El límite entre la fluorita y la roca encajonante viene marcado por un frente de recristalización del carbonato (Figura $21 \mathrm{~b}$ ), de algunos centímetros de grosor, caracterizado por la poligonalización de los bordes de grano de la calcita y la diseminación a favor de estos de pequeños cristales de fluorita (Figura 21c), cuya abundancia decrece en dirección a la caliza fresca.

La fluorita se presenta esencialmente bajo la forma de ritmitas constituidas por la alternancia de bandas de colores variables (violeta, negro, blanco) o translúcidas, ocasionalmente con cuarzo, barita y uraninita como minerales accesorios (Figura 21d). Comúnmente, la substitución de la caliza Morelos no es completa, por lo que es común observar la presencia de bloques relictos de carbonato completamente rodeados por fluorita. El fenómeno de substitución representa una ganancia de porosidad neta debido a la gran abundancia de cavidades parcialmente tapizadas por cubos de fluorita amarilla tardía. Estas texturas ritmíticas son similares a las halladas en otros depósitos mexicanos de fluorita encajonados en carbonatos de edad similar (González-Partida et al., 2003; Levresse et al., 2003; Tritlla et al., 2004b) así como en el resto del mundo (MVT, subtipo fluorítico).

Ocasionalmente aparecen bandas alternantes blancas y negras de hasta $1 \mathrm{~cm}$ de grosor, que adquieren una morfología botroidal o globular, con concreciones de hasta $30 \mathrm{~cm}$ de diámetro. Estos glóbulos están constituidos por cristales esqueléticos de fluorita en disposición radial y con un zoneamiento marcado por la disposición de inclusiones ricas en materia orgánica y fétidas (presencia de $\mathrm{H}_{2} \mathrm{~S}$ ).

Todo el conjunto suele estar afectado por un número indeterminado de fases de fracturación (hidráulica) y recementaciones por diveras generaciones de ritmitas de fluorita subsiguientes (Figura 21d). Al microscopio, los cristales individuales de fluorita presentan mayoritariamente un zoneamiento de crecimiento marcado por cambios de color. Así mismo, es común la presencia de pequeños cristales de hasta $20 \mu \mathrm{m}$ de uraninita como inclusiones (Figura 21e; Pi et al., 2005). Esta uraninita genera “núcleos de color" violeta oscuro producto de la destrucción de la red de la fluorita (metamicto) debido a la radiactividad de la uraninita.

Una de las principales características de este depósito es la presencia de una estructura brechoide constituída por bloques de fluorita decolorados englobados en una roca de color blanco, muy friable, que al romperse se presenta compuesta esencialmente por arcillas y granos de cuarzo con fragmentos reconocibles de ferromagnesianos completamente alterados (Figura 21e). Esta estructura ha hecho pensar a diversos autores (Skewes-Saunders 1938; Osborne
1956; Fernandez, 1956; Florenzani 1974; Clark 1990; Pi et al., 2005; Pi et al., 2005) que el depósito se generó debido al reemplazamiento de los carbonatos de la Fm. Morelos por fluidos que habrían circulado por una falla mayor de dirección SW-NE. Fowler et al. (1948), Tritlla et al. (1999, 2001a) y Tritlla y Levresse (2006) son los únicos autores que sugieren que el cuerpo de fluorita está intruido por un dique riolítico posterior a la formación del depósito, ya que se encuentran xenolitos de fluorita dentro de dicho cuerpo ígneo, así como pequeñas vetas de riolita cruzando la masa de fluorita. En realidad, el manto mineralizado en fluorita se comporta como un encajonante rígido en presencia de un intrusivo, desarrollándose un stoping magmático. La pérdida de color en la fluorita, pasando de su color original violáceo a uno grisáceo, y las evidencias de recristalización son consecuencia del calor aportado por la intrusión del cuerpo ígneo. Es de destacar que estas primeras bandas están a su vez cortadas por fracturas, a favor de las que se desarrollan otras bandas tangentes con las primeras, de escaso desarrollo lateral (de 2 a $3 \mathrm{~cm}$ ).

Tanto los cristales de fluorita como de cuarzo presentan abundantes inclusiones fluidas bifásicas primarias, que suelen estar afectadas por estrangulamiento y/o decrepitación natural. Datos microtermométricos preliminares obtenidos sobre muestras tomadas lejos del dique riolítico indican que este depósito se originó a partir de fluidos de mediana salinidad, con $\mathrm{NaCl}$ y $\mathrm{CaCl}_{2}$ como sales principales, y temperaturas medias comprendidas entre 120 y $150{ }^{\circ} \mathrm{C}$ ( in corrección de presión). Es de destacar que en general se observa una fuerte dispersión en los datos microtermométricos, muy probablemente debido a la intrusión del dique de riolita.

\subsubsection{Depósitos de metales base}

Los depósitos de metales base de baja temperatura encajonados en las plataformas carbonatadas de México hasta el momento han recibido escasa atención por parte del mundo académico.

La mayoría de estos depósitos presentan una alteración supergénica muy avanzada, por lo que la paragénesis primaria está completamente substituida por "calaminas", carbonatos de zinc hidratados (hidrocincita) o anhidros (smithsonita) como en el caso de los depósitos de Sierra Mojada, de la Sierra de la Purísima y San Marcos en el Edo. de Coahuila.

El distrito de Sierra Mojada se localiza en el borde sur de la Cuenca de Sabinas. Este distrito presenta dos mineralizaciones principales, separadas por la falla Sierra Mojada, de dirección E-W (Figura 22). Al norte de la falla, la mineralización se presenta bajo la forma de mantos diseminados estratoligados, masivos mineralizados en esfalerita y galena, con valores de $\mathrm{Cu}$ y $\mathrm{Ag}$. Al S de la falla, la mineralización consiste en mantos de óxidos de $\mathrm{Zn}$ y $\mathrm{Pb}$ (www.metalin. com). Estas dos mineralizaciones aparecen en una columna de unos $100 \mathrm{~m}$ de espesor, si bien los límites no se han podido determinar con precisión. 

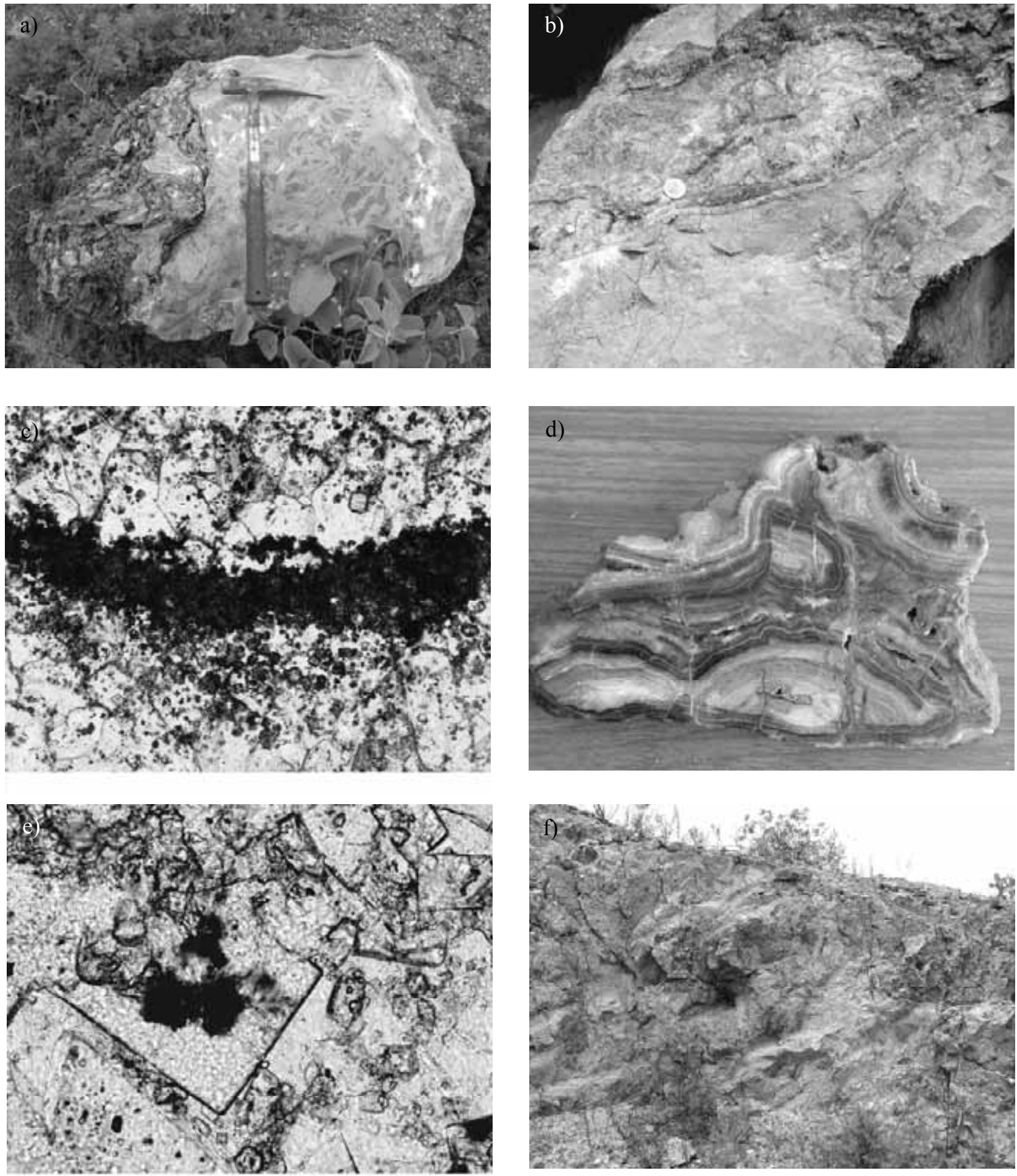

Figura 21. Manto de fluorita mina La Azul (Guerrero). (a) Detalle del contacto entre la fluorita (izquierda) y la caliza fuertemente recristalizada de la Fm. Morelos; nótese como la recristalización avanza por caminos preferentes (fracturas). (b) Detalle del frente de substitución de fluorita, nótese como el cuerpo de fluorita está limitado en su contacto por una banda blanca de alta recristalización del carbonato encajonante. (c) Detalle del borde de recristalización anterior; nótese en la parte superior de la fotografía como el carbonato se presenta recristalizado desarrollándose bordes de grano nítidos, en donde se concentran pequeños cristales de fluorita, y puntos triples. (d) ritmitas de fluorita afectadas por fracturación hidráulica y recementadas por generaciones de ritmitas posteriores (autobrechificación). (e) Detalle de un cristal idiomórfico de fluorita conteniendo varios cristales alotriomóficos de uraninita; nótese la aureola metamíctica desarrollada en la fluorita, producto de la destrucción de la red cristalina de la misma debido a la radioactividad de la uraninita. (f) Detalle del dique de riolita fuertemente alterado conteniendo fragmentos de la mineralización de fluorita altamente recristalizada. 
En 1879 se descubrió en esta zona un depósito de carbonato de plomo (cerusita) con altos contenidos en Ag, que se conoció como el Manto de Plomo. Este manto es subhorizontal, de morfología tabular y ha sido minado en dirección E-W de forma continua durante $3 \mathrm{~km}$ y discontinua durante $2 \mathrm{~km}$ más. Fue el único cuerpo productivo en el distrito hasta 1905, cuando se descubrieron los cuerpos ricos en $\mathrm{Cu}$ y $\mathrm{Ag}$ de la mina San José, al N de la falla de Sierra Mojada. En la década de 1920, la Corporación Peñoles descubrió un manto rico en óxidos y silicatos de $\mathrm{Zn}$ (hemimorfita) en una formación dolomitizada con altos contenidos en Fe, que fue denominado Manto Rojo de Zinc. Este manto también es subhorizontal y ha sido minado por unos $2 \mathrm{~km}$ (minas San Salvador, Encantada, Fronteriza y Oriental).

En la mina San Salvador se descubrió un nuevo cuerpo constituido casi exclusivamente por smithsonita situado por encima del nivel dolomítico que contiene el Manto Rojo de Zinc, conocido como Manto Blanco de Zinc. Este aparece Formación Aurora y tiene continuidad hacia la Formación La Peña, con una potencia reconocida de $70 \mathrm{~m}$. Este manto sólo fue explotado en la mina San Salvador por una longitud de $400 \mathrm{~m}$, y presenta leyes superiores en Zn al Manto Rojo, además de que contiene menos óxidos de Fe.

Estas dos mineralizaciones se encuentran en contacto debido a la falla post-mineral de Sierra Mojada, que pone en contacto las Formaciones San Marcos y Menchaca con la Aurora. Es de destacar que las alteraciones asociadas a la formación de estas mineralizaciones, aparte de la dolomitización del Manto Rojo, son inexistentes por lo que, junto cons sus características morfológicas, texturales y mineralógicas se pueden clasificar como pertenecientes a la tipología MVT.

Es de destacar que esta es la única zona con depósitos de $\mathrm{Pb}-\mathrm{Zn}$-Ag de tipo MVT que está en exploración en estos momentos. La compañia Metallin (www.metalin.com) está evaluando la posible reactivación de este distrito, detectando cuerpos mineralizados en el área de La Norteña en la mina La Encantada así como $\mathrm{Zn}-\mathrm{Pb}-\mathrm{Cu}-\mathrm{Ag}$ en las minas San Salvador, Encantada y Fronteriza.

En la Sierra de la Purísima y San Marcos, el distrito de Mineral de Reforma (minas Reforma, Ojo de Agua y Juárez) fue minado en el siglo XIX y principios del XX. Los cuerpos mineralizados son mantos estratoligados que

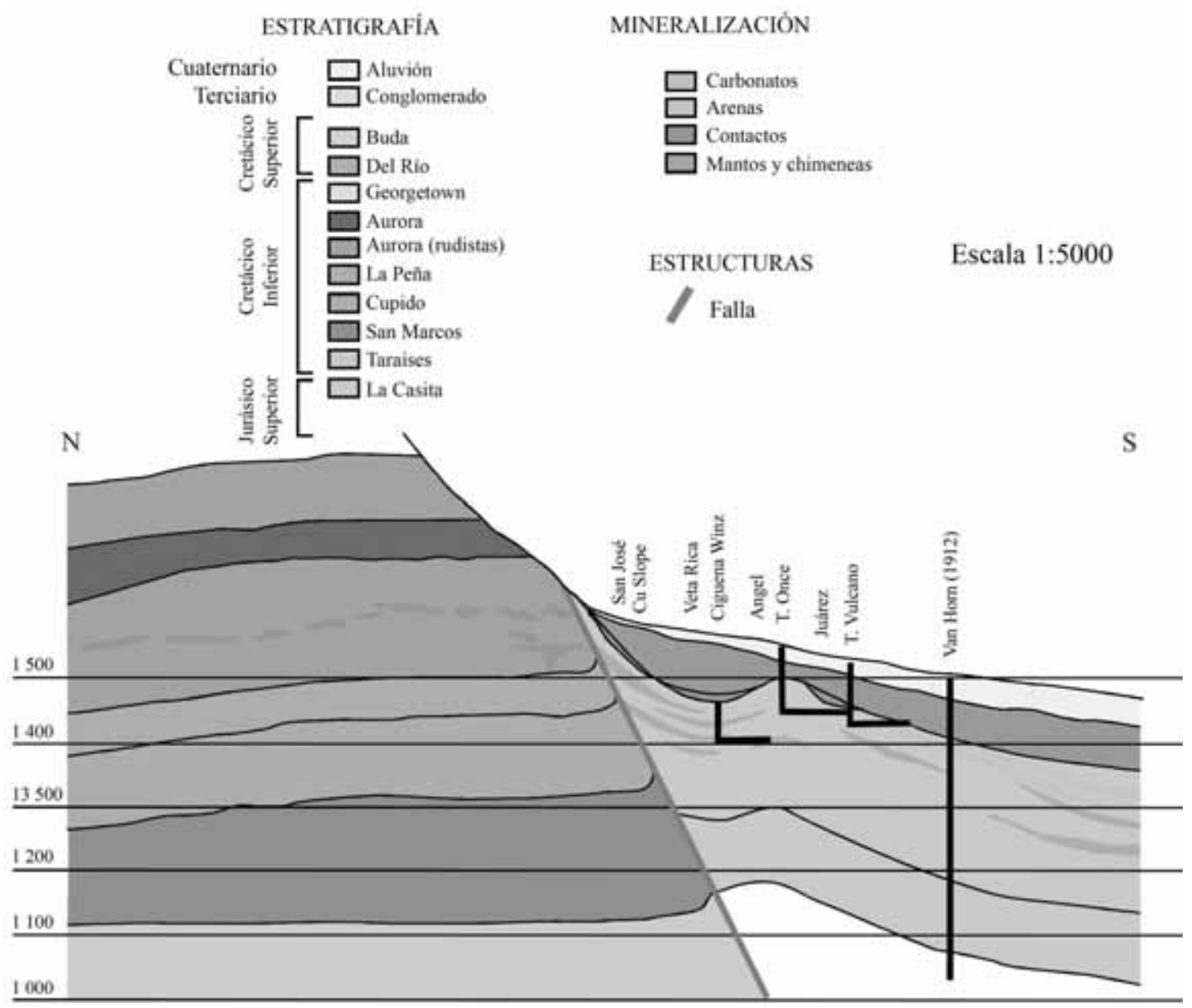

Figura 22. Corte geológico (sin escala) de la geología, estructura y disposición de los cuerpos mineralizados en Pb-Zn de Sierra Mojada (Coahuila). Modificado de www.metalin.com. 
se encuentran confinados y controlados por las facies de calizas oolíticas y arrecifales de la Formación Cupido (González-Ramos, 1984) fuertemente dolomitizadas (Figura 23a). Están esencialmente constituidos por galena, esfalerita, barita y siderita, con trazas de pirita y calcopirita como minerales hipogénicos, aunque los sulfuros aparecen casi siempre como relictos rodeados por los productos de alteración supergénica (smithsonita, hidrocincita, limonita, cerusita, etc; Figura 23b). Los fluidos que originaron la formación de estos cuerpos mineralizados, a diferencia de los de fluorita o barita anteriormente mencionados, alteran los carbonatos arrecifales mediante la formación de un halo de intensa dolomitización que resalta en el paisaje (Figura 23a) y evidencias claras de recristalización de la roca encajonante asociadas a la mineralización (Figura 23c). Las escasas inclusiones fluidas encontradas en los minerales hipogénicos indican temperaturas de formación de entre 100 a $150{ }^{\circ} \mathrm{C}$ con salinidades de alrededor entre 7.5 y $20 \%$ eq. de $\mathrm{NaCl}$.

\section{Conclusiones}

La existencia de depósitos claramente asimilables a los de tipo MVT en México ha quedado demostrada mediante el presente trabajo. La presencia de cuerpos mineralizados
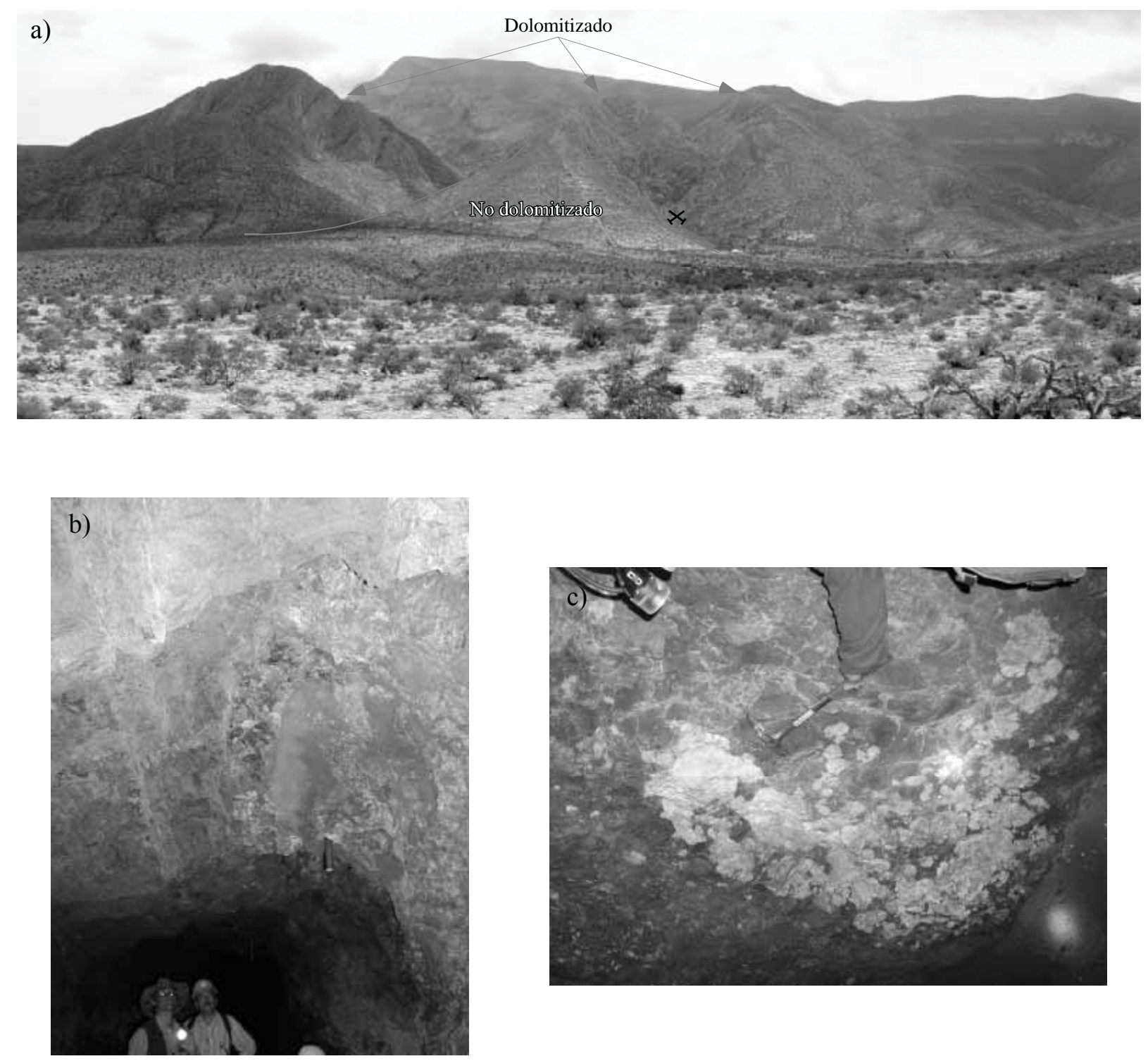

Figura 23. Depósito de Pb-Zn de Mineral de Reforma, Sierra de la Purísima y San Marcos(Coahuila). (a) Vista de paisaje de las rocas encajonantes de la mineralización; nótese el cambio de tonalidad de la roca regional, volviéndose más oscura debido a la dolomitización en la zona mineralizada. (b) Detalle de la mineralización oxidada (calaminas); (c) zona de contacto de la mineralización con la dolomía encajonante en la que se puede observar la alta recristalización de la misma. 
con estas características es mucho más común de lo que se venía pensando hasta el momento, por lo que resulta conveniente efectuar una revisión en profundidad de los depósitos encajonados en series carbonatadas en México cuya relación con intrusivos no sea evidente.

La revisión cuidadosa de las características geológicas y geoquímicas de estos depósitos ha permitido diferenciar cuatro grupos de mineralizaciones: (1) cuerpos estratiformes de barita de gran pureza que substituyen niveles evaporíticos y se localizan en las partes bajas de la serie estratigráfica; (2) cuerpos lenticulares estratoligados de celestina mayoritaria encajonados en la Fm. Cupido y equivalentes; (3) mantos estratoligados de fluorita controlados por fallas de bajo ángulo en los carbonatos arrecifales de la Fm. Aurora (Coahuila) y de la Fm. Morelos (Guerrero); y (4) cuerpos estratoligados, poco estudiados hasta el momento, de $\mathrm{Zn}-\mathrm{Pb}-(\mathrm{Cu}-\mathrm{Ba})$ asociados espacialmente a series dolomitizadas, a menudo alterados en superficie a "calaminas". Todos estos depósitos se caracterizan por presentarse asociados a la presencia de materia orgánica, tanto bajo la forma de inclusiones fluidas de hidrocarburos líquidos, de bitumen o por la presencia de $\mathrm{H}_{2} \mathrm{~S}$ (carbonatos o minerales fétidos).

En todos los casos, estos depósitos están genéticamente desligados de cualquier actividad magmática, aunque es común que estén afectados por episodios magmáticos posteriores (La Azul, Guerrero; La Encantada-Buenavista, Coahuila).

\section{Agradecimientos.}

Quisieramos agradecer a los Ing. Agustín Rodriguez y Samuel Baca, de Fluorita de México S. A. de C.V., tanto por las facilidades prestadas durante las visitas a la mina de La Encantada-Buenavista, como por su inestimable ayuda. Así mismo, al Dr. Noé Piedad Sánchez y al Ing. C. Martínez-Ramos por su ayuda y sus comentarios a la hora de escribir este trabajo. Y finalmente, al Dr. E. GonzálezPartida por sus comentarios durante la redacción de este trabajo, algunos de los cuales se han incorporado al presente trabajo para enriquecer la discusión.

Agradecemos el financiamiento prestado a este estudio a través del proyecto PAPIIT de la UNAM número IN114002.

\section{Referencias bibliográficas}

Anderson, G.M., 1975, Precipitation of Mississippi Valley-type ores: Economic Geology: 70(5), 937-942

Anderson, G.M., 1983, Some geochemical aspects of sulfide precipitation in carbonate rocks., en Kisvarsanyi, G., Grant, S.K., Pratt, W.P., Koenig, J.W. (ed.), International Conference on MVT lead-zinc deposits, Rolla, University of Missouri-Rolla, 61-76.

Anderson, J.M., Macqueen, R.W., 1988, Mississippi Valley-Type Lead Zinc Deposits., en Roberts, R.G., Sheahan, P.A. (ed.), Ore Deposit Models: Geoscience Canada Reprint Series 3, 79-90.

Anderson, W.L., Lydon, J.W., 1990, Sedex and MVT deposits in Juras- sic carbonates of Pakistan., Abstrat of 8th IAGOD Symposium, Ottawa, A257.

Anderson, I.K., Ashton, J.H., Boyce, A.J., Fallick, A.E., Russell, M.J., 1998, Ore depositional processes in the Navan $\mathrm{Zn}-\mathrm{Pb}$ deposit, Ireland: Economic Geology, 93, 535-563.

Arne, D.C., Kissin, S.A., 1989, The significance of the diagenetic crystallization rhythmites at the Nanisivik $\mathrm{Pb}-\mathrm{Zn}-\mathrm{Ag}$ deposit, Baffin Island, Canada: Mineralium Deposita, 24, 210-218.

Arne, D.C., Curtis, L.W., Kissin, S.A., 1991, Internal zonation in a carbonate-hosted $\mathrm{Zn}-\mathrm{Pb}-\mathrm{Ag}$ deposit, Baffin Island, Canada: Economic Geology, 86, 699-717.

Banks, D.A., 1985, A fossil hydrothermal worm assemblage from the Tynagh lead-zinc deposit in Ireland: Nature, 313,128-131.

Banks, D.A., Russell, M.J., 1992, Fluid mixing during the ore deposition at Tynagh base-metal deposit, Ireland: European Journal of Mineralogy, 4, 921-931.

Barnes, H.L., 1983, Ore deposition in Mississippi Valley-type deposits., en Kisvarsanyi, G., Grant, S.K., Pratt, W.P., Koenig, J.W. (ed.), International Conference on MVT lead-zinc deposits, University of. Missouri-Rolla, 77-85.

Barrett, T.J., Anderson, G.M., 1988. The solubility of sphalerite and galena in $1-5 \mathrm{~m} \mathrm{NaCl}$ solutions to 300 degrees C: Geochimica et Cosmochimica Acta 52(4), 813-820

Barton, P.B. Jr., 1967, Possible role of organic matter in the precipitation of the Mississippi Valley ores: Economic Geology Monography 3, 371-378.

Beales, F.W. ,1975, Precipitation mechanisms for Mississippi Valley-type ore deposits: Economic Geology, 70, 943-948.

Beales, F.W., Hardy, J.W., 1980, Criteria for recognition of diverse dolomite types with an emphasis on studies of host rock for Mississippi Valley-type ore deposits, en Zenger, D.H., Dunham, J.B., Ethington R.L. (ed.), Concepts and models of dolomitization, SEPM Special Publication, 28, 197-213.

Beaty, D.W., Landis, G.P., Thompson, T.B.,1990, Carbonate-hosted sulfide deposits of Central Colorado Mineral Belt: Introduction, General Discussion, and Summary: Economic Geology Monograph 7, 1-18.

Bethke, C.M., 1986, Hydrologic constraints on the genesis of the Upper Mississippi Valley mineral district from Illinois basin brines, Economic Geology, 81, 233-249

Bethke, C.M., Marshak, S., 1990, Brine migrations across North America-the plate tectonics of groundwater, Annual Review of Earth and Planetary Science, 18, 228-315

Bjorlykke, A., Sangster, D.F., 1981, An overview of sanstone lead desposits and their relation to red-bed copper and carbonate-hosted lead-zinc deposits: Economic Geology 75th Anniversary Volume, 179-213.

Boni, M., 1985, Les gisements de type Mississippi Valley du Sud-Ouest de la Sardaigne (Italie): une sysnthèse., Chronique de la Recherche Miniere, 479, 7-34.

Boyce, A.J., Little, C.T.S., Russell, M.J., 2003, A new fossil vent biota in the Ballynoe barite deposit, Silvermines, Ireland: evidence for intracratonic sea-floor hydrothermal activity about $352 \mathrm{Ma}$ : Economic Geology, 98, 649-656.

Bradley, D. C., Leach, D.L., 2003, Tectonic controls of Mississippi Valleytype lead-zinc mineralization in orogenic forelands: Mineralium Deposita, 38, 652-667.

Brannon, J. C., Podosek, F.A., McLimans, R.K., 1992, A Permian Rb-Sr age for sphalerite from the Upper Mississippi zinc-lead district, Wisconsin: Nature, 356, 509-511.

Brannon, J. C., Podosek, F.A., Cole, S.C. ,1996a, Radiometric dating of Mississippi Valley-type ore deposits, en Sangster, D.F. (ed.), Carbonate-hosted lead-zinc deposits: SEG special volume, 4, 536-545.

Brannon, J.C., Cole, S.C., Podosek, F.A., Ragan, V.M., Coveney Jr., R.M., Wallace, M.W. , Bradley, A.J. ,1996b, Th-Pb and U-Pb dating or ore stage calcite and Paleozoic fluid flow: Science, 271, 491-493.

Callahan, W.H., 1967, Some spatial and temporal aspects of the localization of Mississippi Valley-Appalachian type ore deposits: Genesis of stratiform lead-zinc-barite-fluorite deposits (Mississippi Valley type deposits)-A symposium, Economic Geology Monographs 14-18.

Cardellach, E., Canals, A., Tritlla, J., 1990, Late and post-hercynian low 
temperature veins in the Catalonian Coastal Ranges. Acta Geológica Hispánica, 25, 5-81.

Carpenter, A.B., Trout, M.L., Pickett, E.E., 1974, Preliminary report on the origin and chemical evolution of lead and zinc oil field brines in Central Mississippi: Economic Geology, 69, 1191-1206.

Cathles, L.M., Smith, A.T. ,1983, Thermal constraints on the formation of Mississippi Valley-type lead-zinc deposits and their implication for episodic basin dewatering and deposit genesis: Economic Geology, 78, 983-1002.

Channer, D. W., Randell, R.N., Bray, C.J., Spooner, E.T.C., 1993, Combined gas and ion chromatographic analysis of fluid inclusion: application to the Polaris MVT Pb-Zn deposit, Canadian Artic Archipielago, en Parnell, J., Moles, N.R. (ed.), Geofluids '93 conference: Belfast, Irlanda, 342-346.

Charleston, S., 1981, A summary of the structural geology and tectonics of the State of Coahuila, México; en Smith, C.I. (ed.), Lower Cretaceous stratigraphy and structure northern Mexico: West Texas Geological Society Publication: Texas, USA, 28-36.

Chi, G., Savard, M.M., 1997, Sources of basinal and Mississippi Valleytype mineralising brines: mixing of evaporated seawater and halitedissolution brine: Chemical Geology, 143, 121-125.

Christensen, J.N., Halliday, A.N., Leigh, K.E., Randell, R.N., Kesler, S.E., 1995a, Direct dating of sulfides by Rb-Sr: a critical test using the Polaris Mississippi Valley-type deposit: Geochimica et Cosmochimica Acta, 59, 5191-5197.

Christensen J.N., Halliday, A.N., Vearnconmbe, K.E., Randell, R.N., Kesler, S.E. ,1995b, Testing models of large-scale crustal fluid flow using direct dating of sulfides: Rb-Sr evidence fro early dewatering and formation of MVT deposits, Canning Basin, Australia: Economic Geology, 90, 877-884.

Clark, K.F. ,1990, Geology and Mineral Deposits of the Taxco Mining District, SEG Guidebook Series, Mexican Silver Deposits, 6, 281-291.

Counter-Benison, K., Lowenstein, T.K., 1997, Carbonate-hosted mineralization of the Lower Ordovician Ogdensburg Formation: evidence for a Paleozoic thermal anomaly in the St.Lawrence-Ottawa lowlands of New York and Ontario, en Montanez, P., Gregg, J.M., Shelton, K.L. (ed.), Basin-wide Diagenetic Patterns: Integrated Petrologic, Geochemical, and Hydrologic Considerations: SEPM Special Publication, 57, 207-218.

Coveney, R.M., Goebel, E.D., Ragan, V.M., 1987, Pressures and temperatures from aqueous fluid inclusions in sphalerite from midcontinent country rocks: Economic Geology, 82, 740-751.

Crawford, M.J., Beales, F.W., 1983, The Shawangunk mine: a possible sandstone-hosted Mississippi Valley-type ore deposit in New York., en Kisvarsanyi, G., Grant, S.K., Pratt, W.P. , Koenig, J.W. (ed.), International Conference on MVT lead-zinc deposits: Missouri, USA, University of Missoure-Rolla, 436-445.

Daniels, E.J., Altaner, S.P., Marshak, S., Eggleston, J.T., 1990, Hydrothermal alteration in anthracite from eastern Pennsylvania: implication for mechanisms of anthracite formation: Geology, 18, 247-250.

Davis, D.W., Lowenstein, T.K., Spencer, R.J., 1990, Melting behavior of fluid inclusions in laboratory-grown halite crystals in the systems $\mathrm{NaCl}-\mathrm{H}_{2} \mathrm{O}, \mathrm{NaCl}-\mathrm{KCl}-\mathrm{H}_{2} \mathrm{O}, \mathrm{NaCl}-\mathrm{MgCl}_{2}, \mathrm{H}_{2} \mathrm{O}$, and $\mathrm{NaCl}, \mathrm{CaCl}_{2}$ $-\mathrm{H}_{2} \mathrm{O}$ : Geochimica et Cosmochimica Acta, 54, 591-601.

De Cserna, Z., Fries, C., 1981, Hoja Taxco 14Q-h (7), Geología de los Estados de Guerrero, México y Morelos: México, D.F., Universidad Nacional Autónoma de México, Instituto de Geología, Cartas Geológicas de México serie 1:100,000, 1 mapa con texto.

De Cserna, Z., 1989, An outline of the geology of Mexico, en Bally, A.W., Palmer, A. R., (ed.), The Geology of North America-An Overview Vol. A.: Geological Society of America, 233-264.

Department of Communications, Marine and Natural Resources, Ireland, 2004, Zinc and Lead in Ireland, Exploration and Mining Division: Dublin, Irlanda, 6 p.

Drovenik, M., 1985, Some geochemical characteristics of lead-zinc deposits in Slovenia, NW Yugoslavia: Berlin-Stuttgart, Gebrüder Borntraeger, Monograph Series on Mineral Deposits 25, 105-120.

Dunham, K., 1983, Ore genesis in the English Pennines: a fluoritic subtype. en Kisvarsanyi, G., Grant, S.K., Pratt, W.P. , Koenig, J.W., (ed.),
International Conference on MVT lead-zinc deposits: Missouri, University of Missouri-Rolla, 86-112.

Dunham, K., 1990a, Geology of the Northern Pennine Orefield. Volume 1: B.G.S. Economic Memoire, Second edition, 299 pp.

Dunham, K., 1990b, Geology of the Northern Pennine Orefield. Volume 2. B.G.S. Economic Memoire, Second edition.299 pp.

Dzulinski, S., Sass-Gustkiewickz, M., 1985, Hydrothermal karst phenomena as a factor in the formation fo Mississippi Valley-type deposits, en Wolf, K.H. (ed.), Handbook of strata-bound and stratiform ore deposits: Amsterdam, Elsevier, 13, 391-439.

Elliot, W.C., Aronson, J.L., 1987, Alleghanian episode of K-bentonite illitization in the southern Appalachian basin: Geology, 15, 735-739.

Everett, C.E., Wilkinson, J.J., Rye, D.M., 1997, The leaky basement: new data on regional fluid flow and $\mathrm{ZN}-\mathrm{Pb}$ mineralization in Ireland, in Dave Johnston Memorial Meeting Abstracts volume, Trinity College, Dublin, sin paginar.

Everett, C.E., Wilkinson, J.J., Rye, D.M., 1999, Fracture-controlledfluid flow in the Lower Palaeozoic basement rocks ofIreland:implications for the genesis of Irish-type $\mathrm{Zn}-\mathrm{Pb}$ deposits, in: McCaffrey, K.J.W., Lonergan, L., Wilkinson, J.J. (ed.), Fractures, Fluid Flow and Mineralization: Londres, Geological Society of London Special Publications, 155, 247-276.

Eyre, S.L., 1998, Geochemistry of dolomitization and $\mathrm{Zn}-\mathrm{Pb}$ mineralization in the Rathdowney Trend, Ireland, University of London, Londres, UK, Tesis doctoral, $220 \mathrm{p}$.

Eyre, S.L., Wilkinson, J.J., Stanley, C.J., Boyce, A.J., 1996, Geochemistry of dolomitisation and zinc-lead mineralisationin the Rathdowney Trend, Ireland. Geol. Soc. Am., Abstr. Progr. 28, A210-211.

Fernández, G., 1956, Nota sobre la mina "La Azul”, en Maldonado-Koerde11, (ed.), Geología a lo largo de la Carretera entre México D.f., Taxco, Gro. Distrito Minero de Taxco. Visita a un Yacimiento de Fluorita en Rocas del Terciario Inferior: México, Congreso Geológico Internacional, Excursiones A-4, C-2, Vigésima Sesión, México.

Florenzani Valderrama, G. ,1974, Estudio geológico minero del distrito de Taxco, Edo. de Guerrero, México, Instituto Politécnico Nacional, Tesis profesional, $93 \mathrm{p}$.

Fowler, G.M., Hernon, R.M., Stone, E.A., 1948, The Taxco mining district, Guerrero, Mexico, en Dunham, K.C. (ed.), Symposium on the geology, paragenesis and reserves of the ored of lead and zinc: London, UK, 18th International Geological Congress, 39(1), 107-116

Fontboté, L., Gorzawski, H., 1990, Genesis of the Mississippi Valley-type $\mathrm{Zn}-\mathrm{Pb}$ deposit of San Vicente, Central Peru: Geologic and isotopic (Sr, O, C, S, Pb) evidence: Economic Geology, 85, 1402-1437.

Fontboté, L., 1993, Self-organization fabrics in carbonated-hosted deposits: the example of diagenetic crystalization rhytmites (DCRs), en Fenoll Hach-Alí, P., Torres-Ruiz, F., Gervilla, F. (ed.), Current Research in Geology Applied to Ore Deposits: Granada, España, Universidad de. Granada, 11-14.

Fontes, J.Ch., Matray, J.M., 1993, Geochemistry and origin of formation brines from the Paris Basin, France. 1. Brines associated with Triassic salts: Chemical Geology, 109, 149-175.

Friedrich, G., Germann, A., Jochum, J., 1993, Schichtgebundene Pb-ZnVorkommen in klastischen Sedimenten vom Type Maubach-Mechernich. Lagerstättenbildung durch intraformationale Prozesse: Mitteilung Osterreich Mineralogie Gesselschaft, 138, 93-105.

Garven, G., 1985, The role of regional fluid flow in the genesis of the Pine Point deposit, western Canada sedimentary basin: Economic Geology, 80,307-324.

Garven G., Freeze, R.A., 1984a, Theoretical analysis of the role of groundwater flow in the genesis of stratabound ore deposits: 1 . Mathematical and numerical model: American Journal of Science, 284, 1125-1174.

Garven G., Freeze, R.A., 1984b, Theoretical analysis of the role of groundwater flow in the genesis of stratabound ore deposits: 2. Quantitative results. American Journal of Science, 284, 1085-1124.

Ge, S., Garven, G., 1992, Hydromechanical modeling of tectonically driven groundwater flow with application to the Arkoma Foreland Basin: Journal of Geophysical Research, 97, 9119-9144.

Gil, P.P., Martinez, R., Velasco, F., 1984, Ritmitas diagenéticas en las mineralizaciones de hierro de Bilbao, en I Congreso Español de 
Geología: Bilbao, España, 491-499.

Gil, P.P., Velasco,F., 1992, Genesis de los yacimientos de hierro de Bilbao (Cretacico inferior, Cuenca Vasco-Cantábrica): Boletín de la Sociedad Española de Mineralogía, 15(1), 238-242.

Gleeson, S.A., Wilkinson, J.J., Shaw, H.F., Herrington, R.J., 2000, Postmagmatic hydrothermal circulation and the origin of base metal mineralisation, Cornwall, UK: Journal of the Geological Society of London, 157, 589-600.

Goldhammer, R.K., 1999, Mesozoic sequence stratigraphy and paleogeographic evolution of Northeast Mexico, en Bartolini, C., Wilson, J.L., Lawton, T.F., Mesozoic sedimentary and tectonic history of north-central Mexico Special Paper, Geological Society of America, 340, 1-58.

Gómez-Fernandez, F., Both, R.A., Mangas, J. y Arribas, A., 2000, Metallogenesis of $\mathrm{Zn}-\mathrm{Pb}$ Carbonate-Hosted Mineralization in the Southeastern Region of the Picos de Europa (Central Northern Spain) Province: Geologic, Fluid Inclusion and Stable Isotope Studies: Economic Geology, 95, 19-40.

González-Partida, E., Carillo-Chavez, A., Grimmer, J.O.W., Pironon, J., Mutterer, J., Levresse, G., 2003, Fluorite deposits at EncantadaBuenavista, Mexico: products of Mississippi Valley type processes: Ore Geology Reviews, 23(3-4), 107-124.

González-Ramos, A., 1984, Estudio geológico -geoquímico regional de la Sierra La Purisima, San Marcos, en el Mpio. de Cuatro Cienegas, Coahuila: México D.F., México, Facultad de Ingeniería, UNAM, tesis de Licenciatura, $128 \mathrm{p}$.

González-Reyna, J., 1956, Riqueza minera y yacimientos minerales de Mexico: Departamento de Investigaciones Industriales, Banco de México, $497 \mathrm{p}$

Górecka, E., 1993, Geological setting of Silesian-Craw Zn-Pb deposits: Geology Quarterly, 37, 127-146.

Gorzawski, H., Fontbote, L., Sureau, J. F., Calvez, J., 1989, Strontium isotope trends during diagenesis in ore-bearing carbonate basins Geologic modeling; aspects of integrated basin analysis and numerical simulation: Geologische Rundschau, 78(1), 269-290.

Grandia, F., Cardellach, E., Canals, A., Banks, D.A., 2003a, Geochemistry of the fluids related to epigenetic carbonate-hosted $\mathrm{Zn}-\mathrm{Pb}$ deposits in the Maestrat basin (Eastern Spain ): Fluid inclusion and isotope (Cl, C, O, S, Sr) evidence: Economic Geology, 98, 933-954.

Grandia, F., Cardellach, E., Banks, D.A., Canals, A., 2003b, Origin of ore forming brines in sedimentary-hosted $\mathrm{Zn}-\mathrm{Pb}$ deposits: seawater $v s$.. halite dissolution: Economic Geology, 98, 1397-1411.

Gregg, J. M., Sibley, D.F., 1984, Epigenetic dolomitization and the origin of xenotopic dolomite texture: Journal of Sedimentary Petrology, 54, 908-931.

Hagni, R.D., 1976, Tri-State ore deposits: the character of their host rocks and theis genesis, en Wolf, K.H. (ed.), Handbook of strata-bound and stratiform ore deposits, vol. 6: $\mathrm{Cu}, \mathrm{Zn}, \mathrm{Pb}$ and $\mathrm{Ag}$ deposits: Amsterdam, Elsevier, 457-491.

Hall, W.E., Friedman, I., 1963, Composition of fluid inclusions, Cavein-Rock fluorite district, Illinois, and Upper Mississippi Valley zinc-lead district: Economic Geology, 58, 886-911.

Hanor, J.S., 1987, History of thought on the origin of subsurface sedimentary brines, in E.R. Landa y S. Ince (ed.), The history of hydrology, American Geophysical Union, 81-91.

Hanor, J.S., 1994, Origin of saline in sedimentary basins. en J. Parnell (ed.), Geofluids: Origin, migration and evolution of fluids in sedimentary basins, Special Publication Geological Society of London: Londres, UK, 78, 151-174.

Hanor, J.S., 1996, Controls on the solubilization of lead and zinc in basinal brines, en: Sangster, D.F. (ed.), Carbonate-hosted Lead-Zinc Deposits, SEG Special Publication: USA, 4, 483-500.

Hearn, P.P., Sutter, J.F., 1985, Authigenic postassium feldspar in Cambrian carbonates: Evidence of Alleghanian brine migration: Science, 228, 1529-1531.

Hearn, P.P., Sutter, J.F., Belkin, H.E., 1987, Evidence for late Paleozoic brine migration in Cambrian carbonate rocks of the central and southern Appalachians: implications for Mississippi Valley-type sulfide mineralization: Geochimica et Cosmochimica Acta, 51, 1323-1334.
Hey, A.V., West, W.S., 1982, Outlying mineral ocurrences related to the Upper Mississippi Valley mineral district, Wisconsin, Iowa, Illinois and Minnesota: Economic Geology, 77, 1803-1817.

Hitzman, M.W., Beaty, D.W., 1996, The Irish Zn-Pb-(Ba) orefield, en Sangster, D.F. (ed.), Carbonate-hosted lead-zinc deposits: Society of Economic Geologists Special Volume, 4, 112-143.

Hitzman, M.W., Redmond, P.B., Beaty, D.W., 2002, The carbonate-hosted Lisheen $\mathrm{Zn}-\mathrm{Pb}-\mathrm{Ag}$ deposit, County Tipperary, Ireland: Economic Geology, 97(8), 1627-1655.

Hoagland, A.D., 1976, Appalachian zinc-lead deposits, en Wolfe, K.H. (ed), Handbook of stratabound and stratiform ore deposits: Amsterdam, Elsevier, 6, 495-534.

Jackson, S.A., Beales, F.W., 1967, An aspect of sedimentary basin evolution: the concentration of Mississippi Valley-type ores during late stages of diagenesis: Canadian Petroleum Geologists Bulletin, 14, 383-433.

Jebrak, M., 1984, Contribution à l'histoire naturelle des filons (F-Ba) du domaine varisque francais-marrocain. Essai de caractérisation estructurale et geochimie des filons en extension et en décrochement: Documents du BRGM, 99, $510 \mathrm{p}$.

Jebrak, M., 1992, Les textures intra-filonnienes, marqueurs des conditions hydrauliques et tectoniques., Chronique de la Recherche Minière, 506, 25-35.

Johnson, C; Cardellach, E., Tritlla, J., Hanan, B., 1996, Cierco Pb-Zn-Ag Vein Deposits: Isotopic and Fluid Inclusion Evidence for Formation During Mesozoic Rifting in the Pyrenees of Spain: Economic Geology, 91(3), 497-506.

Jones, H.D., Kesler, S.E., 1992, Fluid inclusion gas geochemistry in east Tennesseee Mississippi Valley-type districts: evidence for fluid immiscibility and implications for depositional mechanisms: Geochimica et Cosmochimica Acta, 56, 137-154.

Johnston, J.D., 1999, Regional fluid flow and the genesis of Irish Carboniferous base metal deposits: Mineralium Deposita, 34, 571-598.

Kamona, F., Friedrich, G., Sweeney, M.A., Fallick, A.E., 1991, Stable isotopes of the Kabwe lead-zinc deposit., en Pagel, M., Leroy, J.L. (ed.), Source, Transport and Deposition of metals.: Rotterdam Balkema, 313-316.

Kesler, S.E., 1977, Geochemistry of manto fluorite deposits, northern Coahuila, Mexico: Economic Geology, 72, 204-218.

Kesler, S.E., Jones, L.M., 1981, Sulfur and stontium-isotopic geochemistry of celestite, barite and gypsum from the Mesozoic basins of North Eastern Mexico: Chemical Geology, 31, 211-224.

Kesler, S.E., Martini, A.M., Appold, M.S., Walter, L.M., Huston, T.J., Kyle, J.R., 1995, Na-Cl-Br systematics of fluid inclusions from Mississippi-valley type deposits: Geology, 23, 641-644.

Kisvarsanyi, G., Grant, S.K., Pratt, W.P., Koenig, J.W., 1983, International Conference on Mississippi Valley-type Lead-Zinc Dposits, Proceedings Volume: Rolla, University of Missouri-Rolla, 603p.

Larter, R. C. L., Boyce, A. J., Russell, M. J., 1981, Hydrothermal pyrite chimneys from the Ballynoe baryte deposit, Silvermines, County Tipperary, Ireland: Mineralium Deposita, 16, 2, 309-318

Laznicka, P., 1985, Empirical metallogeny. Depositional environments, lithologic associations and metallic ores, Developments in Economic Geology 19, Elsevier, Amsterdam, 1758 p.

Leach, D.L., 1979, Temperature and salinity of the fluids responsible for minor occurrences of sphalerite in the Ozark region of Missouri: Economic Geology, 74, 931-937.

Leach, D.L., Sangster, D.F., 1993, Mississippi Valley-type lead-zinc deposits, en: Kirkham, R.V., Sinclair, W.D., Thorpe, R.I., Duke, J.M. (ed.), Mineral deposit modeling. Geological Association of Canada Special Paper 40: Toronto, Canada, 289-314.

Levresse G., González-Partida E., Tritlla, J., Camprubí, A., CienfuegosAlvarado, E., Morales-Puente, P., 2003, Fluid origin of the Worldclass, carbonate-hosted Las Cuevas fluorite deposit (San Luis Potosí, Mexico): Journal of Geochemical Exploration. 78-79, 537-543.

Levresse, G., Tritlla, J., Villareal, J., González-Partida, E., 2006, The El Pilote fluorite skarn: a crucial deposit to understand the origin and mobilization of $\mathrm{F}$ from northern Mexico deposits: Journal of Geochemical Exploration, Aceptado, en prensa.

Lindblom, S., 1986, Textural and fluid inclusion evidence for the ore 
formation in the $\mathrm{Pb}-\mathrm{Zn}$ deposit at Laisvall, Sweden: Economic Geology, 81, 46-64.

Machel, H.G., 1987, Saddle dolomite as a by-product of chemical compaction and thermochemical sulfate reduction: Geology, 15, 936-940.

Macqueen, R.W., Powell, T.G., 1984, Organic geochemistry of the Pine Point lead-zinc ore field and region. Northwest Territories, Canada: Economic Geology, 78, 1-25.

Maynard, J.B., Okita, P.M., 1991, Bedded barite deposits in the United States, Canada, Germany, and China; two major types based on tectonic setting, Economic Geology, 86, 2, 364-376

McLimans, R.K., Barnes, H.L., Ohmoto, H., 1980, Sphalerite stratigraphy of the Upper Mississippi Valle zinc-lead disrict.: Economic Geology, $75,351-361$

Melgarejo, J.C., 1992, Estudio geológico, metalogenético del paleozoico del sur de las Cordilleras Costeras Catalanas: Memorias del Instituto Tecnológico y Minero de España, 103p.

Michard, A.G., Jebrak, M., Lhegu, J., 1990, Métallogénie tardi-hercynienne des métaux autrs que l'uranium., Chronique de la Recherche Minière, 499, 3-7.

Muñoz J.A., 1992, Evolution of a continental collision belt: ECORS-Pyrenees crustal balanced section. en McClay, K. (ed.), Thrust tectonics: London, Chapman and Hill, 235-246.

Nakai, S., Halliday, A.N., Kesler, S.E., Jones, H.D., Kyle, J.R., Lane, T.E., 1993, Rb-Sr of sphalerites from Mississippi-valley type (MVT) ore deposits: Geochimica et Cosmochimica Acta, 57, 417-427.

Ngoyanadji, N., 1988, Le gisement de Pb-Zn de Largentière (ArdècheFrance): apport de l'étude des inclusions fluides et des isotopes du soufre au problème de sa genèse, Nancy, France, National Polytechnique de Lorraine, tesis doctoral.

Noble, E.A., 1963, Formation of ore deposits by waters of compaction: Economic Geology, 58, 1145-1156.

Norman, D.I., Ting, W., Putnam-Bordan, R. III , Smith, R.W., 1985, Mineralization of the Hansonburg Mississippi-valleytype deposit, New Mexico; insight from composition of gases in fluid inclusions Canadian Mineralogist, 23, 353-368.

Oakes, Ch. S., Bodnar, R. J., Simonson, J. M., 1990, The system NaCl$\mathrm{CaCl}_{2}-\mathrm{H}_{2} \mathrm{O} ; 1$, The ice liquidus at 1 atm total pressure: Geochimica et Cosmochimica Acta, 54(3), 603-610.

Ohle, F. L., 1985, Breccias in Mississippi Valley-type deposits: Economic Geology, 80, 1736-1752.

Oliver, N.H.S., 1986, Fluids expelled tectonically from orogenic belts: their role in hydrocarbon migration and other geological phenomena: Geology, 14, 99-102.

Origlieri, M.,1990, Famous mineral localities: Terlingua, Texas: Mineralogical Record, 21, 221-234.

Osborne, T.C., 1956, Geologia y depositos minerales del Distrito Minero de Taxco, 20th International Geological Congress, Excursiones A-4 and C-2: Mexico, D.F., 75-89.

Palero, F.J., Mangas, J., Both, R.A., Arribas, A., 1991, Metallogeny of sheared $\mathrm{Zn}-\mathrm{Pb}$ vein deposits of Alcudia Valley, Ciudad Real, Spain., en Pagel, M., Leroy, J.L. (ed.), Source, Transport and Deposition of metals: Rotterdam, Balkema, 213-217.

Peace, W.M., Wallace, M.W., 2000, Timing of mineralization at the Navan $\mathrm{Zn}-\mathrm{Pb}$ deposit; a post-Arundian age for Irish mineralization: Geology, 28(8), 711-714.

Pi, T., Sole, J., Taran, Y., 2005, (U-Th)/He dating of fluorite: application to the La Azul fluorspar deposit in the Taxco mining district, Mexico: Mineralium Deposita, 39: 976-982.

Plumlee, G.S., Leach, D.L., Hofstra, A.H., Landis, G.P., Rowan, E.L., Viets, J.G., 1994, Chemical reaction path modeling of ore deposition in Mississippi Valley-type $\mathrm{Pb}-\mathrm{Zn}$ deposits of the Ozark Region, U.S. midcontinent: Economic Geology 89, 1361-1383.

Pohl, W., Siegl, W. ,1986, Sediment-hosted magnesite deposits, en Wolf K.H. (ed.), Handbook of strata-bound and stratiform ore deposits, vol. 14: Regional studies and specific deposits: Amsterdam, Elsevier, 223-300.

Puente-Solís, R., González-Partida, E., Tritlla, J., Levresse, G., 2005, Distribución de los depósitos estratoligados de Barita, celestina, Fluorita , Plomo-Zinc en el Noreste de México en Corona-Esquivel, R., Gómez-Caballero, J.A. (eds.), XXVI Convención Nacional de
Minería,: México D.F., A.I.M.M.G.M., 95-98.

Radke, B.M., Mathis, R,L, 1980, On the formation and occurence of saddle dolomite: Journal of Sedimentary Petrology, 50(4), 1149-1168.

Ramboz, C., Charef, A., 1988, Temperature, pressure, burial history, and paleohydrology of the Les Malines $\mathrm{Pb}-\mathrm{Zn}$ deposit: Reconstruction from aqueous inclusions in barite: Economic Geology, 83, 784-800.

Ramos-Rosique, A., 2004, Comportamiento de los fluidos en la Génesis de los mantos de celestina en la Sierra de Los Alamitos, Coahuila: Querétaro, México, Facultad de Ingeniería, Universidad Nacional Autónoma de México,Tesis de Licenciatura, 54 pp.

Ramos-Rosique, A., Villareal-Fuentes, J., González-Partida, E., Tritlla, J., Levresse, G. ,2005, Los yacimientos estratoligados de celestina de El Venado, El Volcán en la Sierra Los Alamitos, Coahuila, México, in Corona-Esquivel, R., Gómez-Caballero, J.A. (eds.), XXVI Convención Nacional de Minería,: México D.F., A.I.M.M.G.M., 99-104

Rhodes, D., Lantos, E.A., Lantos, J.A., Webb, R.J., Owens, D.C. ,1984, Pine Point orebodies and their relationship to the stratigraphy, structure, dolomitization and karstification of the Middle Devonian barrier complex: Economic Geology, 79, 991-1055.

Richard, D.T., 1983, Precipitation and mixing mechanisms in Laisvall-type sandstone lead-zinc deposits., en Kisvarsanyi, G., Grant, S.K., Pratt, W.P., Koenig, J.W. (ed.), International Conference on MVT lead-zinc deposits: Rolla, University of Missouri-Rolla, 449-458.

Richardson, C., Rye, R.O., Wasserman, D., 1988, The chemical and thermal evolution of the fluids in the Cave-in-Rock fluorspar district, Illinois: Stable isotope systematics at Deardorff mine: Economic Geology, 83, 765-783.

Rickman, D. L., 1977, Origin of celestite (strontium sulfate) ores in the Southwestern United States and northern Mexico: Socorro, Nuevo México, USA, New Mexico Institute of Mining and Technology tesis de maestría, $79 \mathrm{pp}$.

Roedder, E., 1967, Environment of deposition of stratiform (MississippiValley type) ore deposits, from fluid inclusion studies, en Brown, J.S. (ed.), Genesis of stratiform lead-zinc-barite-fluorite deposits- a symposium: Economic Geology Monograph 3: Lancaster, P.A., USA, 349-361.

Russell, M.J., Skauli, H., 1991, A history of theoretical developments in Carbonate-hosted base metal deposits and a new tri-level enthalpy classification, en Hutchinson, R.W., Grauch, R.I. (ed.), Historical prespectives of genetic concepts and case histories of famous discoveries: Economic Geology Monography 8: USA, 96-116.

Salas, G., 1973, Geología de los depósitos de celestita de la Sierra de la Paila, Coahuila, en X Convención Nacional de Minería, A.I.M.M.G.M., 287 -294.

Samson, I.M., Russell, M.J., 1987, Genesis of the Silvermines zinc-leadbarite deposit Ireland: fluid inclusion and stable isotope evidence: Economic Geology, 82, 371-394.

Sangster, D.F., 1983, Sediment-hosted Stratiform lead-zinc Deposits., Short Course Handbook: Toronto, Canada, Mineralogical Association of Canada, 309p

Sangster, D.F., 1990, Mississippi Valley-type and sedex lead-zinc deposits: a comparative examination: Transaction of the Institute of Mining and Metallurgy, (Sect B), B21-B42.

Sangster, D.F., Vaillancourt, P.D., 1990, Geology of the Yava sandstonelead deposit, Cape Breton Island, Nova Scotia, Canada., I Sangster, A.L. (ed), Mineral deposit studies in Nova Scotia, vol.1: Geological Survey Canada Special Paper, 90(8), 203-244.

Sass-Gustkiewicz, M., Dzulynski, S., Ridge, J.D., 1982, The emplacement of zinc-lead sulfide ores in the Upper Silesian district -a contribution to the undestanding of Mississippi Valley-type deposits: Economic Geology, 77, 392-412.

Sawkins, F., 1972, Alpine-Appalachian Type deposits: Journal of Geology, 80, 377-397.

Schneider, J., Haack, U., Ulrich, F., 1999, Direct Rb-Sr dating of sandstone-hosted sphalerites from stratabound $\mathrm{Pb}-\mathrm{Zn}$ deposits in the Northern Eiffel, NW Rhenish Massif, Germany, en Stanley C. et al. (ed.), Mineral Deposits: Processes and Processing: Rotterdam, Balkema, 1287-1290.

Schrijver, K., 1992, Basinal brines and groundwaters as possible metal carriers in the formation of sandstone-hosted lead-zinc deposits: 
Mineralium Deposita, 27, 109-114.

Sharp, J.M. Jr., 1978, Energy and momentum tranport model of the Ouachita basin and its possible impact on formation of economic mineral deposits: Economic Geology, 73, 1057-1068.

Shelton, K.L., Bauer, R.M., Gregg, J.M., 1992, Fluid inclusion studies of regionally extensive epigenetic dolomites, Bonneterre Formation (Cambrian), southeast Missouri lead district: evidence of multiple fluids during dolomitization and lead-zinc mineralization: Geological Society of America Bulletin, 104, 675-683.

Sibson, R.H., Moore, J.M.M., Rankin, A.H., 1975, Seismic pumpinghydrothermal fluid transport mechanism: Journal of Geological Society of London, 131, 635-659.

Sibson, R.H., 1990, Faulting and fluid flow., en Nesbitt, B.E. (ed.), Short Course on fluids in tectonically active regime of the continental crust: Canada, Mineralogical Association of Canada, 93-132.

Singer, D.A., 1995, World class base and precious metal deposits-a quantitative analysis: Economic Geology, 90, 88-104.

Skewes-Saunders, T., 1938, Report upon a deposit of fluorspar near Taxco, Gro, Consejo de Recursos Minerales, México, Archivo 120017-08.

Spirakis, Ch.S., 2004, Fluorite deposits at Encantada-Buenavista, Mexico: products of Mississippi Valley type processes [Ore Geol. Rev. 23 (2003), 107-124]—a discussion: Ore Geology Reviews, 25 (3-4), 327-328.

Sverjensky, D.A., 1981, The origin of Mississippi Valley-type deposit in Virburnum Trend, Southeast Missouri: Economic Geology, 76, 1848-1872.

Sverjensky, D.A. ,1984, Oil field brines as ore forming solutions.: Economic Geology, 79, 23-37.

Sverjensky, D.A., 1986, Genesis of Mississippi Valley-type lead-zinc deposits: Annual Review of Earth and Planetary Sciencies, 14, 177-199.

Sverjensky, D.A. ,1989, The diverse origins of Mississippi Valley-type Zn-Pb-Ba-F deposits., Chron. rech. min., 495, 5-13.

Taylor, S., Andrew, C.J., 1978, Silvermines orebodies, County Tipperary, Ireland: Transactions of the Institution of Mining and Metallurgy, Section B: Applied Earth Sciences, 87, B111-B124

Thiéry, R., Pironon, J., Walgenwitz, F., Montel, F., 2000, PIT (Petroleum Inclusion Thermodynamic): a new modeling tool for the characterization of hydrocarbon fluid inclusions from volumetric and microthermometric measurements: Journal of Geochemical Exploration, 69-70, 701-704.

Thompson, T.B., Hitzman, M.W., Beaty, D.W., 1992, Paragenesis and fluid inclusions of the Lisheen $\mathrm{Zn}-\mathrm{Pb}-\mathrm{Ag}$ deposit, $\mathrm{Co}$. Tipperary, Ireland: Geological Society of America Abstracts with Program, 24, A354.

Tikkanen, 1986, World resources and supply of lead and zinc. en Bush, W.R. (ed.), Economics of internationally traded minerals: USA, Society of Mining Engineers, 242-250.

Tompkins, L.A., Pedone, V.A., Roche, M.T., Groves, D.I., 1994a, The Cadjebut deposit as an example of Mississippi Valley-type mineralization on the Lennard Shelf, Western Australia, single episode or multiple events?: Economic Geology, 89, 450-466

Tompkins, L.A., Rayner, M.J., Groves, D.I., 1994b, Evaporites: in situ sulfur source for rhythmically banded ore in the Cadjebut Mississippi Valley-type $\mathrm{Zn}-\mathrm{Pb}$ deposit, Wertern Australia: Economic Geology, 89, 567-492.

Tornos, F., 1997, Asociaciones minerales en procesos de alteración, relleno hidrotermal sobre roca silicicoalumínicas, in Melgarejo, J.C. (ed.), Atlas de Asociaciones Minerales en Lámina Delgada: Barcelona, Edicions de la Universitat de Barcelona, 249-272.

Tritlla, J., Canals, A., 1997, Mineralizaciones estratoligadas de metales de base en carbonatos, rocas siliciclásticas, en J.C. Melgarejo (ed.) Atlas de Asociaciones Minerales en Lámina Delgada: Barcelona, Edicions de la Universitat de Barcelona, 273-286.
Tritlla, J., Cardellach, E., 1997, Fluid inclusion systematics in pre-ore minerals from carbonate-hosted mercury veins from the Espadán Ranges (East of Spain): Chemical Geology, Vol. 137, pp.91-106

Tritlla J., Camprubí A, Pi, T., Corona-Esquivel, R., 1999, Los depósitos de fluorita del distrito de Taxco (Guerrero): primeros datos, en A. Peralta (ed.), Trabajos Técnicos de la XXIII Convención Nacional A.I.M.M.G.M.: Acapulco, México, 66.

Tritlla, J., Camprubí, A., Corona-Esquivel, R., 2001a, The Taxco fluorite deposit (Mexico): a new pseudo-chromatographic mechanism for rhythmite formation, en Piestrzynski et al. (ed.), Mineral Deposits at the Beginning of the $21^{\text {st }}$ Century: Rotterdam, Balkema, 979-982.

Tritlla, J., Cardellach, E., Sharp, Z.D., 2001b, Origin of vein hydrothermal carbonates in triassic limestones of the Espadán Ranges (Iberian Chain, E Spain): Chemical Geology, 172-2, 291-305.

Tritlla, J., González-Partida, E., Banks, D., Levresse, G., Baca-Gasca, S, Rodríguez-Santos, A., 2004a, Fluid origin of the stratabound fluorite and celestite deposits in Coahuila, Mexico. AGU Fall Meeting Abstracts,V31A-1422.

Tritlla, J., González-Partida, E., Levresse, G., Banks, D., Pironon, J., 2004b, Fluorite deposits at Encantada-Buenavista, Mexico: products of Mississippi Valley type processes [Ore Geol. Rev. 23 (2003), $107-$ 124] - A reply: Ore Geology Reviews, 25, 329-332.

Tritlla, J., Levresse, G., González-Partida, E., Corona-Esquivel, R., Martinez-Ramos, C., 2005, Metalogénia y geoquímica de los fluidos asociados a los depósitos de tipo MVT (Mississippi-Valley Type Deposits) en el centro y norte de México, en Corona-Esquivel, R., Gómez-Caballero, J.A. (eds.), XXVI Convención Nacional de Minería,: México D.F., A.I.M.M.G.M., 113-118.

Tritlla, J., Levresse, G., 2006, Comments to "(U-Th)/He dating of fluorite: application to the La Azul fluospar deposit in the Taxco mining disctrict, Mexico" (Min. Dep., 39, 976-982) by Pi et al.: Mineralium Deposita, En prensa.

Velasco, F., Pesquera, A., Arce, A., Olmedo, F., 1987, A contribution to the ore genesis of the magnesite deposit of Eugui, Navarra (Spain): Mineralium Deposita, 22, 33-41.

Viets, J.H., Leach, D.L., 1990, Genetic implications of regional and temporal Trends in ore fluid geochemistry of Mississippi Valley deposits in the Ozark Region: Economic Geology, 85, 842-861.

Viets, J.G., Hofstra, A.H., Emsbo, P., 1996, Solute compositions of fluid inclusions in sphalerite from North American and European Mississippi Valley-type ore deposits: Ore fluids derived from evaporated seawater, en Sangster, D.F. (ed.), Carbonate-hosted lead-zinc deposits: USA, Society of Economic Geologists Special Volume, 4, 465-482.

Wilkinson, J.J., 2001, Fluid Inclusions in hydrothermal ore deposits: Lithos, 55, 229-272.

William-Jones, A. E., Schrijver, K. Doig, R., Sangster, D.F., 1992, A model for epigenetic $\mathrm{Ba}-\mathrm{Pb}-\mathrm{Zn}$ mineralization in the Appalachian Thust Belt, Quebec: Evidence from fluid inclusions and isotopes: Economic Geology, 87(1), 154-174.

Yates, R.G., Thompson, G.A., 1959, Geology and quicksilver deposits of the Terlingua disctrict, Texas: Geological Survey Profesional Paper, $111 \mathrm{p}$.

Zák, K, Dober, P. ,1991, Stable isotopes and fluid inclusions in hydrothermal deposits: The Príbram ore region: Praha, Publishing House of the Czechoslovak Academy of Sciences, 109p.

Manuscrito recibido: Marzo 15, 2005

Manuscrito corregido recibido: Junio 23, 2005

Manuscrito aceptado: Febrero 24, 2006 